\author{
MINISTÉRIO DA EDUCAÇÃO \\ UNIVERSIDADE FEDERAL DO RIO GRANDE DO NORTE \\ CENTRO DE CIÊNCIAS DA SAÚDE \\ PROGRAMA DE PÓS-GRADUAÇÃO EM CIÊNCIAS DA SAÚDE
}

\begin{abstract}
A FORMAÇÃO EM SAÚDE FRENTE ÀS NECESSIDADES DAS PESSOAS IDOSAS
\end{abstract}

RAFAEL RODOLFO TOMAZ DE LIMA

NATAL/RN 
RAFAEL RODOLFO TOMAZ DE LIMA

\section{A FORMAÇÃO EM SAÚDE FRENTE ÀS NECESSIDADES DAS PESSOAS IDOSAS}

Dissertação apresentada ao Programa de Pós-Graduação em Ciências da Saúde da Universidade Federal do Rio Grande do Norte como requisito para obtenção do título de Mestre em Ciências da Saúde.

Orientador: Prof. Dr. Kenio Costa de Lima.

Coorientadora: Prof. ${ }^{a}$ Dr. $\stackrel{\text { a }}{\text { Janete Lima }}$ de Castro.

\section{NATAL/RN}




\section{FICHA CATALOGRÁFICA}

Lima, Rafael Rodolfo Tomaz de.

A formação em saúde frente às necessidades das pessoas idosas / Rafael Rodolfo Tomaz de Lima. - Natal, 2018.

139f. : il.

Orientador: Prof. Dr. Kenio Costa de Lima.

Coorientadora: Prof. ${ }^{a}$ Dr. ${ }^{a}$ Janete Lima de Castro.

Dissertação (Mestrado) - Programa de Pós-Graduação em Ciências

da Saúde. Centro de Ciências da Saúde. Universidade Federal do Rio

Grande do Norte.

1. Recursos Humanos em Saúde - Dissertação. 2. Saúde do idoso -

Dissertação. 3. Profissional em Saúde - Dissertação. 4. Envelhecimento -

Dissertação. I. Lima, Kenio Costa de. II. Castro, Janete Lima de. III. Título.

RN/UF/BS-CCS

CDU 614:658.3

Bibliotecária: Ana Cristina da Silva Lopes CRB/15 - 263 


\author{
MINISTÉRIO DA EDUCAÇÃO \\ UNIVERSIDADE FEDERAL DO RIO GRANDE DO NORTE \\ CENTRO DE CIÊNCIAS DA SAÚDE \\ PROGRAMA DE PÓS-GRADUAÇÃO EM CIÊNCIAS DA SAÚDE
}

Coordenador do Programa de Pós-Graduação em Ciências da Saúde

Prof. Dr. Eryvaldo Sócrates Tabosa do Egito 
RAFAEL RODOLFO TOMAZ DE LIMA

\section{A FORMAÇÃO EM SAÚDE FRENTE ÀS NECESSIDADES DAS PESSOAS IDOSAS}

Aprovada em 15 de dezembro de 2017

BANCA EXAMINADORA

Prof. Dr. Kenio Costa de Lima (Orientador)

Universidade Federal do Rio Grande do Norte

Prof. a Dr.. Janete Lima de Castro (Coorientadora)

Universidade Federal do Rio Grande do Norte

Prof. ${ }^{\text {a }}$ Dr. ${ }^{\text {a }}$ Rosana Lúcia Alves de Vilar (Examinadora interna)

Universidade Federal do Rio Grande do Norte

Prof. Dr. Marcelo Viana da Costa (Examinador externo) Universidade do Estado do Rio Grande do Norte 
DEDICATÓRIA

Aos meus avôs João e José (in memorian) e às minhas avós Maria das Dores e Maria Soledade. 
EPÍGRAFE

[...] Um novo tempo há de vencer Pra que a gente possa florescer E, baby, amar, amar sem 'temer' [...] Johnny Hooker 


\section{RESUMO}

No Brasil, constata-se um crescimento acentuado da população idosa, onde isso se intensificará nas próximas duas décadas. No âmbito do SUS, a assistência a essa população deve pautar-se em ações desenvolvidas pelas equipes da ESF e do NASF. O estudo teve o objetivo de analisar a formação dos profissionais da ESF e do NASF para atender às necessidades das pessoas idosas. Trata-se de uma pesquisa com abordagem qualitativa, realizada em duas etapas e com procedimentos metodológicos distintos. Na primeira etapa, buscou-se analisar como ocorre a abordagem do envelhecimento na formação dos profissionais que atuam na ESF e no NASF, a partir da leitura dos projetos pedagógicos dos seus cursos de formação. A segunda etapa consistiu em compreender, com a realização de grupos focais, a percepção das pessoas idosas atendidas por equipes da ESF e do NASF sobre as suas necessidades, bem como compreender a percepção das mesmas sobre as competências profissionais necessárias para o cuidado que essa parcela da população precisa. Os resultados da primeira etapa revelaram que a formação profissional para o cuidado à saúde da pessoa idosa está pautada exclusivamente na assistência e condução de doenças crônico-degenerativas, como também na identificação e prevenção de danos à saúde. Ademais, a operacionalização dos grupos focais permitiu classificar as necessidades das pessoas idosas participantes do estudo em duas temáticas: Necessidade de boas condições de vida e necessidade de acesso aos serviços de saúde. De acordo com os participantes, os profissionais da ESF e do NASF são bem qualificados para Ihes atenderem, porém, não possuem autonomia para solucionar as suas necessidades. Para a resolução dessas necessidades, qualificar os gestores (municipais, estaduais e federais) do setor saúde seria o caminho prioritário. Com a realização deste estudo, percebe-se que a discussão acerca da temática do envelhecimento no processo de formação dos profissionais que integram as equipes da ESF e do NASF ainda é incipiente e está desassociada das necessidades de saúde das pessoas idosas. Assim, se faz necessário preparar pessoas que ofereçam atenção integral à crescente população idosa, conhecendo as suas subjetividades e necessidades, bem como para formular e gerir políticas públicas para a mencionada população que é usuária do SUS.

PALAVRAS-CHAVE: Recursos Humanos em Saúde; Formação Profissional em Saúde; Saúde da Família; Envelhecimento; Saúde do Idoso. 


\begin{abstract}
In Brazil, there is a marked increase in the elderly population, where this will intensify in the next two decades. Under the SUS, assistance to this population should be based on actions developed by the ESF and NASF teams. The aim of the study was to analyze the training of ESF and NASF professionals to meet the needs of the elderly. It is a qualitative research, carried out in two stages and with different methodological procedures. In the first stage, we sought to analyze how the aging approach occurs in the training of professionals working in the ESF and NASF, from the reading of the pedagogical projects of their training courses. The second stage consisted in understanding the perception of the elderly people assisted by ESF and NASF teams about their needs, as well as their perception about the professional competencies necessary for the care that this portion of the population needs. The results of the first stage revealed that the professional training for the health care of the elderly is based solely on the assistance and conduction of chronic-degenerative diseases, as well as on the identification and prevention of health damages. In addition, the operationalization of the focus groups allowed to classify the needs of the elderly participants of the study in two thematic ones: Necessity of good conditions of life and necessity of access to the health services. According to the participants, the professionals of the ESF and the NASF are well qualified to attend to them, however, they do not have the autonomy to solve their needs. To solve these needs, qualifying the managers (municipal, state and federal) of the health sector would be the priority path. With the accomplishment of this study, it is noticed that the discussion about the aging issue in the process of training the professionals that integrate the ESF and NASF teams is still incipient and is disassociated with the health needs of the elderly. Thus, it is necessary to prepare people who offer integral attention to the growing elderly population, knowing their subjectivities and needs, as well as formulating and managing public policies for the aforementioned population that is a SUS user.
\end{abstract}

KEYWORDS: Human Resources in Health; Health Human Resource Training; Family Health; Aging; Health of the Elderly. 


\section{LISTA DE ABREVIATURAS E SIGLAS}

APS - Atenção Primária à Saúde

CAPES - Coordenação de Aperfeiçoamento de Pessoal de Nível Superior

CEP - Comitê de Ética em Pesquisa

CNS - Conselho Nacional de Saúde

DCN - Diretrizes Curriculares Nacionais

EC - Emenda Constitucional

ESF - Estratégia Saúde da Família

FHC - Fernando Henrique Cardoso

HUOL - Hospital Universitário Onofre Lopes

IBGE - Instituto Brasileiro de Geografia e Estatística

NASF - Núcleo de Apoio à Saúde da Família

OBSERVARH - Observatório de Recursos Humanos em Saúde

PAB - Piso da Atenção Básica

PACS - Programa de Agentes Comunitários de Saúde

PET-SAÚDE - Programa de Educação pelo Trabalho para a Saúde

PNAB - Política Nacional de Atenção Básica

PNEPS - Política Nacional de Educação Permanente em Saúde

PNSPI - Política Nacional de Saúde da Pessoa Idosa

PPGCSA - Programa de Pós-Graduação em Ciências da Saúde

PRÓ-SAÚDE - Programa Nacional de Reorientação da Formação Profissional em

Saúde

PSF - Programa Saúde da Família

RN - Rio Grande do Norte

SUS - Sistema Único de Saúde

TCLE - Termo de Consentimento Livre e Esclarecido

UBS - Unidade Básica de Saúde

UFRN - Universidade Federal do Rio Grande do Norte 


\section{LISTA DE FIGURAS E QUADROS}

Quadro 1 - Caracterização das equipes da ESF e do NASF. Brasil. 2012.

Quadro 2 - Distribuição do quantitativo de projetos pedagógicos analisados por curso. Rio Grande do Norte. 2016.

Quadro 3-

Figura 1 - Fluxograma da análise dos projetos pedagógicos. Rio Grande do Norte, Brasil. 2016. 


\section{SUMÁRIO}

1. Introdução

1.1. A formação de recursos humanos para o SUS ……......................................13

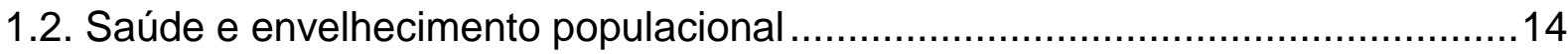

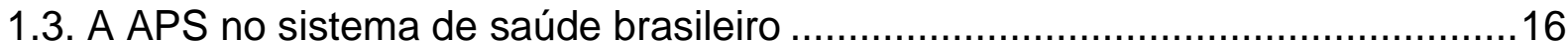

2. Justificativa

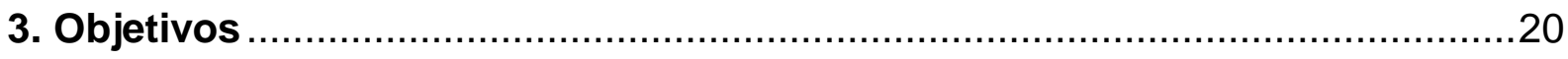

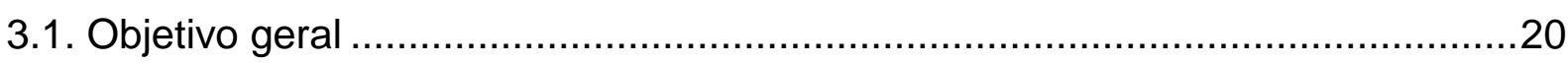

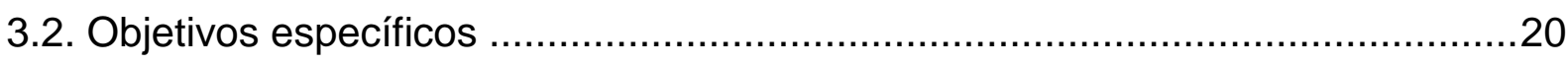

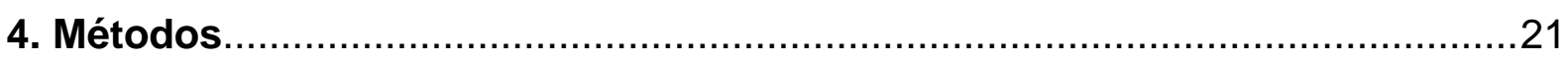

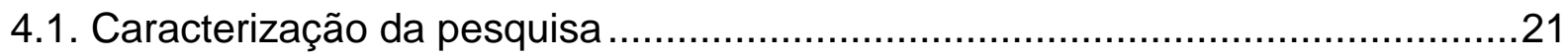

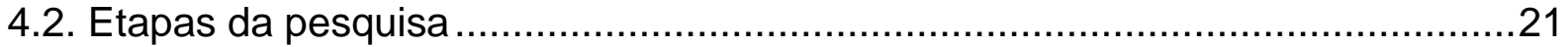

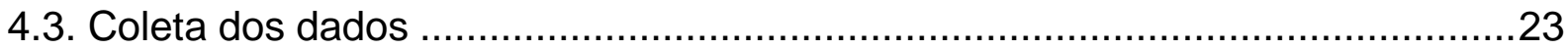

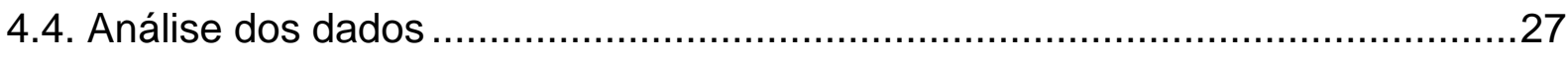

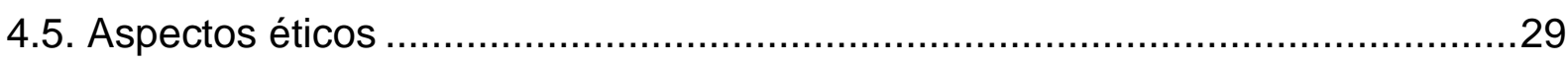

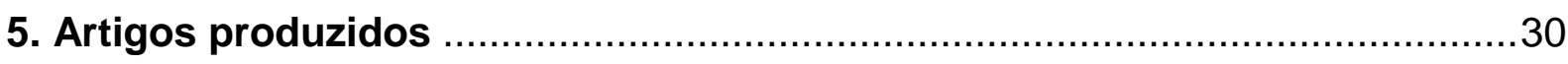

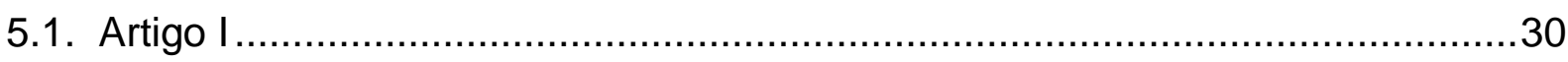

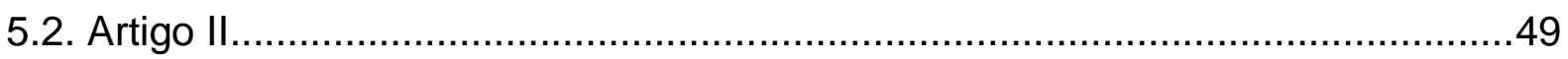

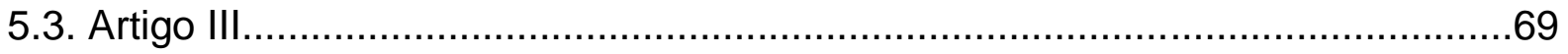

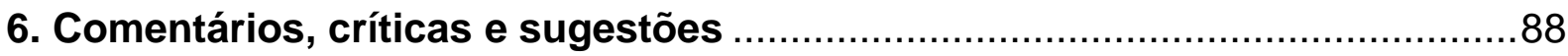

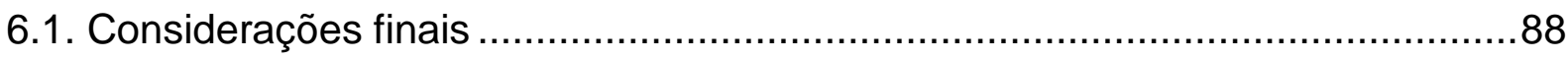

6.2. A trajetória no mestrado acadêmico: relato de um aluno .................................90

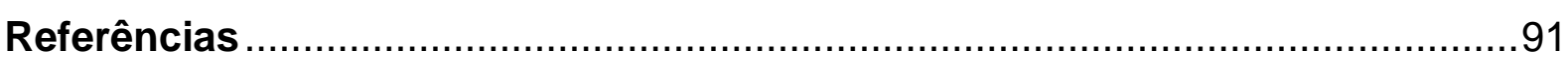

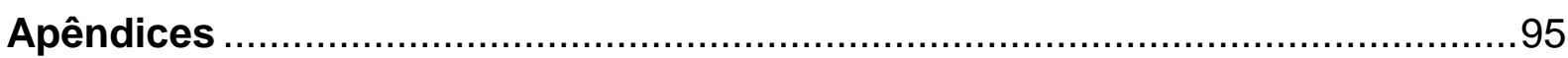

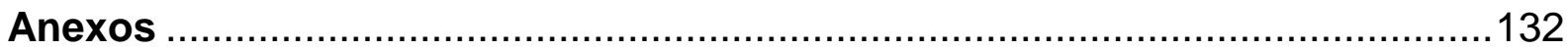




\section{INTRODUÇÃO}

\subsection{A formação de recursos humanos para o SUS}

O SUS, fortemente impulsionado pelo ideal da Reforma Sanitária, pelas propostas da VIII Conferência Nacional de Saúde realizada em 1986 e pela Constituição Federal de 1988, foi legalmente criado em 1990 através das leis n.o 8.080 e n. - 8.142. Além de reorganizar o sistema de saúde brasileiro, o SUS proporcionou transformações na concepção das políticas públicas e sociais até então vigentes em nosso país ${ }^{1 .}$

Ainda de acordo com Lucena ${ }^{1}$, para garantir que a saúde seja um direito de todos os cidadãos brasileiros, o SUS é orientado por princípios doutrinários (universalidade, equidade e integralidade) e por princípios organizativos (regionalização e hierarquização; descentralização e comando único; e participação social). Todavia, a discussão sobre a formação de recursos humanos em saúde no Brasil, comprometidos com o desenvolvimento da autonomia e do protagonismo dos sujeitos, antecede o movimento da Reforma Sanitária e o processo de construção do SUS ${ }^{2}$.

Na segunda metade da década de 1960 , a formação da força de trabalho em saúde tornou-se tema principal da IV Conferência Nacional de Saúde, realizada em 1967 e intitulada "Recursos Humanos para a Saúde". Na ocasião, foram apontadas proposições para fortalecer a área de recursos humanos em saúde, tais como a equiparação no desenvolvimento dos trabalhadores de nível superior com 0 desenvolvimento do reduzido quadro de pessoal de nível médio e auxiliar ${ }^{3}$.

Já na década de 1980, mais precisamente em 1986, a realização da I Conferência Nacional de Recursos Humanos para a Saúde no Brasil oportunizou um debate maior e mais profundo acerca dos recursos humanos em saúde como elementos centrais para a construção do novo sistema de saúde e para a produção dos serviços de saúde 4 . Após 21 anos à realização da IV Conferência Nacional de Saúde, mais precisamente em 1988, o art. 200 do inciso III da Constituição Federal menciona que cabe ao próprio SUS ordenar a formação em saúde, visando romper com o modelo de atenção centrado nos médicos e nos hospitais ${ }^{5}$.

Para que ocorram transformações no sistema de saúde, é preciso provocar mudanças na formação da sua força de trabalho ${ }^{6}$. Tal formação deve estar em 
conformidade com os princípios e diretrizes do $\mathrm{SUS}^{7}$, ser emancipatória e dialogada com a comunidade, bem como com os serviços de saúde, sobretudo os serviços da APS.

Nessa perspectiva, em 2001, o Ministério da Educação homologou as DCN para a área da saúde, com o intuito de atender às demandas do SUS elencadas pelo Ministério da Saúde e orientar a formulação de novos currículos e inserção de novos conteúdos nos projetos pedagógicos dos cursos de formação dos profissionais, com ênfase na integralidade do cuidado ${ }^{7}$. Segundo Alves e Martinez ${ }^{8}$, o projeto pedagógico constitui-se em um documento normativo dos cursos, agregando informações sobre a concepção e estrutura de cada curso, bem como das instituições de ensino. O projeto pedagógico propicia a intencionalidade e 0 direcionamento do papel social das instituições educadoras e dos formandos dos cursos, centrando-se nas ações de ensino, pesquisa e extensão.

Além das DCN, outra estratégia adotada foi a criação da PNEPS, objetivando, principalmente, orientar o desenvolvimento profissional e transformar as práticas de saúde através da educação permanente no trabalho e para o trabalho, envolvendo instituições de ensino, gestores, trabalhadores e usuários ${ }^{9}$. A PNEPS foi instituída pelo Ministério da Saúde em 2004, através da Portaria n. 198. Em 2007, por intermédio da Portaria n. 1.996, o Ministério da Saúde lançou diretrizes para a sua implementação e, em 2014, definiu diretrizes para a implementação da PNEPS no âmbito da própria instituição ${ }^{10}$. Para tornar a PNEPS mais significativa, alguns programas foram criados, a saber: PRÓ-SAÚDE, Programa Nacional de Telessaúde e PET-SAÚDE ${ }^{11}$.

A partir das estratégias adotadas pelos Ministérios da Saúde e da Educação, pretende-se aproximar os estudantes e profissionais da área da saúde com as reais necessidades da população e do SUS, na perspectiva de saná-las. Dentre essas necessidades, destacam-se aqui as necessidades das pessoas idosas $(\geq 60$ anos) $)^{12^{\prime 13}}$.

\subsection{Saúde e envelhecimento populacional}

Em detrimento às conquistas políticas e sociais, bem como ao avanço da ciência e da tecnologia, a expectativa de vida e o aumento da proporção de pessoas 
idosas tem se tornado um fenômeno global, com exceção de alguns países do continente africano ${ }^{14^{4} 15}$. No início dos anos 2000 , a população idosa mundial continha cerca de seiscentos milhões de indivíduos, representando $10 \%$ da população geral. Estima-se que em 2050 existam cerca de dois bilhões de idosos e idosas em todo o mundo ${ }^{16}$.

No Brasil, constata-se uma diminuição da taxa de natalidade e um crescimento acentuado de indivíduos acima de 60 anos ${ }^{17}$, onde isso se intensificará nas próximas duas décadas ${ }^{18}$. $O$ envelhecimento da população brasileira está acontecendo de maneira muito acelerada e significativamente maior do que o modo ocorrido em outros países durante o século XX. Foi preciso mais de cem anos para que a França, por exemplo, visse a sua população idosa aumentar de $7 \%$ para $14 \%$ em relação à população francesa geral ${ }^{19}$.

Envelhecer não é um problema. Como afirmam Louvison e Rosa ${ }^{20}$, envelhecer é um triunfo da humanidade. Todavia, percebe-se que a população está envelhecendo com maiores limitações funcionais e acentuados problemas de saúde ${ }^{21}$. Há doze anos, $70 \%$ das pessoas idosas longevas ( $\geq 80$ anos) já dependiam totalmente do sistema público de saúde brasileiro ${ }^{22}$ e ao acelerado processo de envelhecimento populacional incorpora-se o aumento de morbidades, incapacidades funcionais, diminuição da independência e da autonomia, bem como o aumento no número de internações em unidades de terapia intensiva ${ }^{23}$.

Para dar assistência à população idosa no âmbito do SUS é preciso que seja organizada uma rede integral de atenção à saúde, contendo serviços e profissionais bem qualificados, visto que a referida população possui características e necessidades peculiares adquiridas ao longo da vida ${ }^{24}$. Entretanto, a qualidade da assistência ofertada para a população idosa está aquém das necessidades que ela requer, situação que demonstra a importância em garantir investimentos para enfrentar o fenômeno populacional que vivemos e previsto para se intensificar nos próximos anos ${ }^{2518}$.

Dentre tantos investimentos prioritários, ressalta-se a importância em qualificar a educação profissional em saúde voltada para o cuidado da pessoa idosa ${ }^{26}$. Educação essa que deve ser pautada no ensino sobre o envelhecimento ativo para que os profissionais de saúde sejam agentes transformadores e estimulem a autonomia, a independência, bem como a ação cidadã e participativa aos idosos e às idosas ${ }^{27}$. 
Todavia, nos projetos pedagógicos dos cursos da área da saúde ainda é pouco expressivo o ensino para o cuidado à saúde da pessoa idosa e a contextualização do processo de envelhecimento humano, bem como não há uma oferta significativa de processos de educação permanente para qualificar a força de trabalho atuante nos serviços de saúde ${ }^{28}$.

Ademais, de acordo com a PNSPI, publicada em 1999 por intermédio da Portaria n. -1.395 e atualizada em 2006 pela Portaria n.․ 2.528, ambas do Ministério da Saúde, é preferível que a APS, mais precisamente as equipes da ESF e as equipes do NASF, coordenem o cuidado à saúde da população idosa no SUS, tendo o princípio da integralidade como eixo norteador.

\subsection{A APS no sistema de saúde brasileiro}

No âmbito mundial, a Declaração de Alma-Ata publicada em 1978 foi um marco importante para o desenvolvimento da APS, pois defendia o referido nível de atenção como um fator essencial para os sistemas de saúde ${ }^{29}$. Segundo Starfield ${ }^{30}$, a APS é um nível de cuidado que forma a base de qualquer sistema de saúde, abordando os problemas mais comuns na comunidade, ofertando serviços de prevenção, cura e reabilitação para a população. Ao ser implementada e gerida de maneira correta, a APS é capaz de organizar e racionalizar o uso de recursos, tanto básicos como especializados, direcionados para a promoção e melhoria da saúde ${ }^{30}$.

No Brasil, tentativas de organizar a APS remontam desde 1920, com a formulação de diversas propostas em diferentes regiões do país ${ }^{29}$. Porém, o fortalecimento da APS só teve início na década de 1990 com o processo de descentralização do SUS, garantindo a transferência de recursos federais para estados e municípios. As UBS passaram a estar amplamente inseridas na dinâmica local, garantindo a continuidade de atuação e integrando ações educativas, preventivas e curativas de fácil acesso ${ }^{31}$.

Ainda na década de 1990, mais precisamente em 1994, o Ministério da Saúde criou o PSF, derivado do PACS (fundado em 1991) ) $^{31}$ com o objetivo de reorientar o modelo assistencial a partir da APS e em conformidade com os princípios do SUS ${ }^{32}$. No estado do RN, o PSF também foi instalado em 1994, contendo inicialmente dezoito equipes em quatro cidades, dando cobertura assistencial a $2,4 \%$ da população potiguar daquela época ${ }^{32}$. 
Em Natal, capital do RN, a Secretaria de Saúde, desde a sua criação em 1986, optou por garantir uma assistência baseada nas ações da APS, desenvolvidas por equipes multiprofissionais ${ }^{33}$. Ainda de acordo com Massud ${ }^{33}$, nos primeiros anos da referida instituição, a rede da APS era composta por sete UBS, construídas com recursos próprios do município e que atuavam sob a lógica da territorialização, muito antes do que havia sido preconizado pelo Ministério da Saúde como modelo organizacional para a atenção à saúde.

Tendo como base os princípios da promoção e proteção à saúde, e da prevenção de agravos, seja no âmbito individual ou coletivo, o PSF tornou-se eixo estruturante dos sistemas municipais de saúde, passando a se chamar ESF no ano de $2006^{34}$, durante o primeiro mandato (2003 a 2007) do governo Lula. Na ocasião, houve fomentos importantes para qualificar a cobertura das ações da APS, a saber: Aumento dos recursos do PAB, congelados desde 1988 e passando de $\mathrm{R} \$ 10,00$ para $R \$ 15,00$ per capita; e aumento de $57 \%$ das equipes de saúde da família ${ }^{35}$.

Objetivando dar continuidade às ações progressistas e caminhando no sentido contrário ao governo FHC (1995 a 2002), onde era explícito o favoritismo da reforma neoliberal do Estado a da internacionalização do capita $^{36}$, durante o segundo mandato do governo Lula (2007 a 2010), a expansão da ESF continuou sendo prioridade da agenda política do Ministério da Saúde. Entre 2007 e 2008, por exemplo, foram criadas 2.569 equipes de saúde bucal na APS e 2.500 novas equipes da $\mathrm{ESF}^{35}$.

Segundo a PNAB, instaurada em 21 de outubro de 2011, através da Portaria ก. .02 .488 do Ministério da Saúde, a ESF é a principal porta de entrada do SUS e o principal meio de comunicação dos usuários com as redes de atenção à saúde. $O$ cuidado proporcionado pelos profissionais da equipe multiprofissional da ESF, no âmbito domiciliar ou nas UBS, é capaz de valorizar a singularidade e a história de vida dos sujeitos, proporcionando a criação de vínculo entre os usuários e os serviços de saúde ${ }^{37}$.

Para provocar mudanças no sistema de saúde, bem como nas práticas de atenção à saúde das pessoas idosas, por exemplo, é preciso organizar redes de atenção que sejam coordenadas pelas equipes da APS ${ }^{38}$. Com o objetivo de fortalecer ainda mais a APS no Brasil e ampliar o escopo de atuação dos profissionais da ESF, o Ministério da Saúde criou em 2008 o NASF, através da Portaria n. $\stackrel{0}{154 .}$ 
As equipes multiprofissionais do NASF, juntamente com as equipes da ESF, assumem a função coordenadora do sistema de saúde a partir da APS e com a realização do apoio matricial, visam romper com as práticas de trabalho verticalizadas e hierarquizadas. Além disso, buscam proporcionar a integralidade do cuidado para os demais níveis de atenção ${ }^{39}$. 


\section{JUSTIFICATIVA}

O aumento da expectativa de vida é acompanhado pela mudança do perfil epidemiológico e da existência de desigualdades sociais, econômicas e de gênero entre as pessoas idosas ${ }^{20}$. Para combater essa realidade, é preciso adotar políticas públicas que evitem o risco de agravos à saúde para essas pessoas e que considerem os condicionantes da saúde, como meio ambiente saudável, renda, trabalho, saneamento, alimentação, educação e garantia de ações e de serviços de saúde de boa qualidade, incluindo a qualificação da força de trabalho atuante no SUS.

É necessário propiciar uma formação em saúde que seja pautada na educação do envelhecimento ativo, com foco nas necessidades dos sujeitos e na desconstrução de preconceitos e de estigmas que estão ao redor das pessoas idosas, diferente do atual modelo de ensino, reflexo do modelo de sociedade capitalista e produtivista em que vivemos, onde as pessoas idosas são enxergadas como seres limitados, improdutivos, doentes e dependentes. Essa formação deve ser mais humanística e menos tecnicista para lidar com as múltiplas causas que envolvem o processo de envelhecimento, estimulando 0 protagonismo dos profissionais de saúde na luta para a garantia da permanência dos direitos sociais às pessoas idosas, estabelecidos desde a promulgação da Constituição Federal e ameaçados em tempos tão "temerosos".

Porém, o desenvolvimento de uma formação profissional em saúde voltada para esse segmento da população poderá tornar-se difícil em decorrência da EC n.. 95/2016, que limita, dentre outras coisas, os investimentos em educação e saúde nos próximos vinte anos. Nesse sentido, este estudo pretende saber: (i) De que modo o envelhecimento está sendo discutido na formação dos profissionais da saúde que atuam na ESF e no NASF? (ii) Será que esses profissionais estão qualificados para atenderem essa parcela da população? (iii) Quais são as competências profissionais necessárias para dar assistência às pessoas idosas no âmbito da ESF e do NASF? 


\section{OBJETIVOS}

\subsection{Objetivo geral}

Analisar a formação dos profissionais da ESF e do NASF para atender às necessidades das pessoas idosas.

\subsection{Objetivos específicos}

a) Analisar a abordagem da temática do envelhecimento humano na formação dos profissionais que atuam na ESF e no NASF;

b) Conhecer a percepção das pessoas idosas cobertas pela ESF e pelo NASF quanto às suas necessidades;

C) Compreender a percepção das pessoas idosas assistidas pela ESF e pelo NASF sobre as competências profissionais necessárias para lidar com cuidado à pessoa idosa; 


\section{MÉTODOS}

\subsection{Caracterização da pesquisa}

Esta dissertação é resultante de uma pesquisa com abordagem qualitativa. De acordo com Minayo ${ }^{40}$, as pesquisas qualitativas se preocupam com o nível de realidade que não pode ser quantificado, ou seja, trabalham com um universo de significados, motivos, valores, atitudes, processos e fenômenos que não podem ser reduzidos à operacionalização de variáveis. Portanto, escolheu-se a abordagem qualitativa por ser considerada a mais adequada para a análise do objeto desta pesquisa, isto é, a formação profissional em saúde frente às necessidades das pessoas idosas.

\subsection{Etapas da pesquisa}

Para o alcance dos objetivos propostos, a pesquisa foi realizada em duas etapas com a utilização de procedimentos metodológicos distintos, a saber:

\section{a) Pesquisa documental}

Na primeira etapa, buscou-se analisar como ocorre a abordagem da temática do envelhecimento humano na formação dos profissionais que atuam na ESF e no NASF (quadro 1) através da pesquisa documental. Segundo Kripka, Scheller e Bonotto $^{41}$, a pesquisa documental é aquela onde os dados obtidos são oriundos exclusivamente de documentos, que podem ser impressos, gravados, filmados ou virtualmente expostos, buscando extrair informações neles contidos com a finalidade de compreender um fenômeno. 
Quadro 1 - Caracterização das equipes da ESF e do NASF. Brasil. 2012.

Profissionais da ESF

\begin{tabular}{cc} 
Profissionais de nível médio & $\begin{array}{c}\text { Agente comunitário de saúde, técnico em } \\
\text { saúde bucal, técnico de enfermagem e } \\
\text { auxiliar em saúde bucal }\end{array}$ \\
Profissionais de nível superior & $\begin{array}{c}\text { Cirurgião-dentista, enfermeiro, médico } \\
\text { Profissionais do NASF } \\
\text { Assistente social, profissional de educação } \\
\text { física, farmacêutico, fisioterapeuta, } \\
\text { fonoaudiólogo, nutricionista, psicólogo, } \\
\text { terapeuta ocupacional, arte-educador e } \\
\text { sanitarista }\end{array}$ \\
\hline
\end{tabular}

Fonte: Ministério da Saúde, 2012.

\section{b) Grupo focal}

A segunda etapa da pesquisa consistiu em compreender a percepção das pessoas idosas acerca das suas necessidades, bem como compreender a percepção das mesmas sobre as competências profissionais necessárias para 0 cuidado que essa parcela da população precisa no âmbito da ESF e do NASF. Para isso, realizaram-se grupos focais que possibilitam conhecer, através das discussões coletivas, as atitudes, comportamentos e sentimentos de determinados grupos sociais, formados por participantes que possuem ao menos uma semelhança, sobre determinado assunto ou problema ${ }^{42}$.

Para manter o rigor científico nessa etapa do estudo, foram verificados os itens recomendados pelo Consolidated Criteria for Reporting Qualitative Research (COREQ) para estudos qualitativos que utilizam entrevistas ou grupos focais como recursos metodológicos ${ }^{43}$. 


\subsection{Coleta dos dados}

\section{a) Pesquisa documental}

O cenário da investigação nesta etapa foi o estado do RN, localizado na região Nordeste do Brasil. O Nordeste é a segunda região do país com o maior número de pessoas idosas, concentrando aproximadamente $29 \%$ de toda a população brasileira envelhecida ${ }^{25}$. Além disso, de acordo com o censo demográfico realizado em 2010 pelo IBGE, 10,8\% da população do RN possuía idade $\geq 60$ anos $^{44}$.

Os dados foram coletados a partir da leitura dos projetos pedagógicos dos cursos para as profissões relatadas no quadro 1. Inicialmente foram identificados 70 cursos registrados nos sistemas de informação do Ministério da Educação, ofertados em instituições de ensino públicas e privadas do RN (quadro 2). Para identificar os cursos de nível médio foi consultado o Sistema Nacional de Informações da Educação Profissional e Tecnológica (SISTEC) e para identificar os cursos de nível superior foi consultado o Sistema de Regulação do Ensino Superior (e-MEC).

Em seguida, os projetos pedagógicos foram pesquisados juntamente às coordenações dos cursos identificados, através do acesso às páginas eletrônicas institucionais, e-mail ou pessoalmente, havendo a disponibilização e, por conseguinte, análise de 57 projetos pedagógicos (quadro 2). Todo o processo de coleta dos dados aconteceu entre os meses de junho e agosto de 2016.

Vale ressaltar que o profissional sanitarista, que compõe a equipe do NASF, pode ser qualquer profissional com pós-graduação em Saúde Coletiva, bem como o profissional graduado diretamente nessa área. Neste estudo, optou-se por buscar e analisar somente os projetos pedagógicos das graduações em Saúde Coletiva. 
Quadro 2 - Distribuição do quantitativo de projetos pedagógicos analisados por curso. Rio Grande do Norte. 2016.

\begin{tabular}{|c|c|c|c|c|c|}
\hline Curso & № total de cursos & $\begin{array}{c}\text { № de cursos ofertados } \\
\text { por instituições de } \\
\text { natureza privada }\end{array}$ & $\begin{array}{c}\text { № de projetos } \\
\text { pedagógicos } \\
\text { disponibilizados e } \\
\text { analisados }\end{array}$ & $\begin{array}{c}\text { № de cursos ofertados } \\
\text { por instituições de } \\
\text { natureza pública }\end{array}$ & $\begin{array}{c}\text { № de projetos } \\
\text { pedagógicos } \\
\text { disponibilizados e } \\
\text { analisados }\end{array}$ \\
\hline $\begin{array}{c}\text { Bacharelado em Arte e } \\
\text { Educação }\end{array}$ & 01 & 00 & 00 & 01 & 00 \\
\hline $\begin{array}{l}\text { Bacharelado em } \\
\text { Educação Física }\end{array}$ & 07 & 05 & 05 & 02 & 02 \\
\hline $\begin{array}{l}\text { Bacharelado em } \\
\text { Enfermagem }\end{array}$ & 11 & 09 & 06 & 02 & 02 \\
\hline $\begin{array}{l}\text { Bacharelado em } \\
\text { Farmácia }\end{array}$ & 05 & 04 & 02 & 01 & 01 \\
\hline $\begin{array}{l}\text { Bacharelado em } \\
\text { Fisioterapia }\end{array}$ & 06 & 05 & 04 & 01 & 01 \\
\hline $\begin{array}{l}\text { Bacharelado em } \\
\text { Fonoaudiologia }\end{array}$ & 02 & 01 & 01 & 01 & 01 \\
\hline $\begin{array}{c}\text { Bacharelado em Gestão } \\
\text { em Sistemas e Serviços } \\
\text { de Saúde (Saúde } \\
\text { Coletiva) }\end{array}$ & 01 & 00 & 00 & 01 & 01 \\
\hline
\end{tabular}




\begin{tabular}{|c|c|c|c|c|c|}
\hline $\begin{array}{c}\text { Bacharelado em } \\
\text { Medicina }\end{array}$ & 03 & 01 & 01 & 02 & 02 \\
\hline $\begin{array}{c}\text { Bacharelado em } \\
\text { Nutrição }\end{array}$ & 06 & 05 & 04 & 01 & 01 \\
\hline $\begin{array}{c}\text { Bacharelado em } \\
\text { Odontologia }\end{array}$ & 03 & 01 & 01 & 02 & 02 \\
\hline $\begin{array}{c}\text { Bacharelado em } \\
\text { Psicologia }\end{array}$ & 07 & 06 & 04 & 01 & 01 \\
\hline $\begin{array}{c}\text { Bacharelado em Serviço } \\
\text { Social }\end{array}$ & 11 & 09 & 06 & 02 & 02 \\
\hline $\begin{array}{c}\text { Bacharelado em Terapia } \\
\text { Ocupacional }\end{array}$ & 01 & 01 & 01 & 00 & 00 \\
\hline $\begin{array}{l}\text { Técnico em Agente } \\
\text { Comunitário de Saúde }\end{array}$ & 02 & 00 & 00 & 02 & 02 \\
\hline $\begin{array}{l}\text { Técnico em } \\
\text { Enfermagem }\end{array}$ & 02 & 00 & 00 & 02 & 02 \\
\hline Técnico em Saúde Bucal & 02 & 00 & 00 & 02 & 02 \\
\hline Total & 70 & 47 & 35 & 23 & 22 \\
\hline
\end{tabular}

Fonte: Ministério da Educação, 2016. 


\section{b) Grupo focal}

Foram realizados três grupos focais (quadro 3), conduzidos pelo autor desta dissertação, que é do gênero masculino, especialista em Gestão do Trabalho e da Educação na Saúde e possui experiência na realização de grupos focais. Anterior à realização dos mesmos, uma visita foi feita em três UBS do município de Natal, selecionadas intencionalmente, para apresentar aos profissionais os motivos, as razões, os interesses e os objetivos da pesquisa, bem como para selecionar os sujeitos participantes.

Quadro 3 - Descrição dos grupos focais. Natal, 2017.

\begin{tabular}{|c|c|c|c|c|c|}
\hline Grupo focal & $\begin{array}{l}\text { Local de } \\
\text { realização }\end{array}$ & $\begin{array}{c}\text { Data da } \\
\text { realização }\end{array}$ & $\begin{array}{l}\text { Número de } \\
\text { participantes }\end{array}$ & $\begin{array}{l}\text { Número de } \\
\text { sessões }\end{array}$ & $\begin{array}{l}\text { Duração } \\
\text { média dos } \\
\text { áudios }\end{array}$ \\
\hline $\begin{array}{l}\text { I - Distrito } \\
\text { Sanitário } \\
\text { Norte I }\end{array}$ & $\begin{array}{c}\text { Centro de } \\
\text { Referência de } \\
\text { Assistência } \\
\text { Social (CRAS) }\end{array}$ & 08/03/2017 & 12 & 01 & 1 hora \\
\hline $\begin{array}{l}\text { II - Distrito } \\
\text { Sanitário } \\
\text { Norte II }\end{array}$ & $\begin{array}{l}\text { Unidade } \\
\text { Básica de } \\
\text { Saúde }\end{array}$ & $30 / 03 / 2017$ & 07 & 01 & 1 hora \\
\hline $\begin{array}{c}\text { III - Distrito } \\
\text { Sanitário } \\
\text { Oeste }\end{array}$ & $\begin{array}{l}\text { Conselho } \\
\text { Comunitário } \\
\text { de Saúde }\end{array}$ & $24 / 07 / 2017$ & 12 & 01 & 1 hora \\
\hline
\end{tabular}

Fonte: Dados da pesquisa. Elaboração do autor, 2017.

Destaca-se que em Natal existem 862.044 habitantes e 9,7\% da população natalense possui $\geq 60$ anos $^{44}$. Além disso, o percentual de cobertura da ESF no município equivale a $38,8 \%$, ou seja, apenas 338.100 pessoas são atendidas por noventa e oito equipes da ESF ${ }^{45}$. Quanto à cobertura do NASF, em Natal existem três equipes, todas do tipo I, que dão apoio matricial às equipes da ESF em sete UBS localizadas nos distritos sanitários Norte I, Norte II e Oeste ${ }^{45}$.

As sessões dos grupos focais aconteceram em datas, horários e locais previamente pactuados pessoalmente com pessoas idosas que tinham capacidade de realizar as suas atividades cotidianas de forma independente, que tinham 
cognição e que se dispuseram participar da pesquisa através da assinatura do TCLE (apêndice 1). Além disso, os mencionados sujeitos tinham que ser atendidos e participarem das atividades propostas pelos profissionais da ESF e do NASF de cada UBS selecionada. Ressalta-se que não houve a desistência de nenhum participante.

Para nortear as sessões dos grupos focais, um guia de temas foi elaborado pela equipe de pesquisa e enviado por e-mail para treze especialistas (profissionais do serviço e da universidade) em pesquisa qualitativa, envelhecimento populacional e formação em saúde, na perspectiva de aperfeiçoá-lo e validá-lo. Seis pesquisadoras (três doutoras e três mestras) deram devolutiva com contribuições para o guia, sendo utilizada uma versão final contendo sete questões (apêndice 2).

A operacionalização da coleta dos dados aconteceu a partir do registro de áudio dos grupos focais realizados entre o pesquisador condutor e os participantes, bem como dos registros anotados com as observações de cada encontro.

\subsection{Análise dos dados}

\section{a) Pesquisa documental}

A análise dos dados na etapa da pesquisa documental foi realizada com base no método da análise de conteúdo, na modalidade temática, contemplando as fases de pré-análise, exploração do material e interpretação dos dados ${ }^{40}$. Segundo Minayo ${ }^{40}$, o tema é o elemento significativo que se busca a partir da leitura de um determinado texto, denotando os valores de referência e os modelos de comportamento presentes no discurso.

Nesse sentido, a temática do envelhecimento foi analisada em três unidades de registros pré-estabelecidas: (I) competências e habilidades; (ii) perfil profissional; e (iii) estrutura curricular, conforme explicitado na figura 1. Optou-se por analisar a citada temática nessas três unidades de registro, pois as competências e habilidades, de acordo com o que consta na Lei de Diretrizes e Bases da Educação Nacional ${ }^{46}$, constituem-se na capacidade de mobilizar, articular, colocar em prática valores e conhecimentos necessários para o desempenho eficiente de atividades requeridas no trabalho. 
Diante de tais competências e habilidades, almeja-se que os futuros profissionais tenham um perfil para atuar de forma generalista, humanística, crítica e reflexiva, em consonância com os princípios e diretrizes da Saúde Coletiva e do SUS. Ademais, tais competências e habilidades e perfil profissional podem ser proporcionados através da existência de temas específicos na estrutura curricular de cada formação. Desse modo, as unidades de registro aqui definidas e que devem constar obrigatoriamente nos projetos pedagógicos, influenciam de maneira significativa no saber-fazer de cada profissional de saúde. Ressalta-se que o processo de análise dos dados ocorreu entre os meses de setembro e novembro de 2016.

Figura 1 - Fluxograma da análise dos projetos pedagógicos. Rio Grande do Norte, Brasil. 2016.

PROJETOS PEDAGÓGICOS

LEGENDA:

A: Competências e Habilidades.

B: Perfil Profissional.

C: Estrutura Curricular.

D: Temática do envelhecimento

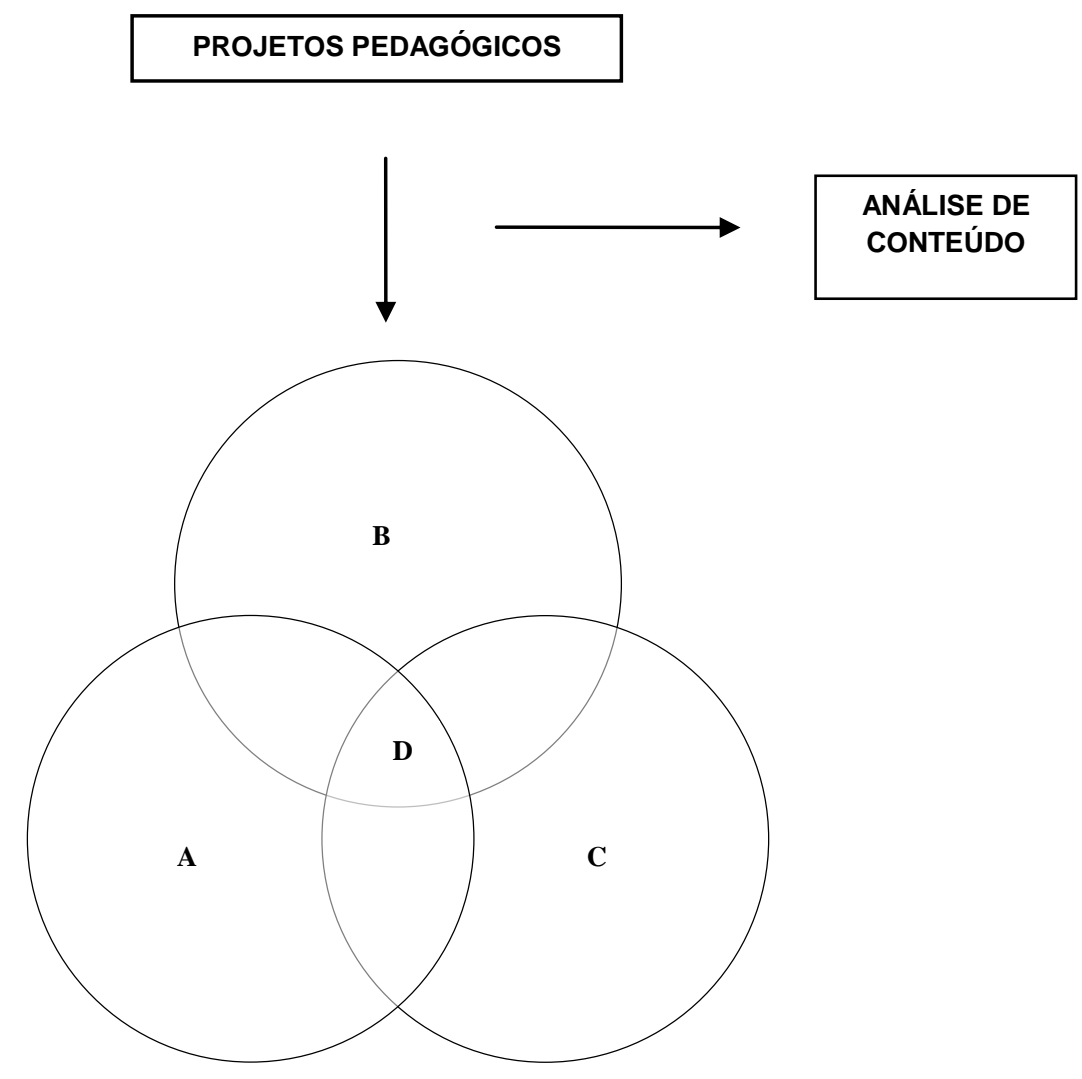

Fonte: Elaboração do autor, 2017. 


\section{b) Grupo focal}

Assim como na pesquisa documental, a análise das falas dos participantes dos grupos focais também foi com base no método da análise de conteúdo, utilizando a modalidade temática ${ }^{39}$. Inicialmente foi realizada a transcrição dos áudios e em seguida a leitura flutuante dos textos, excluindo o que não era relevante para a pesquisa.

Posteriormente, uma nova leitura foi feita com o intuito de identificar as principais temáticas que surgiram a partir das falas dos participantes. A partir disso, a análise das diferentes percepções resultou na identificação de três unidades temáticas: (I) necessidades de boas condições de vida; (ii) necessidades de acesso aos serviços de saúde; (iii) soluções para atender as necessidades elencadas.

Salienta-se que a identificação dos sujeitos foi preservada, sendo atribuído um código aleatório para cada um. Ao todo, foram atribuídos trinta e um codificadores, tais como participante 01, participante 02, participante 03 e assim por diante. Ademais, as UBS não foram identificadas, pois a análise deu-se em relação ao conjunto dos grupos focais e não especificamente para o grupo focal de cada serviço de saúde. Por fim, o processo de análise dos dados ocorreu nos meses de março, abril e julho de 2017 e as transcrições, bem como os resultados finais, não foram retornadas às pessoas idosas para comentários e/ou correções.

\subsection{Aspectos éticos}

Em detrimento às Resoluções n. $9466 / 12$ e n. ${ }^{\circ}$ 510/2016 do CNS, que estabelecem normas para a realização de estudos com seres humanos, a pesquisa que deu origem a esta dissertação teve aprovação do CEP/HUOL/UFRN através do

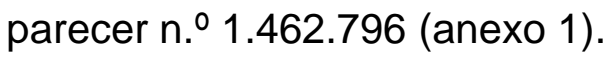




\section{ARTIGOS PRODUZIDOS}

\subsection{Artigo I}

Artigo publicado no periódico International Archives of Medicine (ISSN 17557682), que tem fator de impacto 0.824 , classificado como Qualis B3 na área da Medicina II da CAPES.

\section{UM OLHAR SOBRE A FORMAÇÃO EM SAÚDE COM ÊNFASE NO ENVELHECIMENTO}

O artigo analisa a abordagem da temática do envelhecimento na formação dos profissionais da Estratégia Saúde da Família e do Núcleo de Apoio à Saúde da Família. Trata-se de um estudo com abordagem qualitativa, do tipo documental, realizado no estado do Rio Grande do Norte, situado na região Nordeste do Brasil. Para alcançar o objetivo, realizou-se a análise dos projetos pedagógicos dos cursos para as mencionadas profissões, com base no método da análise de conteúdo, utilizando a técnica da análise temática em três unidades de registro préestabelecidas: (I) competências e habilidades; (ii) perfil profissional; e (iii) estrutura curricular. A partir da operacionalização das análises dos projetos pedagógicos emergiram duas categorias temáticas: Discussão acerca do envelhecimento e formação para atenção à saúde da pessoa idosa. Nesta pesquisa, percebe-se que a discussão acerca da temática do envelhecimento no processo de formação de recursos humanos em saúde ainda é incipiente. Assim, se faz necessário preparar pessoas para oferecer atenção adequada à população idosa, bem como para formular e gerir políticas públicas para a mencionada população usuária do Sistema Único de Saúde.

Palavras-chave: Envelhecimento; Saúde do Idoso; Recursos Humanos em Saúde; Educação em Saúde; Saúde da Família. 


\section{A LOOK AT PROFESSIONAL EDUCATION IN HEALTH WITH EMPHASIS ON AGING}

The article analyzes the approach of the aging thematic in the training of professionals of the Family Health Strategy and the Family Health Support Nucleus. This is a study with a qualitative approach, documental type, carried out in the state of Rio Grande do Norte, located in the Northeast region of Brazil. In order to reach the aim, the pedagogical projects of the courses for the mentioned professions was analyzed, based on the content analysis method, using the thematic analysis technique in three pre-established registration units: (i) skills and abilities, (ii) professional profile, and (iii) curricular structure. From the operationalization of the analysis of the pedagogical projects emerged two thematic categories: Discussion about aging and training for health care of the elderly. In this research, it is noticed that the discussion about the aging issue in the process of human resources training in health is still incipient. Therefore, it is necessary to prepare people to offer adequate attention to the elderly population, as well as formulate and manage public policies for the mentioned user population of the Unified Health System.

Keywords: Aging; Health of the Elderly; Health Manpower; Health education; Family Health.

\section{Introdução}

O aumento da expectativa de vida e da proporção de pessoas idosas (idade $\geq$ 60 anos) tem se tornado um fenômeno global, com exceção de alguns países do continente africano ${ }^{12}$. No início dos anos 2000 , a população idosa mundial continha cerca de seiscentos milhões de indivíduos, representando $10 \%$ da população geral. Em 2050, estima-se que existam cerca de dois bilhões de pessoas idosas em todo o mundo ${ }^{3}$.

No Brasil, o envelhecimento populacional vem acontecendo de maneira muito acelerada e significativamente maior do que o modo ocorrido em outros países durante o século vinte. Foi preciso mais de cem anos para que a França, por exemplo, visse a sua população idosa aumentar de $7 \%$ para $14 \%$ em relação à população francesa geral ${ }^{4}$. Na população brasileira, essa transformação demográfica 
acontecerá nas próximas duas décadas e evidenciará novas demandas e necessidades que precisarão ser reconhecidas e atendidas através de políticas públicas $^{5{ }^{\prime} 6}$.

Envelhecer não é um problema. Entretanto, a população brasileira está envelhecendo com maiores limitações funcionais e acentuados problemas de saúde $^{7}$. Ao acelerado processo de envelhecimento populacional incorpora-se o aumento de morbidades, incapacidades funcionais, diminuição da independência e da autonomia, bem como o aumento no número de internações de pessoas idosas longevas (idade $\geq 80$ anos), segmento etário que mais cresce dentre a população idosa, em unidades de terapia intensiva no âmbito do Sistema Único de Saúde (SUS) ${ }^{8}$.

Além disso, a qualidade da assistência ofertada para a população idosa está aquém das necessidades que ela requer, situação que demonstra a importância em garantir investimentos para enfrentar o fenômeno populacional que vivemos e previsto para se intensificar nos próximos anos ${ }^{9 \prime 10}$. Para provocar mudanças no Sistema de Saúde, bem como nas práticas de atenção à saúde das pessoas idosas, é preciso organizar redes de atenção à saúde que sejam coordenadas pelas equipes da atenção primária, mais precisamente pelas equipes da Estratégia Saúde da Família (ESF) e do Núcleo de Apoio à Saúde da Família (NASF) ${ }^{11}$.

De acordo com a Política Nacional de Atenção Básica (PNAB), instaurada em 21 de outubro de 2011, através da Portaria n.ำ 2.488 do Ministério da Saúde, a ESF é a principal porta de entrada do SUS e o principal meio de comunicação dos usuários com as redes de atenção à saúde. O cuidado proporcionado pela equipe multiprofissional da ESF, no âmbito domiciliar ou nas unidades básicas de saúde, é capaz de valorizar a singularidade e a história de vida dos sujeitos, criando vínculos entre os usuários e os serviços de saúde ${ }^{12}$.

Com o objetivo de fortalecer ainda mais a atenção primária à saúde no Brasil e ampliar o escopo de atuação dos profissionais da ESF, o Ministério da Saúde criou em 2008 o NASF, através da Portaria n. ${ }^{\circ} 154$. Os profissionais do NASF, juntamente com os profissionais da ESF, buscam proporcionar a integralidade do cuidado para os demais níveis de atenção. Além disso, com a realização do apoio matricial, buscam romper com as práticas de trabalho verticalizadas e hierarquizadas ${ }^{13}$.

No que tange à saúde da pessoa idosa, esses profissionais devem atuar à luz da prática colaborativa e promover ações em prol do envelhecimento ativo ${ }^{14^{\prime} 15}$. 
Portanto, para identificar se a formação em saúde está de acordo com o que é almejado para atender essa parcela crescente da população, este artigo tem o objetivo de analisar a abordagem da temática do envelhecimento na formação dos profissionais da ESF e do NASF.

\section{Metodologia}

\section{Caracterização da pesquisa}

Este artigo é resultante de um estudo com abordagem qualitativa, do tipo documental, realizado no estado do Rio Grande do Norte $(R N)$, situado na região Nordeste do Brasil. O Nordeste é a segunda região do país com o maior número de pessoas idosas, concentrando aproximadamente $29 \%$ de toda a população idosa brasileira $^{10}$ e no RN 9,5\% da população possui idade $\geq 60$ anos $^{16}$.

Para alcançar o objetivo deste estudo, foi realizada a busca e análise dos projetos pedagógicos dos cursos para as profissões que compõem as esquipes da ESF e do NASF, relatadas na quadro 1.

Quadro 1 - Caracterização das equipes multiprofissionais da ESF e do NASF. Brasil. 2012.

\begin{tabular}{cc}
\hline & Profissionais da ESF \\
\hline $\begin{array}{c}\text { Profissionais de nível médio } \\
\text { Profissionais de nível superior }\end{array}$ & $\begin{array}{c}\text { Agente comunitário de saúde, técnico em saúde } \\
\text { bucal, técnico de enfermagem }\end{array}$ \\
Profissionais do NASF & Cirurgião-dentista, enfermeiro, médico \\
Profissionais de nível superior & $\begin{array}{c}\text { Assistente social, profissional de educação física, } \\
\text { farmacêutico, fisioterapeuta, fonoaudiólogo, } \\
\text { nutricionista, psicólogo, terapeuta ocupacional, } \\
\text { arte-educador e sanitarista }\end{array}$ \\
\hline
\end{tabular}

Fonte: Ministério da Saúde, 2012.

Destaca-se que o profissional sanitarista pode ser qualquer profissional com pós-graduação em Saúde Pública ou Saúde Coletiva, bem como o profissional graduado diretamente nessas áreas. Neste estudo, optou-se por buscar e analisar somente os projetos pedagógicos das graduações em Saúde Coletiva. 


\section{Coleta dos dados}

Os dados do estudo foram coletados a partir da leitura dos projetos pedagógicos dos cursos para as profissões relatadas no quadro 1. Para ter acesso a esses documentos, que são de domínio público, foi planejada uma estratégia de busca para mapear os cursos ofertados pelas instituições de ensino públicas e privadas do $\mathrm{RN}$, com registro nos sistemas de informação do Ministério da Educação. Para identificar os cursos de nível médio foi consultado o Sistema Nacional de Informações da Educação Profissional e Tecnológica (SISTEC) e para identificar os cursos de nível superior foi consultado o Sistema de Regulação do Ensino Superior (e-MEC).

Em seguida, realizou-se a busca dos projetos pedagógicos junto às coordenações dos cursos nas instituições de ensino, via acesso às páginas eletrônicas institucionais, e-mail ou presencialmente, para uma posterior análise. Todo o processo de coleta dos dados aconteceu entre os meses de junho e agosto de 2016.

\section{Análise dos dados}

A análise dos dados foi realizada com base no método da análise de conteúdo, utilizando a técnica da análise temática, contemplando as fases de préanálise, exploração do material e interpretação dos dados. Segundo Minayo ${ }^{17}$, em pesquisas qualitativas, a análise de conteúdo é utilizada para auxiliar a interpretação subjetiva de textos. Já o tema é o elemento significativo que se busca a partir da leitura de um determinado conteúdo textual, denotando os valores de referência e os modelos de comportamento presentes nos discursos que contribuirão para a formulação das unidades temáticas.

Nesse sentido, a temática do envelhecimento, definida como o objeto de estudo, foi analisada em três unidades de registros pré-estabelecidas: (i) competências e habilidades; (ii) perfil profissional; e (iii) estrutura curricular. Optou-se por analisar a citada temática nessas três unidades de registro, pois as competências e habilidades, de acordo com o que consta na Lei de Diretrizes e Bases da Educação Nacional ${ }^{18}$, constituem-se na capacidade de mobilizar, articular, 
colocar em prática valores e conhecimentos necessários para o desempenho eficiente de atividades requeridas no trabalho.

Diante de tais competências e habilidades, almeja-se que os futuros profissionais tenham um perfil para atuar de forma generalista, humanística, crítica e reflexiva, em consonância com os princípios e diretrizes da Saúde Coletiva e do SUS. Ademais, tais competências e habilidades e perfil profissional podem ser proporcionados através da existência de temas específicos na estrutura curricular de cada formação.

Desse modo, as unidades de registro aqui definidas e que devem constar obrigatoriamente nos projetos pedagógicos, influenciam de maneira significativa no saber-fazer de cada profissional de saúde. Ressalta-se que o processo de análise dos dados ocorreu entre os meses de setembro e novembro de 2016.

\section{Aspectos éticos}

Por se tratar de uma pesquisa documental, onde os documentos analisados são de domínio público, destaca-se que não foi preciso submeter o presente estudo para apreciação e parecer do Comitê de Ética em Pesquisa, conforme orientações das Resoluções n.․ 466/2013 e n.ํ5 510/2016 do Conselho Nacional de Saúde.

\section{Resultados}

Para facilitar a leitura e compreensão dos resultados, consideramos ser necessário descrever primeiramente algumas informações sobre os cursos e as instituições de ensino participantes do estudo. Foram identificados 70 cursos para as 17 profissões que atuam na ESF e no NASF (tabela 1). Tais cursos são ofertados por 16 instituições de ensino, sendo a maioria (82\%) de natureza privada. Ademais, $62 \%$ do quantitativo total de instituições de ensino concentra-se na região metropolitana do município do Natal, capital do RN. 
Tabela 1 - Distribuição do quantitativo de projetos pedagógicos analisados por curso. Rio Grande do Norte. 2016.

\begin{tabular}{|c|c|c|c|c|c|}
\hline Curso & $\begin{array}{c}\text { № total } \\
\text { de cursos }\end{array}$ & $\begin{array}{l}\text { № de cursos } \\
\text { ofertados por } \\
\text { instituições } \\
\text { de natureza } \\
\text { privada }\end{array}$ & $\begin{array}{c}\text { № de projetos } \\
\text { pedagógicos } \\
\text { disponibilizados e } \\
\text { analisados }\end{array}$ & $\begin{array}{c}\text { № de cursos } \\
\text { ofertados por } \\
\text { instituições de } \\
\text { natureza } \\
\text { pública }\end{array}$ & $\begin{array}{c}\text { № de projetos } \\
\text { pedagógicos } \\
\text { disponibilizados e } \\
\text { analisados }\end{array}$ \\
\hline $\begin{array}{l}\text { Bacharelado em } \\
\text { Arte e Educação }\end{array}$ & 01 & 00 & 00 & 01 & 00 \\
\hline $\begin{array}{l}\text { Bacharelado em } \\
\text { Educação Física }\end{array}$ & 07 & 05 & 05 & 02 & 02 \\
\hline $\begin{array}{c}\text { Bacharelado em } \\
\text { Enfermagem }\end{array}$ & 11 & 09 & 06 & 02 & 02 \\
\hline $\begin{array}{c}\text { Bacharelado em } \\
\text { Farmácia }\end{array}$ & 05 & 04 & 02 & 01 & 01 \\
\hline $\begin{array}{c}\text { Bacharelado em } \\
\text { Fisioterapia }\end{array}$ & 06 & 05 & 04 & 01 & 01 \\
\hline $\begin{array}{l}\text { Bacharelado em } \\
\text { Fonoaudiologia }\end{array}$ & 02 & 01 & 01 & 01 & 01 \\
\hline $\begin{array}{l}\text { Bacharelado em } \\
\text { Gestão em } \\
\text { Sistemas e } \\
\text { Serviços de } \\
\text { Saúde (Saúde } \\
\text { Coletiva) }\end{array}$ & 01 & 00 & 00 & 01 & 01 \\
\hline $\begin{array}{c}\text { Bacharelado em } \\
\text { Medicina }\end{array}$ & 03 & 01 & 01 & 02 & 02 \\
\hline $\begin{array}{c}\text { Bacharelado em } \\
\text { Nutrição }\end{array}$ & 06 & 05 & 04 & 01 & 01 \\
\hline $\begin{array}{c}\text { Bacharelado em } \\
\text { Odontologia }\end{array}$ & 03 & 01 & 01 & 02 & 02 \\
\hline $\begin{array}{c}\text { Bacharelado em } \\
\text { Psicologia }\end{array}$ & 07 & 06 & 04 & 01 & 01 \\
\hline $\begin{array}{c}\text { Bacharelado em } \\
\text { Serviço Social }\end{array}$ & 11 & 09 & 06 & 02 & 02 \\
\hline $\begin{array}{c}\text { Bacharelado em } \\
\text { Terapia } \\
\text { Ocupacional }\end{array}$ & 01 & 01 & 01 & 00 & 00 \\
\hline $\begin{array}{c}\text { Técnico em } \\
\text { Agente } \\
\text { Comunitário de } \\
\text { Saúde }\end{array}$ & 02 & 00 & 00 & 02 & 02 \\
\hline Técnico em & 02 & 00 & 00 & 02 & 02 \\
\hline
\end{tabular}




\begin{tabular}{cccccc}
\hline Enfermagem & & & & & \\
\hline Técnico em & 02 & 00 & 00 & 02 & 02 \\
Saúde Bucal & $\mathbf{7 0}$ & $\mathbf{4 7}$ & $\mathbf{3 5}$ & $\mathbf{2 3}$ & $\mathbf{2 2}$ \\
\hline Total & $\mathbf{7 0}$ & \\
\hline
\end{tabular}

Fonte: Ministério da Educação, 2016.

Destaca-se que $81 \%$ dos cursos de Enfermagem, $80 \%$ dos cursos de Farmácia, $83 \%$ dos cursos de Fisioterapia, $86 \%$ dos cursos de Psicologia e $81 \%$ dos cursos de Serviço Social, que formam profissionais que estão contemplados nas equipes da ESF e do NASF, são ofertados por instituições de ensino da rede privada. Dos 70 cursos existentes, 57 (81\%) disponibilizaram os seus projetos pedagógicos para a pesquisa.

Entretanto, 13 cursos (19\%) não tiveram os seus projetos pedagógicos analisados por dois principais motivos: Ou o projeto pedagógico não estava publicado na página eletrônica da instituição de ensino, ou a instituição de ensino recusou-se em disponibilizar o projeto pedagógico. Por isso, não houve análise do projeto pedagógico do curso em Arte e Educação (Arte-educador), pois a única instituição de ensino que oferta essa graduação no $R N$ não disponibilizou o mencionado documento institucional.

A partir da operacionalização das análises das competências e habilidades, perfil profissional e estrutura curricular descritas nos projetos pedagógicos, à luz da temática do envelhecimento, emergiram duas categorias temáticas: Discussão acerca do envelhecimento e formação para atenção à saúde da pessoa idosa.

\section{Categoria 1: Discussão acerca do envelhecimento}

Em algumas situações, tais como no curso Técnico em Agente Comunitário de Saúde da Escola Técnica do SUS do Rio Grande do Norte; curso Técnico em Enfermagem da Escola de Saúde de Natal; curso de Serviço Social do Instituto de Ensino Superior do Rio Grande do Norte; e os cursos de Enfermagem da Universidade Federal do Rio Grande do Norte, da Universidade do Estado do Rio Grande do Norte e da Universidade Potiguar, o envelhecimento e a saúde da pessoa idosa são abordados juntamente com os demais ciclos de vida (saúde da criança, saúde do adolescente e saúde do adulto). 
“[...] Práticas de atenção básica: educação em saúde, vigilância à saúde e epidemiológica e sanitária; imunização; planejamento familiar, pré-natal; prevenção do câncer, prevenção e controle de DST/AIDS e de doenças imunopreveníveis; prevenção e controle de riscos e agravos à saúde mental, à saúde do trabalhador e à saúde do idoso [...]." (Trecho extraído da ementa do componente curricular Atenção Básica e Saúde da Família, do curso de Enfermagem da Universidade Federal do Rio Grande do Norte).

“[...] Desenvolver ações de Promoção e Prevenção à Saúde e prevenir riscos e agravos nos ciclos de vida; apoiar e acompanhar o desenvolvimento do ciclo gravídico; acompanhar o crescimento e desenvolvimento infantil e a situação vacinal das crianças conforme planejamento da equipe de saúde; realizar ações de promoção e prevenção à saúde priorizando as situações de vulnerabilidade dos adolescentes; desenvolver e acompanhar ações da Política Nacional da Saúde do Homem; acompanhar o processo de envelhecimento e as situações de vulnerabilidade da pessoa idosa [...]". (Trecho extraído da ementa do componente curricular A Família e o Trabalho do Agente Comunitário de Saúde, do curso Técnico em Agente Comunitário de Saúde da Escola Técnica do SUS do Rio Grande do Norte).

Em outras situações, como no curso de Medicina da Universidade do Estado do Rio Grande do Norte; curso de Fisioterapia da Faculdade Natalense de Ensino e Cultura; nos cursos de Fisioterapia, Nutrição, Medicina, Psicologia e Terapia Ocupacional da Universidade Potiguar, a contextualização do envelhecimento e da saúde da pessoa idosa está reduzida aos aspectos biológicos e fisiológicos.

"[...] Estudos e práticas profissionais voltados ao idoso, com ações de promoção e prevenção de doenças, estimulação cognitiva e tratamento terapêutico ocupacional de doenças decorrentes das alterações fisicológicas dos idosos [...]." (Ementa do componente curricular Estágio em Geriatria e Gerontologia, do curso de Terapia Ocupacional da Universidade Potiguar).

Apesar dessa predominância em secundarizar ou simplificar a discussão da temática do envelhecimento, destaca-se a existência de componentes curriculares que vão contra essa corrente dominante. No projeto pedagógico da graduação em Fisioterapia da Universidade Federal do Rio Grande do Norte, por exemplo, consta a existência do componente curricular "Gerontologia", que tem como principal objetivo propiciar aos alunos e futuros profissionais de saúde uma compreensão multidimensional do envelhecimento. Porém, o referido componente curricular ainda 
não é ofertado como um requisito obrigatório na formação dos fisioterapeutas e ocorre de modo uniprofissional.

“[...] Reflexão sobre os principais tópicos da Gerontologia e Geriatria, através de um estudo multidimensional do processo de envelhecimento, com enfoque na prevenção e na reabilitação dos problemas que afetam a saúde e a qualidade de vida do idoso. Análise dos elementos teóricos e metodológicos necessários para a avaliação das dimensões de saúde, dos programas de intervenção e suas repercussões no estado de bem-estar das pessoas idosas [...]." (Ementa do componente curricular Gerontologia, do curso de Fisioterapia da Universidade Federal do Rio Grande do Norte).

Vale salientar que na Universidade Federal do Rio Grande do Norte também há o componente curricular "Saúde e Cidadania". Nesse componente curricular os graduandos da área da saúde se inserem em serviços de saúde da atenção primária, com ou sem ESF, para que possam compreender, através da educação interprofissional e do método pedagógico da problematização, as demandas sociais que acometem a população usuária do SUS. Entretanto, nesse componente curricular não há discussão de questões relativas ao envelhecimento.

“[...] A disciplina Saúde e Cidadania - SACI - busca a integração do ensino a partir da interação básico/profissionalizante, teoria/prática, disciplina e cursos com os serviços de saúde e a comunidade. Visa oferecer ao aluno, iniciante dos cursos da área da saúde da UFRN, o ambiente propício à reflexão dos problemas da saúde da população e das atividades de atenção à saúde na comunidade, buscando o estabelecimento da relação educação, saúde e cidadania, através do trabalho interprofissional e interdisciplinar [...]." (Trecho extraído da ementa do componente curricular Saúde e Cidadania, da Universidade Federal do Rio Grande do Norte).

Outro exemplo refere-se ao curso de Medicina da Escola Multicampi de Ciências Médicas do Rio Grande do Norte, vinculado à Universidade Federal do Rio Grande do Norte e localizado no interior do Estado, no município de Caicó. No referido curso, a estrutura curricular está organizada por núcleos de conhecimentos, formados por diferentes componentes curriculares. Dentre esses núcleos de conhecimento há um específico para a atenção à saúde da pessoa idosa, denominado "Geriatria". 
Tal núcleo aborda questões de ordem fisiológica, epidemiológica e social do processo de envelhecimento e do processo de transição demográfica vivenciada no Brasil. Ademais, nesse mesmo núcleo é abordada também a questão da promoção à saúde da população idosa, todavia, de modo uniprofissional.

"Conceitos e aspectos epidemiológicos do envelhecimento. O processo do envelhecimento e alterações fisiológicas. Princípios da prática geriátrica - processo saúde-doença. Grandes síndromes geriátricas: Distúrbios mentais, incontinências e traumatismos (quedas). Doenças degenerativas do sistema nervoso central: Alzheimer, demências, doença de Parkinson. Aspectos farmacológicos e psicológicos [...] Reabilitação geriátrica e promoção da saúde. O impacto do envelhecimento e a perspectiva de morte. Relação Médico-paciente-cuidador. Aspectos éticos em geriatria". (Trecho extraído da ementa do componente curricular Geriatria, do curso de Medicina da Escola Multicampi de Ciências Médicas da Universidade Federal do Rio Grande do Norte).

\section{Categoria 2: Formação para atenção à saúde da pessoa idosa}

A formação profissional em saúde descrita nos projetos pedagógicos analisados está em consonância com o modelo de formação descrito nas Diretrizes Curriculares Nacionais (DCN), almejando uma formação generalista, humanística, crítica e reflexiva aos futuros profissionais de saúde ${ }^{19 ' 20}$, conforme os trechos abaixo:

"O curso forma um profissional com perfil generalista, humanístico, crítico e reflexivo, para atuar nos diversos níveis de atenção à saúde com base no rigor técnico e científico [...] em articulação com as novas tecnologias para diagnóstico e tratamento clínico-cirúrgico [...]". (Trecho extraído do projeto pedagógico do curso Odontologia da Universidade Potiguar).

"O profissional deverá ter uma formação generalista, com competências teórica, metodológica e política e capacidade de análise crítica e propositiva nos diversos espaços de atuação político-profissional [...]". (Trecho extraído do projeto pedagógico do curso de Serviço Social da Universidade do Estado do Rio Grande do Norte).

"[...] O curso propõe, aos seus futuros enfermeiros, uma formação generalista, a partir da qual eles poderão exercer a sua profissão com postura ética e humanista, atuando na assistência direta aos usuários do sistema de saúde e coordenando o processo do cuidar em enfermagem [...]". (Trecho extraído do projeto pedagógico do curso de Enfermagem da Faculdade de Enfermagem Nova Esperança). 
Todavia, em todos os projetos pedagógicos não está previsto o desenvolvimento de competências para que os profissionais possam atuar frente às necessidades de saúde da população idosa. Em especial, no que se refere à atuação que propicie o cuidado integral e o desenvolvimento da autonomia, do protagonismo e da independência do sujeito que envelhece.

"[...] O profissional deverá desenvolver todos os aspectos relacionados ao estudo do medicamento: Pesquisa, produção, comercialização, dispensação, atenção farmacêutica e vigilância. Tal formação também abrange a formação social do farmacêutico como profissional da saúde, bem como a formação para as análises clínicas e toxicológicas e para a indústria de medicamentos [...]". (Trecho extraído do projeto pedagógico do curso de Farmácia da Faculdade Natalense de Ensino e Cultura).

“[...] Realizar consultas, avaliações e reavaliações do paciente colhendo dados, solicitando, executando e interpretando exames propedêuticos e complementares que permitam elaborar um diagnóstico cinético-funcional, para eleger e quantificar as intervenções e condutas fisioterapêuticas apropriadas, objetivando tratar as disfunções no campo da Fisioterapia [...]". (Trecho extraído do projeto pedagógico do curso de Fisioterapia do Centro Universitário do Rio Grande do Norte).

Percebeu-se também a inexistência de cursos que ofertam componentes curriculares abordando o envelhecimento de modo interdisciplinar e interprofissional, exemplificado pelos seguintes trechos:

"O componente curricular tem o objetivo de identificar as principais contribuições teóricas da Psicologia do Desenvolvimento em suas dimensões física, cognitiva e psicossocial para a compreensão do processo saúde/doença no contexto da idade adulta e envelhecimento [...]". (Trecho extraído da ementa do componente curricular Idade Adulta e Envelhecimento no Contexto da Saúde, do curso de Psicologia da Universidade Federal do Rio Grande do Norte - Campus Natal).

"[...] Oportunizar a aquisição de conhecimento teórico e prático sobre o processo de avaliação física e prescrição de exercícios físicos voltado a indivíduos idosos visando a qualidade de vida e saúde [...]." (Trecho extraído da ementa do componente curricular Avaliação e Prescrição de Exercício para Idosos, do curso de Educação Física da Universidade Federal do Rio Grande do Norte). 
Como nos projetos pedagógicos dos citados cursos não estão previstos o desenvolvimento de competências para atuar no cuidado à saúde da pessoa idosa, acredita-se que essa ausência seja a justificativa para não haver conteúdos que possibilitem tal desenvolvimento.

A formação profissional para o cuidado da saúde da pessoa idosa, nessas situações, está pautada exclusivamente na assistência às doenças crônicodegenerativas, bem como na identificação e prevenção de danos à saúde. Além disso, tal formação ocorre de forma uniprofissional, ou seja, de forma isolada entre alunos de um mesmo curso.

"[...] Os profissionais de saúde, dentro de seu âmbito profissional, devem estar aptos a desenvolver ações de prevenção, promoção, proteção e reabilitação da saúde [...]". (Trecho extraído do projeto pedagógico do curso de Nutrição de Centro Universitário Facex).

"[...] Formar um profissional que apresente responsabilidade social, capacitado a atuar na prevenção, reabilitação e cura das pessoas, promovendo melhoria na sua qualidade de vida, jamais abandonando seu senso investigativo e crítico reflexivo, na busca de seu aperfeiçoamento [...]". (Trecho extraído do projeto pedagógico do curso de Fisioterapia do Centro Universitário do Rio Grande do Norte).

\section{Discussão}

No campo do trabalho em saúde, a formação profissional é uma discussão permanente. Entre 1990 e 2010, a maioria (71,2\%) das produções científicas acerca do trabalho e da educação na saúde discorria sobre a qualificação dos recursos humanos para atuação no SUS ${ }^{21}$. Além da produção científica, nota-se no sistema educacional brasileiro uma acentuada expansão na oferta de cursos para a formação profissional na área da saúde, principalmente em instituições de ensino do setor privado ${ }^{22}$. Apesar desse forte crescimento, incentivado primordialmente pelas políticas federais, isso não tem sido suficiente para superar as deficiências no referido sistema educacional.

A concentração regional de instituições de ensino, sobretudo em áreas metropolitanas, bem como a proliferação desordenada de cursos, tem ocasionado a formação de profissionais com perfil inadequado para dar suporte às necessidades 
de saúde da população ${ }^{23}$. Nesse sentido, emerge um grande desafio para a Política Nacional de Gestão do Trabalho e da Educação Saúde: Fortalecer a articulação entre as instituições de ensino, os serviços de saúde e a comunidade para proporcionar uma formação que esteja em consonância com as transformações sociais e as demandas do $\mathrm{SUS}^{24}$, com destaque para as demandas de saúde das pessoas idosas.

A lacuna entre a saúde e a educação torna-se maior quando há um recorte para a relação entre a saúde da pessoa idosa e a formação profissional. Por um lado, destaca-se a forte dependência da população idosa aos serviços de saúde, resultante do processo de transição demográfica que acontece não só no Brasil, mas também em outros países emergentes (Rússia, Índia e China, por exemplo), sobretudo em um contexto de significativa desigualdade social ${ }^{2526}$. Por outro lado, nos projetos pedagógicos dos cursos da área da saúde ainda é pouco expressivo a contextualização do processo de envelhecimento no ensino do cuidado à saúde da pessoa idosa, bem como não há uma oferta significativa de processos de capacitação para qualificar a força de trabalho atuante nos serviços de saúde ${ }^{27}$.

A atenção à saúde da pessoa idosa demanda competências específicas para a contextualização do processo de envelhecimento e exige o desenvolvimento do trabalho interprofissional ${ }^{28 ' 29}$. Essas competências são compreendidas como um conjunto de conhecimentos técnicos e sociais demandados aos estudantes e trabalhadores, devendo estar em consonância com os princípios do $\mathrm{SUS}^{30}$.

Porém, apesar das reformas incentivadas pelas DCN, ainda há uma predominância nos cursos da área da saúde em fazer com que os seus alunos tenham uma formação uniprofissional e cada vez mais especializada ${ }^{31}$. É preciso que a formação em saúde não se limite em conhecimentos especializados e sim, que agrupe conhecimentos de outras áreas e respeite as competências de cada profissão. Sendo assim, diante da leitura dos projetos pedagógicos analisados nesta pesquisa, é possível afirmar que pouco se tem contribuído para a transformação das práticas de ensino e de atenção à saúde.

No que tange à saúde da pessoa idosa, isso significa que o cuidado está resumido à prevenção de doença, desconsiderando os aspectos sociais e subjetivos comuns ao processo de envelhecimento e desfavorecendo a promoção de uma prática de cuidado integral. Os profissionais recém-formados ingressam no mercado 
de trabalho com limitações para a atuação multi e interprofissional, replicando o modelo de atenção centrado na atuação médica e nos hospitais.

Desse modo, a população idosa não é enxergada em sua totalidade pelos profissionais de saúde, com suas subjetividades e interações sociais completamente ignoradas. Além disso, o envelhecimento não é causado por um único aspecto. Pelo contrário, o envelhecimento é multidimensional e complexo e restringir a saúde da pessoa idosa aos aspectos biológicos é tentar tratá-la de forma simples e mais fácili

É necessário compreender também que o envelhecimento é acompanhado por inúmeros outros aspectos, tais como a feminização da velhice ocasionada pela alta mortalidade masculina ${ }^{9}$, bem como o baixo nível de escolaridade dessa parcela da população, o que pode significar, em linhas gerais, um baixo nível socioeconômico ${ }^{10}$.

A integralidade do cuidado à pessoa idosa exige o rompimento do já mencionado modelo de atenção à saúde vigente no Brasil através das ações da ESF e do NASF, priorizando a ampliação do foco na família e a melhoria do acesso ${ }^{33}$. Todavia, com os atuais currículos encontrados nos projetos pedagógicos dos cursos para as profissões estudadas, pouco conseguirá ser alcançado.

Para transformar as práticas de trabalho e, por conseguinte, as práticas assistenciais para a população idosa no cotidiano da atenção primária à saúde e do SUS, é preciso primeiramente qualificar a força de trabalho. Tal qualificação deve partir desde a formação profissional até o desenvolvimento de ações de educação permanente para os trabalhadores já inseridos nos serviços de saúde. Portanto, se faz necessário implantar componentes curriculares obrigatórios que discutam a importância do envelhecimento ativo na formação das profissões da saúde.

Além disso, é preciso sensibilizar o corpo docente das instituições de ensino para transformar as suas práticas pedagógicas. A sensibilização dos docentes para o desenvolvimento de competências incorporadas à saúde da população idosa na formação da futura força de trabalho em saúde nos Estados Unidos, por exemplo, ainda é um nó crítico ${ }^{34}$. Todavia, para afirmar se essa situação é semelhante à realidade brasileira e à realidade do local de realização do presente estudo, é necessário realizar outras pesquisas que extrapolem a análise documental, avaliando a percepção de estudantes e docentes sobre os métodos pedagógicos utilizados durante a formação profissional, com ênfase no envelhecimento, bem 
como investigar a percepção das pessoas idosas acerca do cuidado proporcionado pelos profissionais de saúde que atuam no SUS.

\section{Considerações finais}

Com a realização desta pesquisa, percebe-se que a discussão acerca da temática do envelhecimento no processo de formação de recursos humanos em saúde ainda é incipiente. É necessário preparar pessoas que ofereçam atenção adequada às necessidades de saúde população idosa, bem como para formular e gerir políticas públicas para a mencionada população que é usuária do SUS. Além disso, se faz necessário preparar pessoas para que elas sejam agentes multiplicadores e contribuam com a formação de cuidadores de pessoas idosas.

Ademais, esta pesquisa poderá contribuir com o debate sobre a formação em saúde com ênfase no envelhecimento no estado do $\mathrm{RN}$, bem como em outros estados brasileiros e até de outros países que possuam perfil populacional e políticas de saúde semelhantes ao Brasil, provocando mudanças na formação de recursos humanos em saúde. Essas mudanças devem pautar-se na integração entre o ensino e o serviço, bem como na inclusão da discussão acerca do envelhecimento ativo na agenda da educação permanente do SUS. Afinal, se as necessidades oriundas do acentuado processo de envelhecimento populacional não forem tratadas com prioridade, poderá constituir-se em um grave problema de saúde pública.

\section{Referências}

1. Veras RP. Envelhecimento populacional contemporâneo: demandas, desafios e inovações. Rev Saude Publica 2009; 43(3):548-554.

2. Chaimowicz F, Barcelos EM, Madureira MDS, Ribeiro MTF. Saúde do idoso. 2a Edição. Belo Horizonte: NESCON/UFMG; 2013.

3. Tanjani PT, Motlagh ME, Nazar MM, Najafi F. The health status of the elderly population of Iran in 2012. Arch Gerontolog Geriatr 2015; 60(2):281-287.

4. Veras RP. Envelhecimento populacional e as informações de saúde do PNAD: demandas e desafios contemporâneos. Cad Saude Publica 2007; 23(10):2463-2466 . 
5. Veras RP. Experiências e tendências internacionais de modelos de cuidado para com o idoso. Cien Saude Colet 2012; 17(1):231-238.

6. Louvison MCP, Rosa TEC. Envelhecimento e políticas públicas de saúde da pessoa idosa. In: Berzins MV, Borges MC, organizadores. Políticas públicas para um país que envelhece. $1^{\underline{a}}$ Edição. São Paulo: Martinari; 2012. p. 155-179.

7. Ferreira LMBM, Jerez-Roig J, Andrade FLJP, Oliveira NPD, Araújo JRT, Lima KC. Prevalência de quedas e avaliação da mobilidade em idosos institucionalizados. Rev Bras Geriatr Gerontol 2016; 19(6):995-1003.

8. Menezes TMO, Lopes RLM. Significados do vivido pela pessoa idosa longeva no processo de morte/morrer e luto. Cien Saude Colet 2014; 19(8):3309-3316.

9. Alves KL, Alves MRR, Sá CMCP, Xavier Junior JA, Barros KC, Alves LMRR, Alves MRR, Bezerril JAC, Sá RBCP, Leite RPS, Freitas LIA, Cabral SRSO, Evangelista KM. Nursing professional's working load given to the elderly at the intensive unit care. Int Arch Med 2017; 10(44):1-8.

10. Closs VE, Schwanke CHA. A evolução do índice de envelhecimento no Brasil, nas suas regiões e unidades federativas no período de 1970 a 2010. Rev Bras Geriatr Gerontol 2012; 15(3):443-458.

11. Andrade LM, Sena ELS, Pinheiro GML, Meira EC, Lira LSSP. Políticas públicas para pessoas idosas no Brasil: uma revisão integrativa. Cien Saude Colet 2013; 18(12):3543-3552.

12. Lima RRT, Castro JL. Estudo acerca do perfil: uma contribuição para as políticas de valorização profissional. In: Castro JL, Vilar RLA, Oliveira NHS, organizadoras. As trilhas e os desafios da gestão do trabalho e da educação na saúde. 1를 Edção. Natal: Una; 2016. p. 129-147.

13. Shimizu HE, Fragelli TBO. Competências profissionais essenciais para 0 trabalho no Núcleo de Apoio à Saúde da Família. Rev Bras Educ Med 2016; 40(2):216-225.

14. Costa T, Torres GV, Oliveira RA, Costa MV, Dantas BAS, Miranda JMA, Torres NPL, Souza LA, Vilar RLA. Changes in the quality of life of an elderly group of the Family Health Strategy. Int Arch Med 2016; 9(1):1-9.

15. Belas IA, Rocha JHA, Silva FM, Lustosa JVB, Carneiro WS, Valença AMG, Silva ES, Rodrigues JA. Articulated Actions of the Family Health Strategy 
Teams and Their Centres of Support in the State of Piauí, Brazil. Int Arch Med 2017; 10(5):1-8.

16. Melo LA, Ferreira LMBM, Santos MM, Lima KC. Fatores socioeconômicos, demográficos e regionais associados ao envelhecimento populacional. Rev Bras Geriatr Gerontol 2017; 20(4):494-502.

17. Minayo MCS. O desafio do conhecimento: pesquisa qualitativa em saúde. $13^{\mathrm{a}}$ ed. São Paulo, Rio de Janeiro: Hucitec, Abrasco; 2013.

18. Brasil, 1996. Lei 9.394 de 20 de dezembro de 1996. Estabelece as diretrizes e bases da educação nacional. Diário Oficial da União 1996; 20 dez.

19. Moreira COF, Dias MSA. Curriculum guidelines for health and alterations in health and education models. ABCS Health Sci 2015; 40(3):300-305.

20. Sampaio ATL. Formação e educação permanente em saúde: desafios pedagógicos para um modelo de atenção integral no Brasil. In: Castro JL, Vilar RLA, Oliveira NHS, organizadoras. As trilhas e os desafios da gestão do trabalho e da educação na saúde. 1ª Edição. Natal: Una; 2016. p. 149177.

21. Pinto ICM, Esperidião MA, Silva IV, Soares CM, Santos L, Fagundes TLQ, Viana S, Silva VO, Anjos DSO. Trabalho e educação em saúde no Brasil: tendências da produção científica entre 1990-2010. Cien Saude Colet 2013; 18(6):1525-1534.

22. Teixeira CFS, Coelho MTAD, Rocha MND. Bacharelado interdisciplinar: uma proposta inovadora na educação superior em saúde no Brasil. Cien Saude Colet 2013; 16(6):1635-1646.

23. Pierantoni CR, França T, Magnago C, Nascimento DN, Miranda RG. Graduações em saúde no Brasil: 2000-2010. 1ª Edição. Rio de Janeiro: IMS/UERJ; 2012.

24. Haddad AE, Morita MC, Pierantoni CR, Brenelli SL, Passarella T, Campos FE. Formação de profissionais de saúde no Brasil: uma análise no período de 1991 a 2008. Rev Saude Publica 2010; 44(3):1-9.

25. Guimarães RRM. O futuro do ensino superior nos países BRIC: uma perspectiva demográfica. Rev Bras Estud Popul 2013; 30(2):549-566. 
26. Witt RR, Roos MO, Carvalho NM, Silva AM, Rodrigues CDS, Santos MT. Competências profissionais para o atendimento de idosos em atenção primária à saúde. Rev Esc Enferm USP 2014; 48(5):1018-1023.

27. Motta LB, Aguiar AC, Caldas CP. Estratégia Saúde da Família e a atenção ao idoso: experiências em três municípios brasileiros. Cad Saude Publica 2011; 27(4):779-786.

28. Xavier AS, Koifman L. Educação superior no Brasil e a formação dos profissionais de saúde com ênfase no envelhecimento. Interface (Botucatu) 2011; 15(39):973-984.

29. Arruda LS, Moreira COF. Colaboração interprofissional: um estudo de caso sobre os profissionais do Núcleo de Atenção ao Idoso da Universidade Estadual do Rio de Janeiro (NAI/UERJ), Brasil. Interface (Botucatu) [periódico na Internet]. 2017 Jun [acessado 2017 Ago 10]: [cerca de 12 p.]. Disponível em:

http://www.scielo.br/scielo.php?script=sci_arttext\&pid=S141432832017005010102\&lng=en.

30. Uchimura KY, Bosi MLM. Habilidades e competências entre trabalhadores da Estratégia Saúde da Família. Interface (Botucatu) 2012; 16(40):149160.

31. Almeida Filho NM. Contextos, impasses e desafios na formação de trabalhadores em Saúde Coletiva no Brasil. Cien Saude Colet 2013; 18(6):1677-1682.

32. Schimidt TCG, Silva MJP. Percepção e compreensão de profissionais e graduandos de saúde sobre o idoso e o envelhecimento. Rev Esc Enferm USP 2012; 46(3):609-614.

33. Araújo LUA, Gama ZAS, Nascimento FLA, Oliveira HFV, Azevedo WM, Almeida Júnior HJB. Avaliação da qualidade da atenção primária à saúde sob a perspectiva do idoso. Cien Saude Colet 2014; 19(8):3521-3532.

34. Ford CR, Brown CJ, Sawyer P, Rothrock AG, Ritchie CS. Advancing geriatric education: development of an interprofessional program for health care faculty. Gerontol Geriatr Educ 2015; 36(4):365-383. 


\subsection{Artigo II}

Artigo aceito para publicação no periódico Interface - Comunicação, Saúde e Educação (ISSN 1414-3283), que tem fator de impacto 0.394, classificado como Qualis B3 na área da Medicina II da CAPES.

\section{A educação interprofissional e a temática sobre o envelhecimento: uma análise de projetos pedagógicos na área da saúde}

O artigo analisa a inserção da temática do envelhecimento e da educação interprofissional na formação dos profissionais da Estratégia Saúde da Família (ESF) e do Núcleo de Apoio à Saúde da Família (NASF), a partir da leitura dos projetos pedagógicos dos cursos desses profissionais. A pesquisa que deu origem a este artigo é do tipo documental, com abordagem qualitativa, realizada no Estado do Rio Grande do Norte, Brasil. Os projetos pedagógicos foram analisados com base no método da análise de conteúdo, utilizando o procedimento da análise temática em duas unidades de registro pré-estabelecidas: (I) competências profissionais e (ii) estrutura curricular. Como parte dos resultados, nenhum dos cursos investigados neste estudo oferta uma educação interprofissional em saúde que contemple discussões mais profundas acerca do envelhecimento.

Palavras-chave: Envelhecimento. Saúde do idoso. Educação interprofissional. Formação profissional em saúde. Saúde da família.

\section{La educación interprofesional y la temática sobre el envejecimiento: un análisis de proyectos pedagógicos en el área de la salud}

El artículo analiza la inserción de la temática del envejecimento y de la educación interprofesional en la formación de los profesionales de la Estrategia de Salud de la Familia (ESF) y del Núcleo de Apoyo a la Salud de la Familia (NASF), a partir de la lectura de los proyectos pedagógicos de los cursos de estos profesionales. El estudio que dio origen a este artigo es de tipo documental, de abordaje cualitativo, realizado en el Estado de Rio Grande do Norte, Brasil. Los proyectos pedagógicos fueron analizados en base al método de análisis de contenido, utilizando el procedimiento de análisis temático en dos unidades de registro preestablecidas: $(I)$ 
competencias profesionales y (ii) estructura curricular. Como parte de los resultados, ninguno de los cursos investigados en este estudio oferta una educación interprofesional en salud que contemple discusiones más profundas acerca del envejecimiento.

Palabras clave: Envejecimiento. Salud del anciano. Educación interprofesional. Formación profesional en salud. Salud de la familia.

\section{Interprofessional education and the aging topic: pedagogical projects analysis on the health area}

The article analyzes the insertion of the aging and interprofessional education theme in the training of the Family Health Strategy (ESF) and the Family Health Support Nucleus (NASF) professionals, from the reading of the pedagogical projects of the courses of these professionals. The research giving origin to this article is a documentary type with a qualitative approach, held in the State of Rio Grande do Norte, Brazil. The pedagogical projects were analyzed based on the content analysis method, using the thematic analysis procedure in two pre-established registration units: (i) professional competencies and (ii) curricular structure. As part of the results, none of the courses investigated in this study offer an interprofessional health education addressing deeper discussions about aging.

Keywords: Aging. Health of the elderly. Interprofessional education. Professional education in health. Family Health.

\section{Introdução}

Em detrimento às conquistas políticas e sociais, bem como ao avanço da ciência e da tecnologia, a expectativa de vida e o aumento da proporção de pessoas idosas (idade $\geq 60$ anos) têm se tornado um fenômeno global ${ }^{1}$. No Brasil, constatase uma diminuição da taxa de natalidade e um crescimento acentuado de pessoas idosas, que se intensificará nas próximas duas décadas².

Ao acelerado processo de envelhecimento populacional incorpora-se o aumento de morbidades, incapacidades funcionais, diminuição da independência e da autonomia, bem como o aumento no número de internações em unidades de terapia intensiva ${ }^{3}$. Diante desse momento de transição demográfica, é preciso 
investir no Sistema Único de Saúde (SUS) para dar respostas às necessidades das pessoas idosas ${ }^{4,5}$.

O SUS agrega ações de atenção à saúde, de gestão, de participação social e de educação, sendo definido como um espaço intersetorial e interprofissional ${ }^{6}$. Nesse sentido, ressalta-se a importância em fortalecer a educação e o trabalho interprofissional para qualificar o cuidado integral à saúde da pessoa idosa, configurando-se como alternativa para responder os problemas de saúde dessa parcela da população ${ }^{7,8}$.

A educação interprofissional possui os seus princípios alinhados aos da saúde pública brasileira ${ }^{9}$, pautando-se na formação interativa, significativa e no intercâmbio de saberes entre diferentes profissionais ${ }^{10,11}$. Além do melhor preparo para atuarem em equipe e em consonância aos princípios do SUS, baseando-se na integralidade do cuidado, através da educação interprofissional os estudantes e futuros profissionais de saúde tornam-se mais ágeis para lidarem com as dificuldades presentes no cotidiano do trabalho ${ }^{12}$.

Nas últimas décadas, a educação interprofissional tem se destacado como um componente importante para a transformação da formação e da atenção à saúde, na perspectiva do desenvolvimento do trabalho colaborativo e eficaz ${ }^{13,11}$. Porém, no Brasil, o modelo de formação em saúde predominante ainda é caracterizado como uniprofissional, focado em disciplinas isoladas, na fragmentação do cuidado e da prática biomédica, sendo totalmente destoante do ideal preconizado pelo SUS e pelas Diretrizes Curriculares Nacionais (DCN) para os cursos da saúde ${ }^{14}$.

Ademais, para a atenção à saúde da pessoa idosa é preciso organizar redes de atenção que sejam coordenadas pelas equipes da atenção primária à saúde, mais precisamente pelos profissionais da Estratégia Saúde da Família (ESF) e do Núcleo de Apoio à Saúde da Família $(\mathrm{NASF})^{15}$. As tentativas de organizar a atenção primária à saúde no Brasil remontam desde 1920, com a formulação de diversas propostas em diferentes regiões do País ${ }^{16}$. Contudo, o fortalecimento da atenção primária à saúde só teve início na década de 1990 através do processo de descentralização do SUS, com a garantia da transferência de recursos federais para Estados e Municípios.

Ainda na década de 1990, mais precisamente em 1994, o Ministério da Saúde criou o Programa Saúde da Família (PSF), derivado do Programa de Agentes 
Comunitários de Saúde (PACS), fundado em 1991, com o objetivo de reorientar o modelo assistencial a partir da atenção primária à saúde e em conformidade com os princípios do SUS ${ }^{17}$. Tendo como base a promoção e proteção à saúde, bem como a prevenção de agravos, seja no âmbito individual ou coletivo, o PSF tornou-se eixo estruturante dos Sistemas Municipais de Saúde, passando a se chamar ESF no ano de $2006^{18}$.

Segundo a Política Nacional de Atenção Básica (PNAB), instaurada em 21 de outubro de 2011, através da Portaria n.ำ 2.488 do Ministério da Saúde, a ESF é a principal porta de entrada do SUS e o principal meio de comunicação dos usuários com as redes de atenção à saúde. O cuidado proporcionado pela equipe multiprofissional da ESF, no âmbito domiciliar ou nas unidades básicas de saúde, é capaz de valorizar a singularidade e a história de vida dos sujeitos, criando vínculos entre os usuários e os serviços de saúde ${ }^{19}$.

Com o objetivo de fortalecer ainda mais a atenção primária à saúde no Brasil e ampliar o escopo de atuação dos profissionais da ESF, o Ministério da Saúde criou em 2008 o NASF, através da Portaria n.․ 154. Os profissionais do NASF, juntamente com os profissionais da ESF, assumem a função coordenadora do Sistema de Saúde a partir da atenção primária à saúde, proporcionando a integralidade do cuidado para os demais níveis de atenção. Além disso, com a realização do apoio matricial, buscam romper com as práticas de trabalho verticalizadas e hierarquizadas ${ }^{20}$.

No que tange à saúde da pessoa idosa, o cuidado integral no âmbito da ESF requer a atuação de um elenco de profissionais para além do médico, tais como agente comunitário de saúde, cirurgião-dentista, enfermeiro, técnico de enfermagem, técnico em saúde bucal, bem como os profissionais do $\mathrm{NASF}^{6}$. Esses profissionais devem atuar à luz da prática colaborativa e promover ações em prol do envelhecimento ativo ${ }^{21}$.

Portanto, para identificar se a formação profissional em saúde está de acordo com o que é almejado para atender a população idosa, este artigo tem o objetivo de analisar a inserção da temática do envelhecimento e a da educação interprofissional na formação dos profissionais da ESF e do NASF. 


\section{Metodologia}

\section{Caracterização da pesquisa [subtítulo]}

Este artigo é resultante de uma pesquisa com abordagem qualitativa, do tipo documental, realizada no Estado do Rio Grande do Norte (RN), localizado na região Nordeste do Brasil. O Nordeste é a segunda região do País com o maior número de pessoas idosas, concentrando aproximadamente $29 \%$ de toda a população idosa brasileira $^{22}$. Além disso, de acordo com o censo demográfico realizado em 2010 pelo Instituto Brasileiro de Geografia e Estatística (IBGE), 10,8\% da população do RN possuía idade $\geq 60$ anos $^{23}$.

Para atingir o objetivo da pesquisa, foi realizada a busca e análise dos projetos pedagógicos dos cursos para as profissões que compõem as equipes da ESF e do NASF (quadro 1).

Quadro 1 - Caracterização das equipes multiprofissionais da ESF e do NASF. Brasil.

2012.

\begin{tabular}{cc}
\hline \multicolumn{2}{c}{ Profissionais da ESF } \\
\hline Profissionais de nível superior & Cirurgião-dentista, enfermeiro, médico \\
Profissionais do NASF & Assistente social, profissional de educação física, \\
farmacêutico, fisioterapeuta, fonoaudiólogo, \\
Profissionais de nível superior
\end{tabular}

Fonte: Ministério da Saúde, 2012.

\section{Coleta dos dados [subtítulo]}

Os dados da pesquisa foram coletados a partir da leitura dos projetos pedagógicos dos cursos para as profissões relatadas no quadro 1. Inicialmente foram identificados 70 cursos registrados nos sistemas de informação do Ministério da Educação, ofertados em instituições de ensino públicas e privadas do RN (quadro 2). Para identificar os cursos de nível médio foi consultado o Sistema Nacional de Informações da Educação Profissional e Tecnológica (SISTEC) e para identificar os 
cursos de nível superior foi consultado o Sistema de Regulação do Ensino Superior (e-MEC).

Em seguida, os projetos pedagógicos foram pesquisados juntamente às coordenações dos cursos identificados, através do acesso às páginas eletrônicas institucionais, e-mail ou pessoalmente, havendo a disponibilização e, por conseguinte, análise de 57 projetos pedagógicos (quadro 2). Todo o processo de coleta dos dados aconteceu entre os meses de junho e agosto de 2016.

Quadro 2 - Distribuição do quantitativo de projetos pedagógicos analisados por curso. Rio Grande do Norte. 2016.

\begin{tabular}{|c|c|c|c|c|c|}
\hline Curso & $\begin{array}{c}\text { № total } \\
\text { de cursos }\end{array}$ & $\begin{array}{l}\text { № de cursos } \\
\text { ofertados por } \\
\text { instituições } \\
\text { de natureza } \\
\text { privada }\end{array}$ & $\begin{array}{c}\text { № de projetos } \\
\text { pedagógicos } \\
\text { disponibilizados e } \\
\text { analisados }\end{array}$ & $\begin{array}{c}\text { № de cursos } \\
\text { ofertados por } \\
\text { instituições de } \\
\text { natureza } \\
\text { pública }\end{array}$ & $\begin{array}{c}\text { № de projetos } \\
\text { pedagógicos } \\
\text { disponibilizados e } \\
\text { analisados }\end{array}$ \\
\hline $\begin{array}{l}\text { Bacharelado em } \\
\text { Arte e Educação }\end{array}$ & 01 & 00 & 00 & 01 & 00 \\
\hline $\begin{array}{l}\text { Bacharelado em } \\
\text { Educação Física }\end{array}$ & 07 & 05 & 05 & 02 & 02 \\
\hline $\begin{array}{c}\text { Bacharelado em } \\
\text { Enfermagem }\end{array}$ & 11 & 09 & 06 & 02 & 02 \\
\hline $\begin{array}{c}\text { Bacharelado em } \\
\text { Farmácia }\end{array}$ & 05 & 04 & 02 & 01 & 01 \\
\hline $\begin{array}{c}\text { Bacharelado em } \\
\text { Fisioterapia }\end{array}$ & 06 & 05 & 04 & 01 & 01 \\
\hline $\begin{array}{l}\text { Bacharelado em } \\
\text { Fonoaudiologia }\end{array}$ & 02 & 01 & 01 & 01 & 01 \\
\hline $\begin{array}{c}\text { Bacharelado em } \\
\text { Gestão em } \\
\text { Sistemas e } \\
\text { Serviços de } \\
\text { Saúde (Saúde } \\
\text { Coletiva) }\end{array}$ & 01 & 00 & 00 & 01 & 01 \\
\hline $\begin{array}{c}\text { Bacharelado em } \\
\text { Medicina }\end{array}$ & 03 & 01 & 01 & 02 & 02 \\
\hline $\begin{array}{c}\text { Bacharelado em } \\
\text { Nutrição }\end{array}$ & 06 & 05 & 04 & 01 & 01 \\
\hline $\begin{array}{c}\text { Bacharelado em } \\
\text { Odontologia }\end{array}$ & 03 & 01 & 01 & 02 & 02 \\
\hline $\begin{array}{c}\text { Bacharelado em } \\
\text { Psicologia }\end{array}$ & 07 & 06 & 04 & 01 & 01 \\
\hline
\end{tabular}




\begin{tabular}{|c|c|c|c|c|c|}
\hline $\begin{array}{c}\text { Bacharelado em } \\
\text { Serviço Social }\end{array}$ & 11 & 09 & 06 & 02 & 02 \\
\hline $\begin{array}{c}\text { Bacharelado em } \\
\text { Terapia } \\
\text { Ocupacional }\end{array}$ & 01 & 01 & 01 & 00 & 00 \\
\hline $\begin{array}{c}\text { Técnico em } \\
\text { Agente } \\
\text { Comunitário de } \\
\text { Saúde }\end{array}$ & 02 & 00 & 00 & 02 & 02 \\
\hline $\begin{array}{l}\text { Técnico em } \\
\text { Enfermagem }\end{array}$ & 02 & 00 & 00 & 02 & 02 \\
\hline $\begin{array}{l}\text { Técnico em } \\
\text { Saúde Bucal }\end{array}$ & 02 & 00 & 00 & 02 & 02 \\
\hline Total & 70 & 47 & 35 & 23 & 22 \\
\hline
\end{tabular}

Fonte: Ministério da Educação, 2016.

\section{Análise dos dados [subtítulo]}

Os projetos pedagógicos foram analisados com base no método da análise de conteúdo, na modalidade temática, contemplando as fases de pré-análise, exploração do material e interpretação dos dados. Segundo Minayo ${ }^{24}$, em pesquisas qualitativas, a análise de conteúdo é utilizada para auxiliar a interpretação subjetiva de textos. Já o tema é um elemento significativo identificado a partir da leitura de um determinado conteúdo textual, denotando os valores de referência e os modelos de comportamento presentes no discurso que contribuirão para a formulação das unidades temáticas ${ }^{24}$.

Nesse sentido, as temáticas envelhecimento e educação interprofissional, definidas como objeto deste estudo, foram analisadas em duas unidades de registros pré-estabelecidas: Competências profissionais e estrutura curricular. Optou-se por analisar as citadas temáticas nessas duas unidades de registro, pois as competências, de acordo com a Lei de Diretrizes e Bases da Educação Nacional $^{25}$, consistem na capacidade de mobilizar, articular, colocar em prática valores, habilidades e conhecimentos necessários para o desempenho eficiente de atividades requeridas no trabalho.

Ademais, tais competências podem ser proporcionadas através da existência de temas específicos na estrutura curricular de cada formação. Desse modo, as unidades de registro aqui definidas e que devem constar obrigatoriamente nos 
projetos pedagógicos, influenciam de maneira significativa no saber-fazer de cada profissional de saúde. Ressalta-se que o processo de análise dos dados ocorreu entre os meses de setembro e novembro de 2016.

\section{Aspectos éticos [subtítulo]}

Por se tratar de uma pesquisa documental, onde os documentos analisados são de domínio público, não foi preciso submeter o projeto da pesquisa para apreciação e parecer do Comitê de Ética em Pesquisa, conforme orientações das Resoluções n. 466/2013 e n. ${ }^{\circ}$ 510/2016 do Conselho Nacional de Saúde.

\section{Resultados}

Para facilitar a compreensão dos resultados, julgamos ser necessário descrever primeiramente algumas informações sobre os cursos e as instituições de ensino participantes deste estudo. Foram identificados 70 cursos para as 17 profissões que atuam na ESF e no NASF. Tais cursos são ofertados por 16 instituições de ensino, sendo a maioria (82\%) de natureza privada. Contudo, $62 \%$ do quantitativo total de instituições de ensino concentra-se na região metropolitana do município de Natal, capital do Estado.

Destaca-se que $81 \%$ dos cursos de Enfermagem, $80 \%$ dos cursos de Farmácia, $83 \%$ dos cursos de Fisioterapia, $86 \%$ dos cursos de Psicologia e $81 \%$ dos cursos de Serviço Social, que formam profissionais que estão contemplados nas equipes da ESF e do NASF, são ofertados por instituições de ensino da rede privada. Dos 70 cursos existentes, 57 (81\%) disponibilizaram os seus projetos pedagógicos para a pesquisa.

Entretanto, 13 cursos (19\%) não tiveram os seus projetos pedagógicos analisados por dois principais motivos: Ou o projeto pedagógico não estava publicado na página eletrônica da instituição de ensino, ou a instituição de ensino recusou-se em disponibilizar o projeto pedagógico. Por isso, não houve análise do projeto pedagógico do curso em Arte e Educação (Arte-educador), pois a única instituição de ensino que oferta essa graduação no Estado não disponibilizou o mencionado documento institucional. 
A partir da operacionalização das análises das competências profissionais e estruturas curriculares descritas nos projetos pedagógicos, à luz das temáticas do envelhecimento e da educação interprofissional, emergiram duas categorias analíticas: Formação uniprofissional e secundarização do envelhecimento.

\section{Categoria 1: formação uniprofissional [subtítulo]}

A formação profissional em saúde descrita nos projetos pedagógicos analisados está em consonância com o modelo de formação descrito nas DCN, almejando uma formação generalista, humanística, crítica e reflexiva aos futuros profissionais de saúde, conforme os trechos abaixo:

"O curso forma um profissional com perfil generalista, humanístico, crítico e reflexivo, para atuar nos diversos níveis de atenção à saúde com base no rigor técnico e científico [...] em articulação com as novas tecnologias para diagnóstico e tratamento clínico-cirúrgico [...]". (Trecho extraído do projeto pedagógico do curso Odontologia da Universidade Potiguar).

"O profissional deverá ter uma formação generalista, com competências teórica, metodológica e política e capacidade de análise crítica e propositiva nos diversos espaços de atuação político-profissional [...]". (Trecho extraído do projeto pedagógico do curso de Serviço Social da Universidade do Estado do Rio Grande do Norte).

“[...] O curso propõe, aos seus futuros enfermeiros, uma formação generalista, a partir da qual eles poderão exercer a sua profissão com postura ética e humanista, atuando na assistência direta aos usuários do sistema de saúde e coordenando o processo do cuidar em enfermagem [...]". (Trecho extraído do projeto pedagógico do curso de Enfermagem da Faculdade de Enfermagem Nova Esperança).

Todavia, em todos os projetos pedagógicos não está previsto o desenvolvimento de competências para que os profissionais possam atuar frente às necessidades de saúde da população idosa. Em especial, no que se refere à atuação interprofissional que propicie o cuidado integral e o desenvolvimento da autonomia, do protagonismo e da independência do sujeito que envelhece.

“[...] O profissional deverá desenvolver todos os aspectos relacionados ao estudo do medicamento: Pesquisa, produção, comercialização, dispensação, atenção farmacêutica e vigilância. Tal formação também abrange a formação social do farmacêutico como 
profissional da saúde, bem como a formação para as análises clínicas e toxicológicas e para a indústria de medicamentos [...]". (Trecho extraído do projeto pedagógico do curso de Farmácia da Faculdade Natalense de Ensino e Cultura).

“[...] Realizar consultas, avaliações e reavaliações do paciente colhendo dados, solicitando, executando e interpretando exames propedêuticos e complementares que permitam elaborar um diagnóstico cinético-funcional, para eleger e quantificar as intervenções e condutas fisioterapêuticas apropriadas, objetivando tratar as disfunções no campo da Fisioterapia [...]". (Trecho extraído do projeto pedagógico do curso de Fisioterapia do Centro Universitário do Rio Grande do Norte).

Percebeu-se também a inexistência de cursos que ofertam componentes curriculares abordando o envelhecimento de modo interdisciplinar e interprofissional, exemplificado pelos seguintes trechos:

"O componente curricular tem o objetivo de identificar as principais contribuições teóricas da Psicologia do Desenvolvimento em suas dimensões física, cognitiva e psicossocial para a compreensão do processo saúde/doença no contexto da idade adulta e envelhecimento [...]". (Trecho extraído da ementa do componente curricular Idade Adulta e Envelhecimento no Contexto da Saúde, do curso de Psicologia da Universidade Federal do Rio Grande do Norte - Campus Natal).

“[...] Oportunizar a aquisição de conhecimento teórico e prático sobre o processo de avaliação física e prescrição de exercícios físicos voltado a indivíduos idosos visando a qualidade de vida e saúde [...]." (Trecho extraído da ementa do componente curricular Avaliação e Prescrição de Exercício para Idosos, do curso de Educação Física da Universidade Federal do Rio Grande do Norte).

Como nos projetos pedagógicos dos citados cursos não está previsto o desenvolvimento de competências para atuar no cuidado interprofissional à saúde da pessoa idosa, acredita-se que essa ausência seja a justificativa para não haver conteúdos que possibilitem tal desenvolvimento.

A formação profissional para o cuidado da saúde da pessoa idosa, nessas situações, está pautada exclusivamente na assistência às doenças crônicodegenerativas, bem como na identificação e prevenção de danos à saúde. Além disso, tal formação ocorre de forma uniprofissional, ou seja, de forma isolada entre alunos de um mesmo curso. 
"[...] Os profissionais de saúde, dentro de seu âmbito profissional, devem estar aptos a desenvolver ações de prevenção, promoção, proteção e reabilitação da saúde [...]". (Trecho extraído do projeto pedagógico do curso de Nutrição de Centro Universitário Facex).

"[...] Formar um profissional que apresente responsabilidade social, capacitado a atuar na prevenção, reabilitação e cura das pessoas, promovendo melhoria na sua qualidade de vida, jamais abandonando seu senso investigativo e crítico reflexivo, na busca de seu aperfeiçoamento [...]". (Trecho extraído do projeto pedagógico do curso de Fisioterapia do Centro Universitário do Rio Grande do Norte).

\section{Categoria 2: secundarização do envelhecimento [subtítulo]}

Em algumas situações, tais como no curso Técnico em Agente Comunitário de Saúde da Escola Técnica do SUS do Rio Grande do Norte; curso Técnico em Enfermagem da Escola de Saúde de Natal; curso de Serviço Social do Instituto de Ensino Superior do Rio Grande do Norte; e os cursos de Enfermagem da Universidade Federal do Rio Grande do Norte, da Universidade do Estado do Rio Grande do Norte e da Universidade Potiguar, o envelhecimento e a saúde da pessoa idosa são abordados juntamente com os demais ciclos de vida (saúde da criança, saúde do adolescente e saúde do adulto).

“[...] Práticas de atenção básica: educação em saúde, vigilância à saúde e epidemiológica e sanitária; imunização; planejamento familiar, pré-natal; prevenção do câncer, prevenção e controle de DST/AIDS e de doenças imunopreveníveis; prevenção e controle de riscos e agravos à saúde mental, à saúde do trabalhador e à saúde do idoso [...]." (Trecho extraído da ementa do componente curricular Atenção Básica e Saúde da Família, do curso de Enfermagem da Universidade Federal do Rio Grande do Norte).

“[...] Desenvolver ações de Promoção e Prevenção à Saúde e prevenir riscos e agravos nos ciclos de vida; apoiar e acompanhar o desenvolvimento do ciclo gravídico; acompanhar o crescimento e desenvolvimento infantil e a situação vacinal das crianças conforme planejamento da equipe de saúde; realizar ações de promoção e prevenção à saúde priorizando as situações de vulnerabilidade dos adolescentes; desenvolver e acompanhar ações da Política Nacional da Saúde do Homem; acompanhar o processo de envelhecimento e as situações de vulnerabilidade da pessoa idosa [...]". (Trecho extraído da ementa do componente curricular A Família e o Trabalho do Agente Comunitário de 
Saúde, do curso Técnico em Agente Comunitário de Saúde da Escola Técnica do SUS do Rio Grande do Norte).

Em outras situações, como no curso de Medicina da Universidade do Estado do Rio Grande do Norte; curso de Fisioterapia da Faculdade Natalense de Ensino e Cultura; nos cursos de Fisioterapia, Nutrição, Medicina, Psicologia e Terapia Ocupacional da Universidade Potiguar, a contextualização do envelhecimento e da saúde da pessoa idosa está reduzida aos aspectos biológicos e fisiológicos.

"[...] Estudos e práticas profissionais voltados ao idoso, com ações de promoção e prevenção de doenças, estimulação cognitiva e tratamento terapêutico ocupacional de doenças decorrentes das alterações fisicológicas dos idosos [...]." (Ementa do componente curricular Estágio em Geriatria e Gerontologia, do curso de Terapia Ocupacional da Universidade Potiguar).

Apesar dessa predominância em secundarizar ou simplificar a discussão da temática do envelhecimento, destaca-se a existência de componentes curriculares que vão contra essa corrente dominante. No projeto pedagógico da graduação em Fisioterapia da Universidade Federal do Rio Grande do Norte, por exemplo, consta a existência do componente curricular "Gerontologia", que tem como principal objetivo propiciar aos alunos e futuros profissionais de saúde uma compreensão multidimensional do envelhecimento. Porém, o referido componente curricular ainda não é ofertado como um requisito obrigatório na formação dos fisioterapeutas e ocorre de modo uniprofissional.

"[...] Reflexão sobre os principais tópicos da Gerontologia e Geriatria, através de um estudo multidimensional do processo de envelhecimento, com enfoque na prevenção e na reabilitação dos problemas que afetam a saúde e a qualidade de vida do idoso. Análise dos elementos teóricos e metodológicos necessários para a avaliação das dimensões de saúde, dos programas de intervenção e suas repercussões no estado de bem-estar das pessoas idosas [...]." (Ementa do componente curricular Gerontologia, do curso de Fisioterapia da Universidade Federal do Rio Grande do Norte). 
Vale salientar que na Universidade Federal do Rio Grande do Norte também há o componente curricular "Saúde e Cidadania". Nesse componente curricular os graduandos da área da saúde se inserem em serviços de saúde da atenção primária, com ou sem ESF, para que possam compreender, através da educação interprofissional e do método pedagógico da problematização, as demandas sociais que acometem a população usuária do SUS. Entretanto, nesse componente curricular não há discussão de questões relativas ao envelhecimento.

\begin{abstract}
"[...] A disciplina Saúde e Cidadania - SACl - busca a integração do ensino a partir da interação básico/profissionalizante, teoria/prática, disciplina e cursos com os serviços de saúde e a comunidade. Visa oferecer ao aluno, iniciante dos cursos da área da saúde da UFRN, o ambiente propício à reflexão dos problemas da saúde da população e das atividades de atenção à saúde na comunidade, buscando o estabelecimento da relação educação, saúde e cidadania, através do trabalho interprofissional e interdisciplinar [...]." (Trecho extraído da ementa do componente curricular Saúde e Cidadania, da Universidade Federal do Rio Grande do Norte).
\end{abstract}

Outro exemplo refere-se ao curso de Medicina da Escola Multicampi de Ciências Médicas do Rio Grande do Norte, vinculado à Universidade Federal do Rio Grande do Norte e localizado no interior do Estado, no município de Caicó. No referido curso, a estrutura curricular está organizada por núcleos de conhecimentos, formados por diferentes componentes curriculares. Dentre esses núcleos de conhecimento há um específico para a atenção à saúde da pessoa idosa, denominado "Geriatria".

Tal núcleo aborda questões de ordem fisiológica, epidemiológica e social do processo de envelhecimento e do processo de transição demográfica vivenciada no Brasil. Ademais, nesse mesmo núcleo é abordada também a questão da promoção à saúde da população idosa, todavia, de modo uniprofissional.

"Conceitos e aspectos epidemiológicos do envelhecimento. O processo do envelhecimento e alterações fisiológicas. Princípios da prática geriátrica - processo saúde-doença. Grandes síndromes geriátricas: Distúrbios mentais, incontinências e traumatismos (quedas). Doenças degenerativas do sistema nervoso central: Alzheimer, demências, doença de Parkinson. Aspectos farmacológicos e psicológicos [...] Reabilitação geriátrica e promoção da saúde. O impacto do envelhecimento e a perspectiva de morte. Relação Médico-paciente-cuidador. Aspectos éticos em 
geriatria". (Trecho extraído da ementa do componente curricular Geriatria, do curso de Medicina da Escola Multicampi de Ciências Médicas da Universidade Federal do Rio Grande do Norte).

\section{Discussão}

No campo do trabalho em saúde, a formação profissional é uma discussão permanente. Entre 1990 e 2010, por exemplo, a maioria $(71,2 \%)$ das produções científicas sobre trabalho e educação em saúde discorria sobre a qualificação dos recursos humanos para atuação no SUS ${ }^{26}$. Além da produção científica, observa-se no sistema educacional brasileiro uma acentuada expansão na oferta de cursos para a formação profissional em saúde ${ }^{27}$.

Todavia, a concentração regional de instituições de ensino em saúde, principalmente em áreas metropolitanas, bem como a proliferação desordenada de cursos, sobretudo de nível superior, tem ocasionado a formação de profissionais com perfil inadequado para dar suporte às necessidades de saúde da população ${ }^{28}$. O ensino na saúde tende a hipervalorizar áreas específicas, limitando a formação dos profissionais em conhecimentos específicos, sem reconhecer a abrangência e a complexidade das necessidades de saúde ${ }^{6}$. Nesse sentido, emerge um grande desafio para a Política Nacional de Gestão do Trabalho e da Educação na Saúde: Fortalecer o diálogo entre as instituições de ensino e os serviços de saúde, a fim de proporcionar uma formação pautada na educação interprofissional e que esteja em consonância com as transformações sociais e as demandas do SUS ${ }^{29,9}$.

A lacuna na interface entre saúde e educação torna-se maior quando se destaca a relação entre a saúde da pessoa idosa e a educação profissional. Por um lado, evidencia-se a forte dependência das pessoas idosas aos serviços de saúde, especialmente das pessoas idosas longevas (idade $\geq 80$ anos), que no cenário atual, representa o segmento etário mais crescente dentre a população idosa ${ }^{30}$.

Nos próximos anos essa dependência tenderá a ser maior ${ }^{31}$, sendo resultante do processo de transição demográfica que acontece não só no Brasil, mas também em outros Países emergentes, como Rússia, Índia e China, sobretudo em um contexto de significativa desigualdade social $^{32,33}$. Por outro lado, nos projetos pedagógicos dos cursos da área da saúde, a contextualização do processo de 
envelhecimento humano ainda é pouco expressiva, ocorrendo de forma uniprofissional e muitas vezes sendo incoerente com a prática profissional.

A formação profissional na área da saúde exerce um importante papel para a sociedade, tendo em vista que os alunos dos cursos existentes serão futuros trabalhadores que prestarão assistência à saúde da população ${ }^{34}$. Por conseguinte, a atenção à saúde da pessoa idosa demanda competências específicas para a contextualização do processo de envelhecimento e exige o desenvolvimento do trabalho interprofissional ${ }^{35}$.

Nesse sentido, se faz necessário integrar o processo de ensino às práticas cotidianas dos serviços de saúde, sobretudo dos serviços da atenção primária, para que o exercício profissional esteja cada vez mais alinhado com as necessidades da população. No caso em questão, as necessidades de saúde da população idosa. Além da integração entre o ensino e o serviço na formação em saúde com ênfase no envelhecimento, é necessário garantir o desenvolvimento de práticas de ensino e de trabalho interprofissional. Para aperfeiçoar o cuidado às pessoas idosas é preciso confiar no poder das equipes interprofissionais ${ }^{8}$.

Entretanto, nenhum dos cursos investigados neste estudo contempla uma discussão mais profunda acerca da temática do envelhecimento de modo interprofissional. Esse fato pode estar ligado à desarticulação das instituições de ensino com a dinâmica social e, por conseguinte, com a dinâmica dos serviços de saúde, além do desinteresse do corpo docente em transformar as suas práticas de ensino.

A sensibilização dos docentes para o desenvolvimento de competências incorporadas à saúde da população idosa na formação da futura força de trabalho em saúde nos Estados Unidos, por exemplo, ainda é um nó crítico ${ }^{36}$. Todavia, para afirmar se essa situação é semelhante à realidade brasileira e à realidade do local de realização deste estudo, é necessário realizar outras pesquisas que extrapolem a análise documental, avaliando a percepção de estudantes e docentes sobre os métodos pedagógicos utilizados durante a formação profissional, com ênfase no envelhecimento, bem como investigar a percepção das pessoas idosas acerca do cuidado proporcionado pelos profissionais de saúde atuantes no SUS.

Para que a atenção à saúde da pessoa idosa deixe de ser excludente e dotada de estigmas e preconceitos acerca do envelhecimento, é preciso incentivar mudanças no modelo educacional ${ }^{37}$. Tal mudança deve estar pautada na formação 
interprofissional para o cuidado integral e na educação sobre o envelhecimento ativo, para que os profissionais de saúde sejam agentes multiplicadores e incentivem às pessoas idosas a viverem de forma autônoma, independente e participativa $^{38}$.

Portanto, se faz necessário implantar componentes curriculares obrigatórios na formação de profissionais de saúde que discutam sobre envelhecimento de modo interprofissional. Os referidos componentes curriculares deverão pautar-se na compreensão de uma dimensão mais ampla sobre o envelhecimento humano, envolvendo aspectos econômicos e sociais, e não somente a cura de doenças.

O não atendimento desses requisitos ocasionará a continuidade da fragmentação do trabalho em saúde, sendo cada vez mais destoante do que é preconizado pelas políticas de saúde no Brasil. Dentre elas, a Política Nacional de Saúde da Pessoa Idosa, onde a atenção à saúde da pessoa idosa deve estar em consonância com os princípios do SUS, bem como ser ordenada pela ESF e pelo NASF para atender as necessidades dessa parcela da população ${ }^{39}$.

\section{Considerações finais}

Esta pesquisa evidenciou que a formação uniprofissional é uma realidade dominante nos cursos investigados, fazendo com que os seus alunos tenham uma formação que pouco contribui para a transformação do modelo de atenção à saúde da pessoa idosa existente no local de realização do estudo. Isso significa dar continuidade a um cuidado que desconsidera os aspectos sociais e subjetivos comuns ao processo de envelhecimento, desfavorecendo a integralidade do cuidado e o trabalho colaborativo.

Nesse contexto, defende-se que a formação em saúde não deve se limitar aos conhecimentos especializados, mas sim, que agrupe conhecimentos de outras áreas e respeite as competências de cada profissão. Para transformar as práticas de trabalho e, por conseguinte, as práticas assistenciais para a população idosa no cotidiano da atenção primária à saúde e do SUS, afirmamos que é preciso lidar com a temática do envelhecimento de forma interprofissional. 


\section{Referências}

1. Coyle CE, Mutchler JE. Aging with disability: advancement of a crossdisciplinary research network. Res. Aging. 2017; 39(6): 683-92.

2. Ferreira LMBM, Jerez-Roig J, Andrade FLJP, Oliveira NPD, Araújo JRT, Lima KC. Prevalência de quedas e avaliação da mobilidade em idosos institucionalizados. Rev. Bras. Geriatr. Gerontol. 2016; 19(6):995-1003.

3. Alves KL, Alves MRR, Sá CMCP, Xavier Junior JA, Barros KC, Alves LMRR, et al. Nursing professional's working load given to the elderly at the intensive unit care. Int. Arch. Med. 2017; 10(44):1-8.

4. Xavier AS, Koifman L. Higher education in Brazil and the education of health care professional with emphasis on aging. Interface (Botucatu). 2011; 15(39):973-84.

5. Miranda GMD, Mendes ACG, Silva ALA. Public policies challenges on the background of demographic transition and social changes in Brazil. Interface (Botucatu). 2017; 21(61):309-20.

6. Peduzzi M. O SUS é interprofissional. Interface (Botucatu). 2016; 20(56):199-201.

7. Martins JJ, Schier J, Erdmann AL, Albuquerque GL. Políticas públicas de atenção à saúde do idoso: reflexão acerca da capacitação dos profissionais da saúde para o cuidado com o idoso. Rev. Bras. Geriatr. Gerontol. 2007; 10(3):1809-17.

8. Arruda LS, Moreira COF. Interprofessional collaboration: a case study regarding the professionals of the Care Center for Elderly, Rio de Janeiro State University (NAI/UERJ), Brazil. Interface (Botucatu). [Internet]. [acesso em 10 Ago 2017] Disponível em:

http://www.scielo.br/scielo.php?script=sci_arttext\&pid=S1414$32832017005010102 \& \operatorname{lng}=$ en.

9. Costa MV, Vilar MJ, Azevedo GD, Reeves S. Interprofessional education as an approach for reforming health professions education in Brazil: emerging findings. J. Interprof. Care. 2014; 28(4):379-80.

10. Peduzzi M, Norman IJ, Germani ACCG, Silva JAM, Souza GC. Educação interprofissional: formação de profissionais de saúde para o trabalho em equipe com foco nos usuários. Rev. Esc. Enferm. USP. 2013; 47(4):97783. 
11. Reeves S. Why we need interprofessional education to improve the delivery of safe and effective care. Interface (Botucatu). 2016; 20(56):18596.

12. Batista NA, Batista SHSS. Educação interprofissional na formação em saúde: tecendo redes e práticas de saberes. Interface (Botucatu). 2016; 20(56):202-4.

13. ORGANIZAÇÃO MUNDIAL DA SAÚDE. Marco para ação em educação interprofissional e prática colaborativa. Genebra: Organização Mundial da Saúde; 2010.

14. Silva JAM, Peduzzi M, Orchard C, Leonello VM. Educação interprofissional e prática colaborativa na atenção primária à saúde. Rev. Esc. Enferm. USP. 2015; 49(Esp2):16-24.

15. Belas IA, Rocha JHA, Silva FM, Lustosa JVB, Carneiro WS, Valença AMG, et al. Articulated Actions of the Family Health Strategy Teams and Their Centres of Support in the State of Piauí, Brazil. Int. Arch. Med. 2017; 10(5):1-8.

16. Arantes LJ, Shimizu HE, Merchán-Hamann E. Contribuições e desafios da Estratégia Saúde da Família na atenção primária à saúde no Brasil: revisão da literatura. Ciênc. Saúde Coletiva. 2016; 21(5): 1499-1509.

17. Andrade RS, Caldas LBSN, Falcão MLP, Goes PSA. Processo de trabalho em uma unidade de saúde da família e a educação permanente. Trab. Educ. Saúde. 2016; 14(2):505-21.

18. Miranda GMD, Mendes ACG, Silva ALA, Santos Neto PM. A ampliação das equipes de saúde da família e o Programa Mais Médicos nos municípios brasileiros. Trab. Educ. Saúde. 2017; 15(1): 131-45.

19. Lima RRT, Castro JL. Estudo acerca do perfil: uma contribuição para as políticas de valorização profissional. In: Castro JL, Vilar RLA, Oliveira NHS, organizadoras. As trilhas e os desafios da gestão do trabalho e da educação na saúde. 1a ed. Natal: Una; 2016. p. 129-47.

20. Shimizu HE, Fragelli TBO. Competências profissionais essenciais para o trabalho no Núcleo de Apoio à Saúde da Família. Rev. Bras. Educ. Med. 2016; 40(2): 216-25.

21. Costa T, Torres GV, Oliveira RA, Costa MV, Dantas BAS, Miranda JMA, et al. Changes in the quality of life of an elderly group of the Family Health Strategy. Int. Arch. Med. 2016; 9(381):1-9. 
22. Andrade LM, Sena ELS, Pinheiro GML, Meira EC, Lira LSSP. Public policies for the elderly in Brazil: an integrative review. Ciênc. Saúde Coletiva. 2013; 18(12):3543-52.

23. INSTITUTO BRASILEIRO DE GEOGRAFIA E ESTATÍSTICA. Censo Demográfico 2010. [Internet]. [acesso em 11 Ago 2017]. Disponível em: http://www.ibge.gov.br/estadosat/temas.php?sigla=rn\&tema=censodemog 2010_snig.

24. Minayo MCS. O desafio do conhecimento: pesquisa qualitativa em saúde. 13a ed. São Paulo: Hucitec; 2013.

25. Brasil, 1996. Lei 9.394, sancionada em 20 de dezembro de 1996, a qual "estabelece as diretrizes e bases da educação nacional". [Internet]. [acesso em 11 ago. 2017]. Disponível em http://www.planalto.gov.br/ccivil_03/leis/L9394.htm.

26. Pinto ICM, Esperidião MA, Silva IV, Soares CM, Santos L, Fagundes TLQ, et al. Work and education in health in Brazil: trends in scientific output between 1990-2010. Ciênc. Saúde Coletiva. 2013; 18(6):1525-34.

27. Teixeira CF, Coelho MTAD, Rocha MND. Interdisciplinary Bachelor's degree in Health: an innovative proposal in higher education in Health in Brazil. Ciênc. Saúde Coletiva. 2013; 16(6):1635-46.

28. Pierantoni CR, França T, Magnago C, Nascimento DN, Miranda RG. Graduações em saúde no Brasil: 2000-2010. 1a ed. Rio de Janeiro: IMS/UERJ; 2012.

29. Haddad AE, Morita MC, Pierantoni CR, Brenelli SL, Passarella T, Campos FR. Undergraduate programs for health professionals in Brazil: an analysis from 1991 to 2008. Rev. Saúde Pública. 2010; 44(3):1-8.

30. Menezes TMO, Lopes RLM. Significados do vivido pela pessoa idosa longeva no processo de morte/morrer e luto. Ciênc. Saúde Coletiva. 2014; 19(8):3309-16.

31. Veras RP. Population aging and health information from the National Household Sample Survey: contemporary demands and challenges. Cad. Saúde Pública. 2007; 23(10):2463-66.

32. Guimarães RRM. The future of higher education in BRIC countries: a demographic perspective. Rev. Bras. Estud. Popul. 2013; 30(2):549-66. 
33. Witt RR, Roos MO, Carvalho NM, Silva AM, Rodrigues CDS, Santos MT. Professional competencies in primary health care for attending to older adults. Rev. Esc. Enferm. USP. 2014; 48(5):1018-23.

34. Ribeiro IL, Medeiros Júnior A. Graduação em saúde, uma reflexão sobre ensino-aprendizado. Trab. Educ. Saúde. 2016; 14(1):33-53.

35. Lima RRT, Castro JL, Lima KC. Saúde do idoso e formação profissional: Como ocorre essa relação em uma instituição de ensino superior? Saúde em Redes. 2016; 2(1):1287-89.

36. Ford CR, Brown CJ, Sawyer P, Rothrock AG, Ritchie CS. Advancing Geriatric Education: Development of an Interprofessional Program for Health Care Faculty. Gerontol. Geriatr. Educ. 2015; 36(4): 365-83.

37. Golden GM, Gammonley D, Hunt D, Olsen E, Issenberg B. The atitudes of graduate healthcare students toward older adults, personal aging, health care reform, and interprofessional collaboration. J. Interprof. Care. 2014; 28(1):40-4.

38. Lima KC. Educação em saúde para o envelhecimento ativo. In: Nacif PGS, Queiroz AC, Gomes LM, Rocha RG, organizadores. Coletânea de textos CONFINTEA Brasil+6: tema central e oficinas temáticas. 1a ed. Brasília: Ministério da Educação; 2016. p. 252-58.

39. Uchimura KY, Bosi MLM. Abilities and skills among Family Health Strategy workers. Interface (Botucatu). 2012; 16(40):149-60. 


\subsection{Artigo III}

Artigo enviado para publicação no periódico Interface - Comunicação, Saúde e Educação (ISSN 1414-3283), que tem fator de impacto 0.394, classificado como Qualis B3 na área da Medicina II da CAPES.

\section{Identificando necessidades e propondo soluções: com a palavra, pessoas idosas na atenção primária à saúde}

Resumo: O objetivo do artigo é compreender a percepção de pessoas idosas, assistidas por profissionais da Estratégia Saúde da Família e do Núcleo de Apoio à Saúde da Família, sobre as suas necessidades. Trata-se de uma pesquisa qualitativa, realizada no município do Natal, Rio Grande do Norte, Brasil. Utilizou-se o grupo focal como recurso metodológico e a análise dos dados foi realizada com base no método da análise de conteúdo, na modalidade temática. Os resultados foram classificados em três unidades temáticas: (I) Necessidade de boas condições de vida; (II) Necessidade de acesso aos serviços de saúde; e (III) Soluções para atender as necessidades elencadas. A realização desta pesquisa evidencia que as necessidades das pessoas idosas, no cenário estudado, demandam por ações intersetoriais para serem resolvidas.

Palavras-chave: Necessidades. Envelhecimento. Atenção Primária à Saúde. Saúde da Família. Pesquisa Qualitativa.

\section{Introdução}

No âmbito internacional, a Declaração de Alma-Ata, resultante da Conferência Internacional sobre Cuidados Primários de Saúde realizada no Cazaquistão, entre 6 e 12 de setembro de 1978, foi um marco importante para o desenvolvimento da Atenção Primária à Saúde (APS), pois reiterou a meta "Saúde para Todos nos Anos 2000", definida durante a Assembleia Mundial de Saúde realizada em 1977, e defendeu a APS como um fator essencial para o desenvolvimento dos países ${ }^{1 / 2}$. Segundo Starfield $^{3}$, a APS é um nível de cuidado que forma a base de qualquer sistema de saúde, abordando os problemas mais comuns na comunidade, ofertando serviços de prevenção, cura e reabilitação à população. Ao ser implementada e 
gerida de maneira correta, a APS é capaz de organizar e racionalizar o uso de recursos, tanto básicos como especializados, direcionados para a promoção e melhoria da saúde ${ }^{3}$.

No Brasil, a adaptação do conceito de "cuidados primários de saúde" à realidade e às necessidades do país incluiu a inserção de atividades de educação, vacinação, nutrição, saneamento, organização sócio comunitária, dentre outras, significando uma ampliação do escopo da proposta original ${ }^{4}$. Porém, o fortalecimento da APS só teve início na década de 1990 com o processo de descentralização do Sistema Único de Saúde (SUS). Ainda na década de 1990, mais precisamente em 1994, o Ministério da Saúde criou o Programa Saúde da Família (PSF), derivado do Programa de Agentes Comunitários de Saúde (PACS), fundado em 1991, com o objetivo de reorientar o modelo assistencial a partir da APS $^{56}$.

Tendo como base os princípios da promoção e proteção à saúde, e da prevenção de agravos, seja no âmbito individual ou coletivo, o PSF tornou-se eixo estruturante dos sistemas municipais de saúde, passando a se chamar Estratégia Saúde da Família (ESF) no ano de $2006^{7}$. De acordo com a Política Nacional de Atenção Básica (PNAB), revisada em 21 de setembro de 2017 através da Portaria n. 2.436 do Ministério da Saúde, a ESF é a medida prioritária para expansão, consolidação e qualificação da APS. Além disso, é a principal porta de entrada do SUS e o principal meio de comunicação dos usuários com as redes de atenção à saúde. O cuidado proporcionado pelos profissionais da equipe multiprofissional da ESF, no âmbito domiciliar ou nas Unidades Básicas de Saúde da Família (UBSF), é capaz de valorizar a singularidade e a história de vida dos sujeitos, estimulando a criação de vínculos entre os usuários e os serviços de saúde ${ }^{8}$.

Para provocar mudanças nas práticas de atenção à saúde é preciso organizar redes de atenção que sejam coordenadas pelas equipes da APS ${ }^{9^{\prime 1} 10}$. Com o objetivo de fortalecer ainda mais a APS no Brasil e ampliar o escopo de atuação dos profissionais da ESF, o Ministério da Saúde criou em 2008 o Núcleo de Apoio à Saúde da Família (NASF), através da Portaria n.ำ154. A partir da APS, as equipes multiprofissionais do NASF, juntamente com as equipes da ESF, assumem a função coordenadora do SUS e com a realização do apoio matricial, visam romper com as práticas de trabalho verticalizadas e hierarquizadas ${ }^{11}$. Ademais, buscam proporcionar a integralidade do cuidado para os demais níveis de atenção ${ }^{12}$. 
No contexto atual, onde o envelhecimento tem se tornado um fenômeno mundial $^{13}$, a saúde da pessoa idosa (idade $\geq 60$ anos) vem ganhando prioridade no $S_{S}{ }^{14}$. O Pacto pela Vida e a Política Nacional de Saúde da Pessoa Idosa (PNSPI), normativas publicadas em 2006, definiram que a qualidade da atenção à saúde da população idosa deve pautar-se na integralidade do cuidado e no desenvolvimento prioritário de ações no âmbito da APS ${ }^{15}$. Tais ações devem partir da identificação das necessidades das pessoas idosas, compreendendo que elas não são somente de ordem biológica, nem tampouco individuais e homogêneas ${ }^{16}$.

Tomando como base os estudos de Cecilio ${ }^{17}$, Paim e Almeida-Filho ${ }^{18}$, e Mendes-Gonçalves ${ }^{19}$, neste artigo definimos que as necessidades são representadas por condições que permitem aproveitar a vida, constituindo-se em algo que precisa ser resolvido para que o indivíduo esteja satisfeito e continue a viver. As necessidades sempre irão variar, tornando-se amplas e diversificadas e dependerão do estilo de vida de cada sujeito, bem como das oportunidades de acesso e de consumo dos serviços dos setores saúde, educação, trabalho, habitação, alimentação, dentre outros ${ }^{18^{\prime} 19}$.

Ademais, de acordo com Cecilio ${ }^{17}$, as necessidades podem ser entendidas como: 1) Necessidade de boas condições de vida, 2) Necessidade de garantia de acesso às tecnologias que melhorem e prolonguem a vida; 3) Necessidade de vínculo com um profissional ou equipe de saúde; e 4) Necessidade de autonomia e autocuidado na escolha do modo de viver.

Apesar dos importantes avanços da APS no Brasil, bem como no cuidado à saúde das pessoas idosas, alguns impasses e problemas ainda persistem e precisam ser discutidos para que soluções sejam encontradas. É preciso envolver a participação das pessoas idosas em todos os espaços organizacionais, políticos, sociais e culturais para a promoção do envelhecimento ativo e saudável, bem como adequar a formação e o processo de trabalho das equipes da ESF e do NASF à realidade desse segmento etário.

Diante do exposto, $\mathrm{o}$ presente artigo tem $\mathrm{O}$ objetivo de compreender a percepção de pessoas idosas, assistidas por profissionais da ESF e do NASF, sobre as suas necessidades. 


\section{Percurso metodológico}

\section{Caracterização da pesquisa [subtítulo]}

Este artigo é oriundo de uma pesquisa qualitativa, cujo cenário de investigação foi a APS do município do Natal, Rio Grande do Norte, Brasil. Em 2010, a população total da cidade do Natal era composta por 862.044 habitantes, onde $9,7 \%$ dessa população era idosa ${ }^{20}$. Em conformidade com as regiões administrativas da cidade, a rede pública de saúde está dividida em cinco distritos sanitários (Norte I, Norte II, Leste, Oeste e Sul), mantendo em funcionamento 55 UBSF e com o percentual de cobertura igual a $38,8 \%$.

338.100 pessoas são atendidas por 98 equipes da ESF, quando o ideal, de acordo com os parâmetros da PNAB, era que houvesse 215 equipes para cobrir assistencialmente $100 \%$ da população do município ${ }^{21}$. Quanto à cobertura do NASF, no município estudado existem três equipes, todas do tipo I, que dão apoio matricial às equipes da ESF em sete UBSF, localizadas nos distritos sanitários Norte I, Norte Il e Oeste.

Para manter o rigor científico do estudo, foram verificados os itens recomendados pelo Consolidated Criteria for Reporting Qualitative Research (COREQ) para estudos qualitativos que utilizam entrevistas ou grupos focais como recursos metodológicos ${ }^{22}$.

\section{Coleta dos dados [subtítulo]}

Utilizou-se o grupo focal como recurso metodológico, pois, através das discussões coletivas, é possível conhecer os comportamentos e sentimentos de grupos sociais sobre determinado assunto ou problema ${ }^{23}$, sendo esse recurso considerado o mais adequado para os objetivos da pesquisa. Foram realizados três grupos focais (quadro 1), conduzidos pelo autor principal do artigo, que é do gênero masculino, mestre em Ciências da Saúde e possui experiência na realização de grupos focais.

Anterior à realização dos mesmos, uma visita foi feita em três UBSF, selecionadas intencionalmente por estarem localizadas nos três distritos sanitários onde as equipes do NASF atuam, para apresentar os motivos, as razões, os 
interesses e os objetivos da pesquisa, bem como para selecionar os sujeitos participantes.

Quadro 1 - Descrição dos grupos focais. Natal, 2017.

\begin{tabular}{|c|c|c|c|c|c|}
\hline Grupo focal & $\begin{array}{l}\text { Local de } \\
\text { realização }\end{array}$ & $\begin{array}{l}\text { Data da } \\
\text { realização }\end{array}$ & $\begin{array}{l}\text { Número de } \\
\text { participantes }\end{array}$ & $\begin{array}{l}\text { Número de } \\
\text { sessões }\end{array}$ & $\begin{array}{l}\text { Duração } \\
\text { média dos } \\
\text { áudios }\end{array}$ \\
\hline $\begin{array}{l}\text { I - Distrito } \\
\text { Sanitário } \\
\text { Norte I }\end{array}$ & $\begin{array}{c}\text { Centro de } \\
\text { Referência de } \\
\text { Assistência } \\
\text { Social (CRAS) }\end{array}$ & 08/03/2017 & 12 & 01 & 1 hora \\
\hline $\begin{array}{c}\text { II - Distrito } \\
\text { Sanitário } \\
\text { Norte II }\end{array}$ & $\begin{array}{l}\text { Unidade } \\
\text { Básica de } \\
\text { Saúde da } \\
\text { Família }\end{array}$ & $30 / 03 / 2017$ & 07 & 01 & 1 hora \\
\hline $\begin{array}{c}\text { III - Distrito } \\
\text { Sanitário } \\
\text { Oeste }\end{array}$ & $\begin{array}{l}\text { Conselho } \\
\text { Comunitário } \\
\text { de Saúde }\end{array}$ & $24 / 07 / 2017$ & 12 & 01 & 1 hora \\
\hline
\end{tabular}

Fonte: Dados da pesquisa. Elaboração dos autores.

As sessões dos grupos focais aconteceram em datas, horários e locais previamente pactuados pessoalmente com as pessoas idosas com idade $\geq 60$ anos, respeitando a definição adotada pela Organização Mundial da Saúde (OMS) para as pessoas consideradas idosas em países subdesenvolvidos ${ }^{24}$, com capacidade de realizar as suas atividades cotidianas de forma independente, que tinham cognição e que se dispuseram participar da pesquisa através da assinatura do Termo de Consentimento Livre e Esclarecido (TCLE). Além disso, os mencionados sujeitos tinham que ser atendidos e participarem das atividades desenvolvidas pelos profissionais da ESF e do NASF de cada UBSF selecionada. Ressalta-se que não houve a desistência de nenhum participante.

Para nortear as sessões dos grupos focais, um guia de temas foi elaborado pela equipe de pesquisa e enviado por e-mail para treze profissionais, do serviço ou da universidade, com expertise em pesquisa qualitativa, ou em envelhecimento populacional ou em formação em saúde, na perspectiva de aperfeiçoá-lo e validá-lo. 
Seis pesquisadoras (três doutoras e três mestras) deram devolutiva com contribuições para o guia, sendo utilizada uma versão final contendo sete questões.

A operacionalização da coleta dos dados aconteceu a partir do registro de áudio dos grupos focais realizados entre o pesquisador condutor e os participantes, bem como dos registros anotados com as observações de cada encontro.

\section{Análise dos dados [subtítulo]}

A análise dos dados foi realizada com base no método da análise de conteúdo, na modalidade temática, contemplando as fases de pré-análise, exploração do material e interpretação dos achados ${ }^{25}$. Em pesquisas qualitativas, a análise de conteúdo é utilizada para auxiliar a interpretação subjetiva de textos. Já o tema é um elemento significativo identificado a partir da leitura de um determinado conteúdo textual, denotando os valores de referência e os modelos de comportamento presentes no discurso que contribuirão para a formulação das unidades temáticas ${ }^{25}$.

Inicialmente foi realizada a transcrição dos áudios na íntegra e em seguida a leitura flutuante dos textos, excluindo o que não era relevante para a pesquisa. Posteriormente, uma nova leitura foi feita com o intuito de identificar as principais temáticas que surgiram a partir das falas dos participantes.

Para preservar a identificação dos sujeitos participantes deste estudo durante a análise e a divulgação dos resultados, atribuiu-se um código para cada um. Ao todo, foram atribuídos trinta e um codificadores, tais como participante 01 , participante 02, participante 03 e assim por diante.

Ademais, as UBSF não foram identificadas, pois a análise deu-se em relação ao conjunto dos grupos focais e não especificamente para o grupo focal de cada serviço de saúde. Por fim, o processo de análise dos dados ocorreu concomitante ao período de realização dos grupos focais.

\section{Aspectos éticos [subtítulo]}

Em detrimento às Resoluções n. 0 466/2012 e n.ำ 510/2016 do Conselho Nacional de Saúde, que estabelecem normas para a realização de estudos com seres humanos, a pesquisa que deu origem ao presente artigo teve aprovação do 
Comitê de Ética em Pesquisa da Universidade Federal do Rio Grande do Norte, sob o parecer n.ำ 1.462.796/2016.

\section{Resultados e discussão}

Além de serem pessoas idosas, a maioria (97\%) dos 31 sujeitos participantes do estudo é do gênero feminino e 84\% quando busca por assistência à saúde, utiliza somente os serviços da rede pública. Durante a realização dos grupos focais, os participantes foram estimulados a refletir sobre as suas necessidades, bem como sobre as possíveis estratégias para solucioná-las. A partir disso, a análise das diferentes percepções resultou na identificação de três unidades temáticas, estruturadas conforme a árvore de codificação (quadro 2) e detalhadas em seguida.

Quadro 2 - Descrição da árvore de codificação. Natal, 2017.

\begin{tabular}{|c|c|}
\hline Unidades Temáticas & Temas presentes \\
\hline \multirow{2}{*}{$\begin{array}{l}\text { Unidade temática I: Necessidades de boas } \\
\text { condições de vida }\end{array}$} & Violência \\
\hline & Insegurança \\
\hline \multirow{4}{*}{$\begin{array}{l}\text { Unidade temática II: Necessidades de acesso } \\
\qquad \text { aos serviços de saúde }\end{array}$} & Falta de prioridade no atendimento \\
\hline & Escassez de oferta de medicamentos \\
\hline & Ausência de médicos na APS \\
\hline & $\begin{array}{l}\text { Oferta insuficiente de consultas e exames } \\
\text { especializados }\end{array}$ \\
\hline \multirow{2}{*}{$\begin{array}{l}\text { Unidade temática III: Soluções para atender } \\
\qquad \text { as necessidades elencadas }\end{array}$} & Qualificação dos gestores em saúde \\
\hline & $\begin{array}{c}\text { Boas condições de trabalho para os } \\
\text { profissionais da ESF e do NASF }\end{array}$ \\
\hline
\end{tabular}

Fonte: Dados da pesquisa. Elaboração dos autores.

\section{Unidade temática I: Necessidades de boas condições de vida [subtítulo]}

De acordo com os participantes dos grupos focais, a violência e a ineficiência da segurança pública são condições que afetam o bem-estar, a saúde e a qualidade de vida das pessoas idosas. 
de casa fora de hora. De dia a gente sai com medo, imagine a noite." (Participante 22).

"Já aconteceu em outro dia deles virem assaltando da outra parada de ônibus, de parada em parada [...] Um cara numa bicicleta. Pegaram celular, dinheiro... O que tiver eles levam." (Participante 26).

A violência é um fenômeno complexo e de múltipla causalidade que afeta pessoas em todo o mundo, independente do gênero, faixa etária ou classe social, configurando-se em um problema global responsável por gerar impactos sociais, econômicos e psicológicos ${ }^{26}$. Apesar da sua multicausalidade, a violência pode ser definida como o uso da força física ou do poder contra si, ou contra outro(s) indivíduo(s), resultando em lesão, dano psicológico ou morte ${ }^{27}$.

No Brasil, a violência, juntamente com os acidentes, ocupa as principais posições no ranking das causas de morbimortalidade, representando um desafio atual para o SUS, pois, evidencia a necessidade de formular políticas públicas específicas para enfrentar esse dano, bem como estruturar e organizar redes de serviços para assistir as pessoas acometidas ${ }^{28}$.

No estado do Rio Grande do Norte, entre 2010 e 2014, por exemplo, ocorreu um aumento significativo de mortes por violência, sobretudo de homicídios. Ao todo, foram cerca de 10.000 óbitos por agressão ${ }^{29}$, concentrados principalmente na Região Metropolitana do $\mathrm{Natal}^{30}$. Como já debatido neste artigo, a violência tem múltiplas causas, entretanto, o contingente da força policial é uma medida paliativa importante para garantir a segurança pública e diminuir o coeficiente de mortalidade por violência.

Em 2000 e em 2010, o estado de Santa Catarina ocupou a segunda colocação no ranking das Unidades Federativas menos violentas e com menor coeficiente de homicídio por 100 mil habitantes no Brasil ${ }^{30}$. Acredita-se que essa permanência é justificada, principalmente, pelo aumento e pela qualificação da guarda policial no estado catarinense, existindo 1 policial para 475 habitantes.

Ainda de acordo com Lima et al. ${ }^{30}$, no mesmo ranking, o Rio Grande do Norte saiu da $24^{a}$ posição em 2000 para a 19a posição em 2010, mantendo o contingente de 1 policial para cada 376 habitantes e tornando-se um estado moderadamente violento. Mesmo não sendo o segmento etário mais atingido pela violência e pelas 
mortes por agressão, as pessoas idosas sofrem com a insegurança que amedronta amigos e familiares mais jovens, conforme trecho a seguir:

"Um dia entraram no posto de saúde e levaram o celular de todo mundo, até do meu filho que estava lá para ser atendido. Eu fico doente com essa situação, eu fico preocupada com o meu filho... Eu fico muito nervosa! Eu queria muito um psicólogo, um neurologista bom aqui no posto de saúde porque eu preciso muito... Essa situação me deixa muito nervosa." (Participante 14).

No cenário de crise política e econômica vivenciada em todo o Rio Grande do Norte, atingindo os setores da saúde, educação e, especificamente, a segurança pública, policiais civis e militares usam o direito constitucional de greve para reivindicar por melhores condições de trabalho e pelo pagamento dos salários atrasados. Sendo assim, buscam melhorar a segurança pública e, em última análise, contribuir com a qualidade da saúde física, emocional e mental das pessoas idosas.

Diante da realidade descrita, bem como do conceito de atenção à saúde que incorpora os determinantes sociais, é preciso desenvolver ações de promoção da saúde em prol do envelhecimento ativo e saudável, na perspectiva de ampliar as formas de cuidado e garantir uma qualidade de vida independente e autônoma às pessoas idosas ${ }^{31}$.

Considerando os princípios e diretrizes do SUS, tais ações devem estar articuladas com outros setores para diminuir as vulnerabilidades que afetam o modo de vida da população idosa e reverberam em problemas de saúde. Além disso, é preciso envolver a participação das pessoas idosas nos espaços, incluindo as UBSF, responsáveis pelo planejamento e desenvolvimento de ações de promoção da saúde.

Entretanto, este estudo revela que isso é cada vez mais difícil de ser garantido em virtude da falta de espaço físico adequado, conforme os trechos abaixo, e da inacessibilidade presente nos serviços da APS, elucidado nos trechos da próxima unidade temática.

"As reuniões eram pra ser lá no posto, mas não tem espaço. Depois da reforma nos tiraram de lá e agora nós estamos aqui." (Participante 20). 
"Aqui a gente tem o espaço, mas não é da saúde, entendeu? É do CRAS. Nós tínhamos lá no posto de saúde só que agora retiraram até a cobertura que estava caindo, retiraram e abandonaram lá. Quer dizer, então a gente não tem espaço pra ficar. Segunda-feira a gente foi fazer uma aula de artesanato e ficamos numa salinha pequenininha, éramos mais de 30, entendeu? Então é um espaço pro idoso que nós não temos aqui." (Participante 03).

\section{Unidade temática II: Necessidades de acesso aos serviços de saúde [subtítulo]}

Ao procurarem os serviços de saúde, especialmente as UBSF, as pessoas idosas afirmam existir obstáculos que dificultam a garantia do acesso, tais como: Falta de prioridade no atendimento, escassez de oferta de medicamentos, ausência de médicos na APS e oferta insuficiente de consultas e exames especializados nos demais estabelecimentos da rede de atenção à saúde.

"A pessoa vai pra uma fila e quando... Aquelas gestantes tudinho tem direito também a nossa fila, né?! Bota um bebezinho no braço, tem direito... O menino já andando, mas tem direito também porque tá no braço [...] no colo. Aí a gente olha... Fica esperando". (Participante 18).

"É difícil. É porque são 20 fichas, né?! Que elas dão. Eu acho que assim, devia ser a metade, né?! Acho que são 4 ou 5 pro idoso e o resto pros outros. Quem não pegou, volta. Acho que não era pra ser assim [...]". (Participante 14).

"Não tem remédio suficiente pra gente tomar no posto de saúde [...] não tem médico pra atender a gente direito". (Participante 04).

"[...] é um atendimento precário, né?! Num dia não tem médico, pra marcar uma consulta ou um exame é um sacrifício, não tem hora e nem tem dia. A saúde tá precária!". (Participante 03).

"Você chega no posto de saúde e não tem gaze, não tem esparadrapo, não tem medicamento... Você vai tirar do seu bolso pra comprar? Você não vai". (Participante 10).

"Faz bem uns três meses que eu tô pra marcar um exame, doente que só, só não morri porque não chegou o dia [...] Eu dei um telefone, mas ele faliu e nunca tive condições de dar outro número, porque quando eu chego lá eu sou atendida muito mal". (Participante 07). 
"Já faz bem um ano que eu fui marcar um exame do coração no posto de saúde e até hoje não fiz esse exame. Estou com mais três exames indicados pra fazer que o médico passou". (Participante 11).

$\mathrm{Na}$ sociedade brasileira, pessoas vinculam cada vez mais as suas necessidades aos projetos ou ideais de saúde, compreendendo que tais necessidades são supridas, impreterivelmente, pelo consumo de serviços e tecnologias de saúde ${ }^{18}$. Essa distorção fortalece a interpretação de que ser saudável é ter somente acesso aos estabelecimentos de saúde, com concentração na dependência ao conhecimento técnico-científico do profissional médico, reforçando o fenômeno conhecido como medicalização da sociedade ${ }^{18}$. Atrelado a esse fenômeno está a dependência da população, sendo aqui a população idosa, às prescrições médicas, aos medicamentos, aos exames laboratoriais e aos conhecimentos especializados, disseminando a ideia do indivíduo doente e subordinado ao médico ${ }^{32}$.

Mundialmente, a assistência centrada no médico e no conhecimento biológico vem tentando ser rompido desde 1920, com a publicação do Relatório Dawson. O referido relatório analisou os problemas do sistema de saúde da Inglaterra e foi um dos primeiros documentos a destacar o protagonismo da APS para atender as necessidades das populações ${ }^{1}$. No Brasil, destaca-se o movimento da Reforma Sanitária Brasileira, a criação do SUS e a expansão da APS, com foco no trabalho da ESF e do NASF, para coordenar o cuidado em saúde e atender as necessidades da sociedade ${ }^{1}$.

O cuidado integral no âmbito da ESF requer a atuação de um elenco de profissionais para além do médico, tais como o agente comunitário de saúde, cirurgião-dentista, enfermeiro, técnico de enfermagem, técnico em saúde bucal, bem como os profissionais do NASF ${ }^{33}$. Porém, os achados deste estudo nos mostra que a percepção das pessoas idosas sobre o cuidado em saúde vai ao encontro do modelo de saúde hegemônico centrado no conhecimento biomédico.

Apesar disso, é preciso respeitar a percepção das pessoas idosas que contribuíram com o presente estudo e compreender que as necessidades delas não são totalmente reconhecidas, havendo barreiras para o acesso aos serviços de saúde e para usufruir o direito à saúde, assegurado constitucionalmente pelo 
Estado, de forma ampla e integral. Dentre essas barreiras, está a falta de prioridade no atendimento.

De acordo com o Estatuto do Idoso, instaurado em 1ํ de outubro de 2003 através da Lei $n .{ }^{\circ} 10.741$, cabe à família, à sociedade e ao Poder Público assegurar o atendimento prioritário, preferencial, imediato e individualizado das pessoas idosas nos órgãos, públicos e privados, prestadores de serviços à população. Em 2017, mais precisamente no dia 12 de julho, o Governo Federal publicou a Lei n. 13.466 que altera o Estatuto do Idoso e dá atendimento preferencial às pessoas idosas longevas (idade $\geq 80$ anos) em relação às demais pessoas idosas.

No âmbito do SUS, ainda segundo a Lei n.․ 13.466, dentre as pessoas idosas, as pessoas longevas também terão prioridade no atendimento, exceto nos casos de urgência. Tal iniciativa é justificada pela forte dependência das pessoas idosas aos serviços de saúde, especialmente das pessoas idosas longevas, que no cenário atual representa o segmento etário mais crescente no $\mathrm{Brasil}^{34}$.

Outro entrave destacado nas falas das pessoas idosas que participaram dos grupos focais diz respeito à dificuldade para ter acesso aos serviços especializados de saúde. A oferta insuficiente de atenção especializada repercute em longos tempos de espera e impossibilita o cuidado imediato e integral, por mais afinado que esteja o elo entre os serviços de saúde ${ }^{35}$.

Para a integralidade do cuidado, é preciso garantir o acesso e articular os diferentes níveis de atenção para dar resolutividade às necessidades das pessoas idosas. Nesse sentido, a APS tem o poder de interferir diretamente no desempenho da atenção especializada, uma vez que é a partir do nível primário de atenção que é gerado a maior parte da demanda para os demais serviços de saúde ${ }^{36}$.

A implementação da ESF e do NASF se consolidará com a provocação de mudanças nos serviços de saúde para além da APS. A partir disso, acontecerão transformações nos processos de trabalho do sistema de saúde e, consecutivamente, no modelo de atenção à saúde vigente. No cuidado para com as pessoas idosas, resultará na compreensão de indivíduos em suas totalidades. 


\section{Unidade temática III: Soluções para atender as necessidades elencadas [subtítulo]}

Apesar de sempre terem em mente a figura do médico, quando questionadas sobre a atuação da equipe multiprofissional da ESF e do NASF, as pessoas idosas relatam que os profissionais são bem qualificados e que há uma boa satisfação quanto ao trabalho que eles realizam. Do mesmo modo, reconhecem que as soluções para as necessidades elencadas não estão no alcance dos profissionais em questão, pois, extrapolam as suas atribuições e responsabilidades.

"Todas nós achamos que somos bem atendidas porque eles nos atendem muito bem, principalmente nós idosas somos muito bem cuidadas, né?!". (Participante 14).

"Eles sabem atender, mas não podem fazer nada, coitados. Não recebem nem o dinheiro que trabalham". (Participante 20).

Ainda de acordo com as pessoas idosas, qualificar os gestores das três esferas de governo (federal, estadual e municipal) do setor saúde seria o caminho prioritário para a resolução das necessidades elencadas. A partir da qualificação dos gestores para o planejamento e desenvolvimento de ações voltadas para as necessidades das pessoas idosas, seria possível criar serviços de saúde contendo atendimento prioritário para essas pessoas, bem como com boas condições de trabalho para os profissionais de saúde, diferente da realidade encontrada nas UBSF.

"Está faltando tudo para a saúde e o povo não pode fazer nada, porque quem deve fazer são os governantes e eles não fazem. Aí eles vão fazer o quê, coitados? Trabalhar de graça? Tentam ajudar, mas não podem. Está todo mundo aqui querendo marcar exames, mas cadê as condições para eles trabalharem? Falta o pagamento deles, falta tudo... O material falta e eles vão fazer o quê? Vão tirar do bolso deles sem puder? Falta os governantes tomarem providência com isso". (Participante 30).

"[...] tem que mudar os governantes. Eu acho que não são os profissionais, porque tem profissional aqui que atende de mão cheia, só falta até dar a cura da gente, mas não pode fazer nada, né?! Se chegar alguém para fazer um curativo elas procuram 
uma gaze e não tem, procura uma seringa para aplicar e não tem... Então vem lá de cima". (Participante 31).

"Quem pode resolver tudo isso é, por exemplo... As autoridades federal, estadual, né?! [...] o Secretário de Saúde também, que faz parte... Que eu acho que é um dos principais pra resolver isso aí". (Participante 14).

Com o incremento do processo de implantação e descentralização do SUS, a gestão em saúde passou a ser definida como um dos critérios importantes para a melhoria da qualidade da atenção à saúde ${ }^{8}$. O bom gestor em saúde é visto como aquele que se compromete com os objetivos finais da instituição em que atua, sendo capaz de desenvolver de maneira satisfatória os seus conhecimentos gerenciais, extrapolando o cumprimento de atividades meramente administrativas e preventivas e desenvolvendo ações voltadas para a integralidade, universalidade e equidade do cuidado $^{37}$.

Porém, a gestão em saúde também é um dos desafios atuais para a consolidação do SUS. No setor público brasileiro, o modelo de gestão encontrado nas instituições de saúde é fruto do modelo de administração implantado em meados do século XIX, cujos princípios norteadores foram a impessoalidade, o controle rígido dos processos administrativos, dentre outros ${ }^{38} 39$.

Com isso, as organizações públicas perderam a noção do seu principal objetivo, que é dar respaldo às necessidades da sociedade. No campo da saúde pública, isso implica diretamente na qualidade da assistência ofertada à população. Essa forma de organização nas instituições de saúde desencadeia em ambientes de trabalho complexos, onde os profissionais tornam-se cada vez mais desvalorizados e desmotivados, desenvolvendo com dissabor práticas de trabalho e, consecutivamente, de atenção à saúde ${ }^{40}$.

Para qualificar o trabalho no interior das instituições de saúde, frisa-se aqui as UBSF, é preciso valorizar a força do trabalho por intermédio da qualificação profissional e de boas condições de trabalho. Ademais, é preciso praticar uma gestão em saúde que conte com os profissionais e a população, destaca-se aqui a população idosa, para o planejamento e tomada de decisões. 


\section{Considerações finais}

O estudo realizado, apesar de não haver o retorno das transcrições e dos resultados finais para comentários e/ou correções dos participantes, compreende que as necessidades das pessoas idosas demandam por ações intersetoriais para serem resolvidas. Outrossim, aponta elementos para uma reflexão crítica sobre a importância da adoção de estratégias nas três esferas de gestão para melhorar os determinantes sociais e diminuir os agravos à saúde dessas pessoas, levando em consideração diferentes aspectos, tais como: Meio ambiente saudável, renda, trabalho, saneamento, alimentação, educação, segurança pública e garantia de ações e serviços de boa qualidade no SUS.

No que concerne ao setor saúde, o princípio da integralidade talvez seja o mais acometido diante das fragilidades apresentadas e o que diretamente necessita de mudanças para que seja efetivado. Ademais, para garantia desse princípio é necessário uma junção de práticas individuais e coletivas com garantia de acesso e articulação dos níveis de atenção.

Para contribuir com a transformação do modelo de atenção à saúde existente no país para as pessoas idosas é preciso, primeiramente, conscientizá-las sobre os seus direitos, bem como sobre a organização da APS e sobre o papel dos profissionais da ESF e do NASF. Dessa forma, as pessoas idosas poderão exercer a cidadania, a participação cidadã, a autonomia e independência, compreendendo que o cuidado em saúde e o desenvolvimento do envelhecimento saudável não estão condicionados ao consumo de serviços de saúde e aos saberes especializados.

Por fim, diante do acelerado crescimento da população idosa e do uso desse segmento etário dos serviços do SUS, se as necessidades das pessoas idosas não forem compreendidas e discutidas amplamente poderão se tornar grandes problemas para a saúde coletiva.

\section{Referências}

1. Aquino R, Medina MG, Nunes CA, Sousa MF. Estratégia Saúde da Família e reordenamento do sistema de serviços de saúde. In: Paim JS, Almeida-Filho N, organizadores. Saúde coletiva: teoria e prática. Rio de Janeiro: MedBook; 2014. p. 353-372. 
2. Arantes LJ, Shimizu HE, Merchán-Hamann E. Contribuições e desafios da Estratégia Saúde da Família na atenção primária à saúde no Brasil: revisão da literatura. Cien Saude Colet. 2016; 21(5): 1499-1509.

3. Starfield B. Atenção primária: equilíbrio entre necessidades de saúde, serviços e tecnologia. Brasília: UNESCO; 2004.

4. Carnut L. Cuidado, integralidade e atenção primária: articulação essencial para refletir sobre o setor saúde no Brasil. Saúde Debate. No prelo 2017.

5. Santana JP, Castro JL. Os sanitaristas de Jucás e o agente de saúde: entrevista com Antonio Carlile Holanda Lavor e Miria Campos Lavor. 1.ed. Natal: Una; 2017.

6. Castro JL, Araújo D, Pessoa MGA, Bezerra O, Vilar RLA, Oliveira NJM. Programa Saúde da Família: flexibilidade e precarização no trabalho. In: Castro JL, organizadora. Gestão do trabalho no SUS: entre o visível e o oculto. 1.ed. Natal: Observatório RH NESC/UFRN; 2007. p. 17-42.

7. Miranda GMD, Mendes ACG, Silva ALA, Santos Neto PM. A ampliação das equipes de saúde da família e o Programa Mais Médicos nos municípios brasileiros. Trab Educ Saúde. 2017; 15(1): 131-145.

8. Lima RRT, Castro JL. Estudo acerca do perfil: uma contribuição para as políticas de valorização profissional. In: Castro JL, Vilar RLA, Oliveira NHS, organizadoras. As trilhas e os desafios da gestão do trabalho e da educação na saúde. 1.ed. Natal: Una; 2016. p. 129-147.

9. Belas IA, Rocha JHA, Silva FM, Lustosa JVB, Carneiro WS, Valença AMG, Silva ES, Rodrigues JA. Articulated Actions of the Family Health Strategy Teams and Their Centres of Support in the State of Piauí, Brazil. Int Arch Med. 2017; 10(5): 1-8.

10. Almeida PF, Marin J, Casotti E. Estratégias para consolidação da coordenação do cuidado pela atenção básica. Trab Educ Saúde. 2017; 15(2): 373-398.

11. Shimizu HE, Fragelli TBO. Competências profissionais essenciais para o trabalho no Núcleo de Apoio à Saúde da Família. Rev Bras Educ Med. 2016; 40(2): 216-225.

12. Santos DS, Mishima SM, Merhy EE. Processo de trabalho na Estratégia Saúde da Família: potencialidades da subjetividade do cuidado para reconfiguração do modelo de atenção. Cien Saude Colet. No prelo 2016.

13. Melo LA, Ferreira LMBM, Santos MM, Lima KC. Fatores socioeconômicos, demográficos e regionais associados ao envelhecimento populacional. Rev Bras Geriatr Gerontol. 2017; 20(4): 494-502. 
14. Miranda GMD, Mendes ACG, Silva ALA. Desafios das políticas públicas no cenário da transição demográfica e mudanças sociais no Brasil. Interface (Botucatu). 2017; 21(61): 309-320.

15. Martins $A B$, D'Avila OP, Hilgert JB, Hugo FN. Atenção primária à saúde voltada às necessidades dos idosos: da teoria à prática. Cien Saude Colet. 2014; 19(8): 3403-3416.

16. Moraes PA, Bertolozzi MR, Hino P. Percepções sobre necessidades de saúde na atenção básica segundo usuários de um serviço de saúde. Rev Esc Enferm USP. 2011; 45(1): 19-25.

17. Cecilio LCO. As necessidades de saúde como conceito estruturante na luta pela integralidade e equidade na atenção em saúde. In: Pinheiro $R$, Mattos RA, organizadores. Os sentidos da integralidade na atenção e no cuidado à saúde. 6.ed. Rio de Janeiro: IMS/UERJ; 2006. p. 115-128.

18.Paim JS, Almeida-Filho N. Análise da situação de saúde: o que são necessidades e problemas de saúde? In: Paim JS, Almeida-Filho N, organizadores. Saúde coletiva: teoria e prática. Rio de Janeiro: MedBook; 2014. p. 29-40.

19. Mendes-Gonçalves RB. Prática de saúde: processo de trabalho e necessidades. In: Ayres JRCM, Santos L, organizadores. Saúde, sociedade e história. Porto Alegre: Rede Unida; 2017. p. 298-374.

20. Instituto Brasileiro de Geografia e Estatística - IBGE. Censo Demográfico 2010. [Internet]. [acesso em 20 nov. 2017]. Disponível em http://www.ibge.gov.br/estadosat/temas.php?sigla=rn\&tema=censodemog201 $0 \_$snig.

21. Ministério da Saúde. Sala de Apoio à Gestão Estratégica - SAGE. [internet]. [acesso em 20 nov. 2017]. Disponível em http://sage.saude.gov.br/\#

22. Tong A, Sainsbury $P$, Craig J. Consolidated criteria for reporting qualitative research (COREQ): a 32-item checklist for interviews and focus groups. Int $J$ Qual Health Care. 2007; 19(6): 349-357.

23. Lopes BEM. Grupo focal na pesquisa em ciências sociais e humanas. Rev Educ Polit Debate. 2014; 3(2): 482-492.

24.World Health Organization. (1984). The Uses of Epidemiology in the Study of the Elderly. Geneva: WHO; 1984. 
25. Minayo MCS. O desafio do conhecimento: pesquisa qualitativa em saúde. 13.ed. São Paulo: Hucitec; 2013.

26. Minayo MCS. A violência social sob a perspectiva da saúde pública. Cad Saude Publica. 1994; 10(Supl.): 7-18.

27. Veloso MMX, Magalhães CMC, Dell'Aglio DD, Cabral IR, Gomes MM. Notificação da violência como estratégia de vigilância em saúde: perfil de uma metrópole do Brasil. Cien Saude Colet. 2013; 18(5): 1263-1272.

28. Souto RMCV, Barufaldi LA, Nico LS, Freitas MG. Perfil epidemiológico do atendimento por violência nos serviços públicos de urgência e emergência em capitais brasileiras, Viva 2014. Cien Saude Colet. 2017; 22(9): 2811-2823.

29. Amador AE, Marques MV, Nunes ADS, Miranda GMD, Barbosa IR. Desigualdade espacial na mortalidade por agressão no estado do Rio Grande do Norte, Brasil: 2010 a 2014. J Health Biol Sci. 2017; 5(1): 24-30.

30. Lima ALB, Lima KC, Maia LTS, Oliveira TC. Tendência crescente de violência homicida na região metropolitana de Natal-RN, Brasil. Rev Cienc Plural. 2015; 1(2): 19-28.

31. Miranda GMD, Mendes ACG, Silva ALA. O envelhecimento populacional brasileiro: desafios e consequências atuais e futuras. Rev Bras Geriatr Gerontol. 2016; 19(3): 507-519.

32. Moraes GVO, Giacomin K, Santos WJ, Firmo JOA. A percepção dos idosos sobre o saber biomédico no cuidado à velhice e às "coisas da idade". Physis: Rev Saude Colet. 2016; 26(1): 309-329.

33.Peduzzi M. O SUS é interprofissional. Interface (Botucatu). 2016; 20(56): 199201.

34. Menezes TMO, Lopes RLM. Significados do vivido pela pessoa idosa longeva no processo de morte/morrer e luto. Cien Saude Colet. 2014; 19(8): 33093316.

35. Almeida PF, Giovanella L, Nunan BA. Coordenação dos cuidados em saúde pela atenção primária à saúde e suas implicações para a satisfação dos usuários. Saúde Debate. 2012; 36(94): 375-391. 
36. Silveira MSD, Cazola LHO, Souza AS, Pícoli RP. Processo regulatório da Estratégia Saúde da Família para a assistência especializada. Saúde Debate. No prelo 2017.

37. Cunha MLS, Hortale VA. Características dos cursos voltados para a formação em gestão em saúde no Brasil. Saúde Debate. 2017; 41(113): 425-440.

38. Castro JL. Gerência de pessoal nos serviços de saúde. In: Santana JP, Castro JL, organizadores. Capacitação em desenvolvimento de recursos humanos de saúde - CADRHU. 1.ed. Natal: EDUFRN; 1999. p. 313-327.

39. Rodrigues PHA. Desafios políticos para a consolidação do Sistema Único de Saúde: uma abordagem histórica. Hist Cienc Saude-Manguinhos. 2014; 21(1): 37-60.

40. Lima RRT, Castro JL. A produção científica acerca da negociação coletiva do trabalho em saúde. In: Castro JL, Lima RRT, organizadores. Negociação do trabalho no Sistema Único de Saúde. 1.ed. Natal: Una; 2017. p. 187-210. 


\section{COMENTÁRIOS, CRÍTICAS E SUGESTÕES}

\subsection{Considerações finais}

Este trabalho, fruto do desenvolvimento do projeto de pesquisa Competências profissionais frente às necessidades de saúde das pessoas idosas, foi realizado em duas etapas, como já dito na metodologia, com recursos metodológicos diferentes e, por conseguinte, com o alcance de resultados em dimensões distintas.

Na primeira etapa, a análise documental dos projetos pedagógicos dos cursos para as profissões que integram as equipes da ESF e do NASF evidenciou que a discussão acerca da temática do envelhecimento no processo de formação destes ainda é incipiente. Os cursos investigados não contribuem para a transformação da atenção à saúde das pessoas idosas, onde tais pessoas não são enxergadas em sua totalidade pelos atuais e futuros profissionais de saúde, tendo suas necessidades, subjetividades e interações sociais completamente ignoradas.

A formação é direcionada para a prevenção de doença, desconsiderando os aspectos sociais e subjetivos comuns ao processo de envelhecimento e desfavorecendo o trabalho colaborativo e a prática de cuidado integral à saúde. Nesse contexto, defende-se que a formação em saúde não deve se limitar aos conhecimentos especializados, mas sim, que agrupe conhecimentos de outras áreas e respeite as competências de cada profissão. Para transformar as práticas de trabalho e, por conseguinte, as práticas assistenciais para a população velha no cotidiano da APS, afirmamos que é preciso primeiramente qualificar a força de trabalho.

Tal qualificação deve partir desde a formação profissional até o desenvolvimento de ações de educação permanente para os trabalhadores já inseridos nos serviços de saúde, pautando-se na identificação das necessidades das pessoas idosas, compreendendo que tais necessidades não são somente de ordem biológica, nem tampouco individuais e homogêneas. Pelo contrário, o envelhecimento é multidimensional e complexo, e restringir a saúde da pessoa idosa aos aspectos biológicos é tentar tratá-la de forma simplista.

A operacionalização dos grupos focais permitiu conhecer a percepção das pessoas idosas participantes do estudo sobre as suas necessidades, classificandoas em duas temáticas: Necessidade de boas condições de vida e necessidade de 
acesso aos serviços de saúde. De acordo com os participantes, a violência e a ineficiência da segurança pública, bem como a falta de espaços para lazer e para a realização de atividades de promoção à saúde propostas pelas equipes da ESF e do NASF, são condições que afetam o bem-estar, a saúde e a vida das pessoas idosas.

Ademais, ao procurarem os serviços de saúde, especialmente as UBS, as pessoas idosas afirmam a existência de obstáculos que dificultam a garantia do acesso, tais como: Falta de prioridade no atendimento, escassez de oferta de medicamentos, ausência de médicos na APS e oferta insuficiente de consultas e exames especializados nos demais estabelecimentos da rede de atenção à saúde. $\mathrm{Na}$ percepção dos mesmos, qualificar os gestores (municipais, estaduais e federais) do setor saúde seria o caminho prioritário para a resolução das necessidades elencadas.

A partir da qualificação dos gestores para o planejamento e desenvolvimento de ações voltadas para as pessoas idosas, seria possível criar novos serviços de saúde específicos para essa parcela da população. Além do atendimento prioritário, os referidos serviços devem conter boas condições de trabalho para os profissionais, diferente da realidade encontrada nos serviços da APS, ainda de acordo com a percepção dos participantes deste estudo.

É necessário preparar pessoas que ofereçam atenção adequada à população idosa, bem como para formular e gerir políticas públicas para a mencionada população usuária do SUS. Além disso, se faz necessário preparar pessoas para que elas sejam agentes multiplicadores e contribuam com a formação de cuidadores de pessoas idosas.

Esta pesquisa poderá auxiliar também no desenvolvimento de estudos com populações idosas de outros estados brasileiros e até de outros países que possuam perfil populacional e políticas de saúde semelhantes ao Brasil, além de colaborar com a educação em saúde, provocando mudanças na formação dos profissionais da saúde. Essas mudanças devem pautar-se na integração entre o ensino e o serviço, bem como na inclusão da discussão acerca do envelhecimento ativo na agenda da educação permanente do SUS. Afinal, se o acentuado envelhecimento populacional não for tratado como prioridade, poderá constituir-se em um grave problema de saúde pública. 


\subsection{A trajetória no mestrado acadêmico: relato de um aluno}

Não se detendo mais a pesquisa e ao desenvolvimento da dissertação, mas sim ao meu aprendizado durante a trajetória no mestrado acadêmico do PPGCSA/UFRN, reflito e vejo o quanto cresci pessoalmente e profissionalmente. O retorno ao grupo de pesquisa do OBSERVARH/UFRN, o qual eu fiz parte durante o período da graduação, me deu a oportunidade de realizar novas publicações, de me inserir em novos projetos de pesquisa e de extensão, bem como participar de reuniões acadêmicas e eventos científicos (nacionais e internacionais).

Ademais, retornando ao OBSERVARH/UFRN, eu tive o prazer de estar mais próximo de amigas queridas e de conhecer outras pessoas, onde criei novos laços de amizade para compartilhar experiências e conhecimentos cotidianamente. Com a inserção no curso de mestrado em si, pude conhecer melhor uma das minhas referências acadêmicas, o meu orientador, que me mostrou com mais clareza o que é fazer ciência e me aproximou do tema do envelhecimento.

Apesar da ótima relação com o meu orientador, confesso que o mestrado deixou a minha saúde mental adoecida. Não por culpa dele, pois como já mencionei, tivemos uma respeitosa relação professor-aluno, mas sim pelo rumo que a pósgraduação vem tomando. Um sistema onde o estudante é obrigado a produzir constantemente, como uma máquina, sem levar em consideração as suas limitações humanas e as suas subjetividades geram angústias, ansiedade, depressão, dentre outros transtornos.

Discentes são pressionados a publicarem algo o mais rápido possível para tornarem-se mestres ou doutores, ao invés de serem incentivados a fazerem ciência com qualidade para posteriormente publicarem os resultados de suas pesquisas, fomentando melhorias para a sociedade. Considerando a responsabilidade social em ser cientista, é preciso rever urgentemente o que significa ciência, ou o que significa ser mestre ou doutor na atualidade.

Sei que por enquanto não tenho autoridade e nem poder para transformar essa realidade. Porém, preciso expor sobre como esse modelo de formação da pósgraduação stricto sensu tem afetado a vida de pessoas que sonham em seguir a carreira acadêmica. 


\section{REFERÊNCIAS}

1. Lucena RCB. A descentralização na vigilância sanitária: trajetória e descompasso. Rev. Adm. Publica. 2015; 49(5): 1107-1120.

2. Vendruscolo $C$, Prado ML, Kleba ME. Formação de recursos humanos em saúde no Brasil: uma revisão integrativa. Educ. Rev. 2014; 30(1): 215-244.

3. Simões AP. Os núcleos de desenvolvimento de recursos humanos para a saúde. Cad. Saúde Pública. 1986; 2(4): 553-560.

4. Castro JL. Protagonismo silencioso: a presença da OPAS na formação de recursos humanos em saúde no Brasil. 1.ed. Natal: Observatório RH NESC/UFRN; 2008.

5. Brasil. Constituição, 1988. Constituição da República Federativa do Brasil. Brasília: Senado Federal; 1988.

6. Lima SAV, Albuquerque PC, Wenceslau LD. Educação permanente em saúde segundo os profissionais da gestão de Recife, Pernambuco. Trab. Educ. Saúde. 2014; 12(2): 425-441.

7. Sampaio ATL. Formação e educação permanente em saúde: desafios pedagógicos para um modelo de atenção integral no Brasil. In: Castro JL, Vilar RLA, Oliveira NHS. As trilhas e os desafios da gestão do trabalho e da educação na saúde. 1.ed. Natal: Una; 2016. p. 149-177.

8. Alves CGL, Martinez MR. Lacunas entre a formação do nutricionista e o perfil de competências para atuação no Sistema Único de Saúde (SUS). Interface (Botucatu). 2016; 20(56): 159-169.

9. França T, Medeiros KR, Belisario SA, Garcia AC, Pinto ICM, Castro JL, et al. Política de Educação Permanente em Saúde no Brasil: a contribuição das Comissões Permanentes de Integração Ensino-Serviço. Ciênc. Saúde Coletiva. 2017; 22(6): 1817-1828.

10. Andrade RS, Caldas LBSN, Falcão MLP, Goes PSA. Processo de trabalho em unidade de saúde da família e a educação permanente. Trab. Educ. Saúde. 2016; 14(2): 505-521.

11.Pierantoni CR, França T, Garcia AC, Santos MR, Varella TC, Matsumoto KS. Gestão do trabalho e da educação em saúde. 1.ed. Rio de Janeiro: IMS/UERJ; 2012.

12. Vieira LM, Sgaviolli CAPP, Simionato EMRS, Inoue ESY, Heubel MTCD, Conti MHS, et al. Formação profissional e integração com a rede básica de saúde. Trab. Educ. Saúde. 2016; 14(1): 293-304. 
13. Mendes J, Soares VMN, Massi GAA. Speech therapy and nursing undergraduates' perceptions on aging processes and education for elders' care. Rev. CEFAC. 2015; 17(2): 576-585.

14. Veras RP. Envelhecimento populacional contemporâneo: demandas, desafios e inovações. Rev. Saúde Pública. 2009; 43(3): 548-554.

15. Chaimowicz F, Barcelos EM, Madureira MDS, Ribeiro MTF. Saúde do idoso. 2.ed. Belo Horizonte: NESCON/UFMG; 2013.

16. Tanjani PT, Motlagh ME, Nazar MM, Najafi F. The health status of the elderly population of Iran in 2012. Arch. Gerontolog. Geriatr. 2015; 60(2): 281-287.

17.Ferreira LMBM, Jerez-Roig J, Andrade FLJP, Oliveira NPD, Araújo JRT, Lima KC. Prevalência de quedas e avaliação da mobilidade em idosos institucionalizados. Rev. Bras. Geriatr. Gerontol. 2016; 19(6): 995-1003.

18. Andrade LM, Sena ELS, Pinheiro GML, Meira EC, Lira LSSP. Políticas públicas para pessoas idosas no Brasil: uma revisão integrativa. Ciênc. Saúde Coletiva. 2013; 18(12): 3543-3552.

19. Veras RP. Envelhecimento populacional e as informações em saúde do PNAD: demandas e desafios contemporâneos. Cad. Saúde Pública. 2007; 23(10): 2463-2466.

20.Louvison MCP, Rosa TEC. Envelhecimento e políticas públicas de saúde da pessoa idosa. In: Berzins MV, Borges MC. Políticas públicas para um país que envelhece. São Paulo: Martinari, 2012. p. 155-179.

21. Albala C, Lebrão ML, Díaz EML, Ham-Chande R, Hennis AJ, Palloni A, et al. Encuesta Salud, Bienestar y Envejecimiento (SABE): metodologia de la encuesta y perfil de la población estudiada. Rev. Panam. Salud Publica. 2005; 17(5-6): 307-322.

22. Lebrão ML, Laurenti R. Saúde, bem-estar e envelhecimento: o estudo SABE no município de São Paulo. Rev. Bras. Epidemiol. 2005; 8(2): 127-141.

23. Alves KL, Alves MRR, Sá CMCP, Xavier Junior JA, Barros KC, Alves LMRR, et al. Nursing professional's working load given to the elderly at the intensive unit care. Int. Arch. Med. 2017; 10(44): 1-8.

24. Veras RP, Caldas CP, Motta LB, Lima KC, Siqueira RC, Rodrigues RTSV, et al. Integration and continuity of care in health care network models for frail older adults. Rev. Saúde Pública. 2014; 48(2): 357-365.

25. Closs VE, Schwanke CHA. A evolução do índice de envelhecimento no Brasil, nas suas regiões e unidades federativas no período de 1970 a 2010. Rev. Bras. Geriatr. Gerontol. 2012; 15(3): 443-458. 
26. Martins JJ, Schier J, Erdmann AL, Albuquerque GL. Políticas públicas de atenção à saúde do idoso: reflexão acerca da capacitação dos profissionais de saúde para o cuidado com o idoso. Rev. Bras. Geriatr. Gerontol. 2007; 10(3): 371-382.

27. Lima KC. Educação em saúde para o envelhecimento ativo. In: Nacif PGS, Queiroz AC, Gomes LM, Rocha RG. Coletânea de textos CONFINTEA Brasil+6: tema central e oficinas temáticas. 1.ed. Brasília: Ministério da Educação; 2016. p. 252-258.

28. Motta LB, Aguiar AC, Caldas CP. Estratégia Saúde da Família e a atenção ao idoso: experiências de três municípios brasileiros. Cad. Saúde Pública. 2011; 27(4): 779-786.

29. Arantes LJ, Shimizu HE, Merchán-Hamann E. Contribuições e desafios da Estratégia Saúde da Família na Atenção Primária à Saúde no Brasil: revisão da literatura. Ciênc. Saúde Coletiva. 2016; 21(5): 1499-1509.

30. Starfield B. Atenção primária: equilíbrio entre necessidades de saúde, serviços e tecnologia. Brasília: UNESCO; 2004.

31. Santana JP, Piola SF, Vianna S, Rodrigues VA, Ramos ZVO. Caracterização do processo de trabalho em atenção básica/saúde da família: aspectos institucionais, do emprego e da atividade do médico nos municípios de Campo Grande/MS, Cuiabá/MT, Goiânia/GO e Palmas/TO. 1.ed. Brasília: UnB/CEAM/NESP/ObservaRH; 2010.

32. Castro JL, Araújo D, Pessoa MGA, Bezerra O, Vilar RLA, Oliveira NJM. Programa Saúde da Família: flexibilidade e precarização no trabalho. In: Castro JL. Gestão do trabalho no SUS: entre o visível e o oculto. 1.ed. Natal: Observatório RH NESC/UFRN; 2007. p. 17-42.

33. Massud SG. Análise da política de gestão da atenção básica no município de Natal. Natal. Monografia [Especialização em Saúde Pública] - Universidade Federal do Rio Grande do Norte; 2001.

34. Miranda GMD, Mendes ACG, Silva ALA, Santos Neto PM. A ampliação das equipes de saúde da família e o Programa Mais Médicos nos municípios brasileiros. Trab. Educ. Saúde. 2017; 15(1): 131-145.

35. Menicucci TMG. A política de saúde no Governo Lula. Saúde Soc. 2011; 20(2): 522-532.

36. Costa NR, Lamarca I. Os Governos FHC e Lula e a política para a força de trabalho civil do Governo Central Brasileiro. Ciênc. Saúde Coletiva. 2013; 18(6): 1601-1611. 
37. Lima RRT, Castro JL. Estudo acerca do perfil: uma contribuição para as políticas de valorização profissional. In: Castro JL, Vilar RLA, Oliveira NHS. As trilhas e os desafios da gestão do trabalho e da educação na saúde. 1.ed. Natal: Una; 2016. p. 129-147.

38. Belas IA, Rocha JHA, Silva FM, Lustosa JVB, Carneiro WS, Valença AMG, et al. Articulated Actions of the Family Health Strategy Teams and Their Centres of Support in the State of Piauí, Brazil. Int. Arch. Med. 2017; 10(5): 1-8.

39. Shimizu HE, Fragelli TBO. Competências profissionais essenciais para o trabalho no Núcleo de Apoio à Saúde da Família. Rev. Bras. Educ. Méd. 2016; 40(2): 216-225.

40. Minayo MCS. O desafio do conhecimento: pesquisa qualitativa em saúde. 13.ed. São Paulo: Hucitec; 2013.

41. Kripka RML, Scheller M, Bonotto DL. Pesquisa documental na pesquisa qualitativa: conceitos e caracterização. Rev. Investigaciones. 2015; 14(2): 5573.

42.Lopes BEM. Grupo focal na pesquisa em ciências sociais e humanas. Rev. Educ. Polít. Debate. 2014; 3(2): 482-492.

43. Tong A, Sainsbury P, Craig J. Consolidated criteria for reporting qualitative research (COREQ): a 32-item checklist for interviews and focus groups. Int. J. Qual. Health Care. 2007; 19(6): 349-357.

44. Instituto Brasileiro de Geografia e Estatística - IBGE. Censo Demográfico 2010. [Internet]. [acesso em 30 abr. 2017]. Disponível em http://www.ibge.gov.br/estadosat/temas.php?sigla=rn\&tema=censodemog201 0_snig.

45. Ministério da Saúde. Sala de Apoio à Gestão Estratégica - SAGE. [internet]. [acesso em 17 jul. 2017]. Disponível em http://sage.saude.gov.br/\#

46. Brasil, 1996. Lei 9.394, sancionada em 20 de dezembro de 1996, a qual "estabelece as diretrizes e bases da educação nacional". [Internet]. [acesso em 23 jun. 2017]. Disponível em http://www.planalto.gov.br/ccivil_03/leis/L9394.htm. 


\section{APÊNDICES}

\section{Apêndice I}

\section{TERMO DE CONSENTIMENTO LIVRE E ESCLARECIDO (TCLE)}

Este é um convite para você participar da pesquisa intitulada "Competências profissionais frente às necessidades de saúde da população idosa”, que será realizado pelo pesquisador Rafael Rodolfo Tomaz de Lima. Sua participação é voluntária, o que significa que você poderá desistir a qualquer momento, retirando seu consentimento, sem que isso lhe traga nenhum prejuízo ou penalidade.

Esta pesquisa tem como principal objetivo analisar a formação dos profissionais atuantes na Estratégia Saúde da Família (ESF) e no Núcleo de Apoio à Saúde da Família (NASF) para atender às necessidades da população idosa. Seus objetivos específicos são:

A. Conhecer a percepção das pessoas idosas cobertas pela ESF e pelo NASF quanto às suas necessidades;

B. Compreender a percepção das pessoas idosas assistidas pela ESF e pelo NASF sobre as competências profissionais necessárias para lidar com cuidado à pessoa idosa.

Para alcançar os citados objetivos, serão realizados grupos focais com idosos atendidos pelas equipes da ESF e do NASF. Cada grupo focal será composto por dez idosos que, além de serem atendidos pelas mencionadas equipes, deverão ter idade acima de 60 anos, que tenha cognição, que seja capaz de realizar as suas atividades cotidianas de forma independente e que tenha interesse em contribuir com este estudo, a partir da assinatura deste Termo.

Os grupos focais serão realizados em sessão única, terão no máximo duas horas e deverão ser realizados em locais previamente pactuados com todos os participantes. Os referidos locais terão condições condignas, confortáveis, que protejam a privacidade dos voluntários e que possibilite um bom registro do que é discutido. Para esse registro, será realizada gravação em áudio que, posteriormente, será transcrita.

$\mathrm{Na}$ tentativa de amenizar possíveis riscos em relação à sua identificação, será atribuído um código ou um pseudônimo à você durante a realização dos grupos focais, durante a transcrição dos áudios, bem como durante a análise e publicação dos resultados. As informações coletadas ficarão guardadas sob a responsabilidade do pesquisador responsável por cinco anos e depois serão incineradas.

Ademais, será garantido o respeito à sua dignidade e à sua autonomia, reconhecendo sua vulnerabilidade, assegurando sua vontade de contribuir e permanecer, ou não, na pesquisa, por intermédio de manifestação expressa, livre e esclarecida. 
Ressaltamos que você tem a plena liberdade de recusar-se a participar ou retirar o seu consentimento, em qualquer fase da pesquisa, sem penalização alguma. Além disso, se você tiver algum gasto que seja devido à sua participação na pesquisa, você será ressarcido, caso solicite. Em qualquer momento, se você sofrer algum dano comprovadamente decorrente desta pesquisa, você terá direito a indenização.

A sua participação não tem finalidade de prevenção, diagnóstico ou terapêutica e ajudará para contribuir com o conhecimento científico na área do envelhecimento humano e na formação de recursos humanos em saúde, auxiliando no desenvolvimento de outros estudos com populações idosas de outros estados e até de outros países que possuam perfil populacional e políticas de saúde semelhantes ao Brasil.

Você ficará com uma cópia deste Termo e toda a dúvida que você tiver a respeito desta pesquisa, poderá perguntar diretamente para o pesquisador responsável, através do e-mail limarrt@gmail.com ou pelo telefone (84) 998108 464. Salientamos que esta pesquisa terá como base a Resolução n.. 466/12 do Conselho Nacional de Saúde, que dispõe sobre as diretrizes e normas para as pesquisas que envolvem seres humanos.

Dúvidas a respeito da ética desta pesquisa poderão ser questionadas ao Comitê de Ética em Pesquisa, localizado no Espaço Acadêmico Prof. ․ João Machado, no primeiro andar do prédio administrativo do Hospital Universitário Onofre Lopes. Caso prefira, as dúvidas também poderão ser sanadas pelo telefone (84) 3342-5003, ou através do e-mail cep_huol@yahoo.com.br.

Participante:

Rafael Rodolfo Tomaz de Lima

\section{Pesquisador responsável pela pesquisa}




\section{Apêndice II}

\section{GUIA DE TEMAS PARA O GRUPO FOCAL}

1. Quais são as necessidades de vocês? Do que vocês precisam no dia-a-dia?

2. Essas necessidades que foram relatadas por vocês são atendidas pela equipe de saúde?

3. Como a equipe e os serviços de saúde atendem essas necessidades?

4. Vocês estão satisfeitos com esse atendimento? Por que?

5. A equipe de saúde está preparada para lidar com as necessidades de vocês? Por que vocês acham isso?

6. Se vocês fizessem parte dessa equipe de saúde, como vocês tratariam as necessidades que foram levantadas?

7. Seria necessário inserir outros profissionais na equipe para atender essas necessidades? Que profissionais seriam esses? 


\section{Apêndice III}

TRADUÇÃO DO CHECKLIST UTILIZADO PARA A VALIDAÇÃO DA COLETA E ANÁLISE DOS DADOS DOS GRUPOS FOCAIS

\begin{tabular}{|c|c|c|}
\hline N.. & ITEM & $\begin{array}{c}\text { PERGUNTAS/ } \\
\text { DESCRIÇÃO DO GUIA }\end{array}$ \\
\hline \multicolumn{3}{|c|}{ 1- DOMÍNIO: Equipe de pesquisa e reflexividade } \\
\hline \multicolumn{3}{|c|}{ Características pessoais } \\
\hline 01 & Entrevistador / facilitador & $\begin{array}{l}\text { Qual autor (a) conduziu a } \\
\text { entrevista ou grupo focal? }\end{array}$ \\
\hline 02 & Formação & $\begin{array}{l}\text { Qual o nível de formação do } \\
\text { entrevistador (a) ou facilitador } \\
\text { (a)? Por exemplo: Especialista, } \\
\text { Mestre (a) ou Doutor (a). }\end{array}$ \\
\hline 03 & Ocupação & $\begin{array}{l}\text { Qual a ocupação do (a) } \\
\text { entrevistador (a) ou facilitador (a) } \\
\text { no momento do estudo? }\end{array}$ \\
\hline 04 & Gênero & $\begin{array}{l}\text { Qual o gênero do (a) } \\
\text { entrevistador (a) ou facilitador } \\
\text { (a)? }\end{array}$ \\
\hline 05 & Experiência ou treinamento & $\begin{array}{c}\text { Que experiência ou treinamento } \\
\text { o (a) entrevistador (a) teve? }\end{array}$ \\
\hline \multicolumn{3}{|c|}{ Relacionamento com os participantes } \\
\hline 06 & $\begin{array}{l}\text { Relacionamento } \\
\text { estabelecido }\end{array}$ & $\begin{array}{c}\text { Algum relacionamento foi } \\
\text { estabelecido antes do início do } \\
\text { estudo? }\end{array}$ \\
\hline 07 & $\begin{array}{l}\text { Participante com } \\
\text { conhecimento do (a) } \\
\text { entrevistador (a) ou } \\
\quad \text { facilitador (a) }\end{array}$ & $\begin{array}{c}\text { O que os (as) participantes } \\
\text { conheceram sobre o (a) } \\
\text { pesquisador (a)? Por exemplo: } \\
\text { Objetivos pessoais, razões para } \\
\text { fazer a pesquisa etc. }\end{array}$ \\
\hline 08 & $\begin{array}{l}\text { Características do (a) } \\
\text { entrevistador (a) ou } \\
\text { facilitador (a) }\end{array}$ & $\begin{array}{l}\text { Quais características foram } \\
\text { relatadas sobre o (a) } \\
\text { entrevistador (a) ou facilitador } \\
\text { (a)? Por exemplo: Pressupostos, } \\
\text { razões e interesses no tópico da } \\
\text { pesquisa. }\end{array}$ \\
\hline \multicolumn{3}{|c|}{ 2o DOMíNIO: Desenho do estudo } \\
\hline
\end{tabular}




\begin{tabular}{|c|c|c|}
\hline \multicolumn{3}{|c|}{ Quadro teórico } \\
\hline 09 & $\begin{array}{c}\text { Orientação metodológica e } \\
\text { teórica }\end{array}$ & $\begin{array}{l}\text { Qual orientação metodológica foi } \\
\text { declarada para apoiar o estudo? } \\
\text { Por exemplo: Análise do } \\
\text { discurso, etnografia, } \\
\text { fenomenologia, análise de } \\
\text { conteúdo etc. }\end{array}$ \\
\hline \multicolumn{3}{|c|}{ Seleção dos (as) participantes } \\
\hline 10 & Amostragem & $\begin{array}{l}\text { Como os (as) participantes foram } \\
\text { selecionados (as)? Por exemplo: } \\
\text { Proposital, conveniência, } \\
\text { consecutiva, bola de leve etc. }\end{array}$ \\
\hline 11 & Método de aproximação & $\begin{array}{l}\text { Como os (as) participantes se } \\
\text { aproximaram? Por exemplo: } \\
\text { Cara a cara, telefone, e-mail etc. }\end{array}$ \\
\hline 12 & Tamanho da amostra & $\begin{array}{c}\text { Quantos sujeitos participaram do } \\
\text { estudo? }\end{array}$ \\
\hline 13 & Não participação & $\begin{array}{c}\text { Quantos sujeitos se recusaram a } \\
\text { participar ou abandonaram o } \\
\text { estudo? Quais os motivos? }\end{array}$ \\
\hline \multicolumn{3}{|c|}{ Estratégia de busca } \\
\hline 14 & Local da coleta de dados & $\begin{array}{l}\text { Onde os dados foram } \\
\text { recolhidos? Por exemplo: } \\
\text { Residência, serviço de saúde, } \\
\text { local de trabalho etc. }\end{array}$ \\
\hline 15 & $\begin{array}{l}\text { Presença de não } \\
\text { participantes }\end{array}$ & $\begin{array}{c}\text { Alguém estava presente além } \\
\text { dos (as) participantes e } \\
\text { pesquisadores (as)? }\end{array}$ \\
\hline 16 & Descrição da amostra & $\begin{array}{c}\text { Quais são as características } \\
\text { importantes da amostra? Por } \\
\text { exemplo: Dados demográficos, } \\
\text { data etc. }\end{array}$ \\
\hline \multicolumn{3}{|c|}{ Coleta dos dados } \\
\hline 17 & $\begin{array}{l}\text { Guia de entrevista ou do } \\
\text { grupo focal }\end{array}$ & $\begin{array}{c}\text { Foram perguntas, solicitações, } \\
\text { guias fornecidos pelos (as) } \\
\text { autores (as)? Houve teste piloto? }\end{array}$ \\
\hline 18 & $\begin{array}{c}\text { Repetição de entrevistas ou } \\
\text { grupos focais }\end{array}$ & $\begin{array}{l}\text { Foram realizadas mais de uma } \\
\text { sessão? Se sim, quantas vezes? }\end{array}$ \\
\hline 19 & Gravação de áudio / vídeo & $\begin{array}{l}\text { A pesquisa usou gravação de } \\
\text { áudio ou vídeo para a coleta dos }\end{array}$ \\
\hline
\end{tabular}




\begin{tabular}{|c|c|c|}
\hline & & dados? \\
\hline 20 & Notas de campo & $\begin{array}{l}\text { Foram feitas anotações de } \\
\text { campo durante e/ou após a } \\
\text { realização das entrevistas ou dos } \\
\text { grupos focais? }\end{array}$ \\
\hline 21 & Duração & $\begin{array}{l}\text { Qual foi a duração das } \\
\text { entrevistas ou dos grupos focais? }\end{array}$ \\
\hline 22 & Saturação de dados & $\begin{array}{l}\text { A saturação de dados foi } \\
\text { discutida? }\end{array}$ \\
\hline 23 & Retorno das transcrições & $\begin{array}{c}\text { As transcrições foram retornadas } \\
\text { aos (às) participantes para } \\
\text { comentários e/ou correções? }\end{array}$ \\
\hline \multicolumn{3}{|c|}{ 3 DOMíNIO: Análise e resultados } \\
\hline \multicolumn{3}{|c|}{ Análise dos dados } \\
\hline 24 & $\begin{array}{l}\text { Número de codificadores de } \\
\text { dados }\end{array}$ & $\begin{array}{l}\text { Quantos codificadores de dados } \\
\text { codificaram os dados? }\end{array}$ \\
\hline 25 & $\begin{array}{l}\text { Descrição da árvore de } \\
\text { codificação }\end{array}$ & $\begin{array}{l}\text { Os autores forneceram uma } \\
\text { descrição da árvore de } \\
\text { codificação? }\end{array}$ \\
\hline 26 & Derivação de temas & $\begin{array}{l}\text { Os temas foram previamente } \\
\text { identificados ou derivados dos } \\
\text { dados? }\end{array}$ \\
\hline 27 & Software & $\begin{array}{l}\text { Se aplicável, qual foi o software } \\
\text { utilizado para auxiliar a análise } \\
\text { dos dados? }\end{array}$ \\
\hline 28 & Verificação de participantes & $\begin{array}{c}\text { Os (as) participantes forneceram } \\
\text { comentários sobre os } \\
\text { resultados? }\end{array}$ \\
\hline \multicolumn{3}{|c|}{ Relatórios } \\
\hline 29 & Falas apresentadas & $\begin{array}{l}\text { As falas dos (as) participantes } \\
\text { foram apresentadas para ilustrar } \\
\text { os temas encontrados? Cada } \\
\text { fala utilizada foi identificada? Por } \\
\text { exemplo: Código do (a) } \\
\text { participante. }\end{array}$ \\
\hline 30 & $\begin{array}{l}\text { Dados e conclusões } \\
\text { consistentes }\end{array}$ & $\begin{array}{c}\text { Havia consistência entre os } \\
\text { dados apresentados e os } \\
\text { encontrados? }\end{array}$ \\
\hline 31 & $\begin{array}{c}\text { Clareza dos principais } \\
\text { temas }\end{array}$ & $\begin{array}{l}\text { Os principais temas foram } \\
\text { claramente apresentados? }\end{array}$ \\
\hline
\end{tabular}




\begin{tabular}{|l|l|c|}
\hline 32 & Clareza dos temas menores & $\begin{array}{c}\text { Existe uma descrição de casos } \\
\text { diversos ou discussão de temas } \\
\text { menores? }\end{array}$ \\
\hline
\end{tabular}

Fonte: Tong, Sainsbury e Craig ${ }^{43}$. Adaptação do autor. 


\section{Apêndice IV}

\section{RESUMO PUBLICADO EM ANAIS DE CONGRESSO}

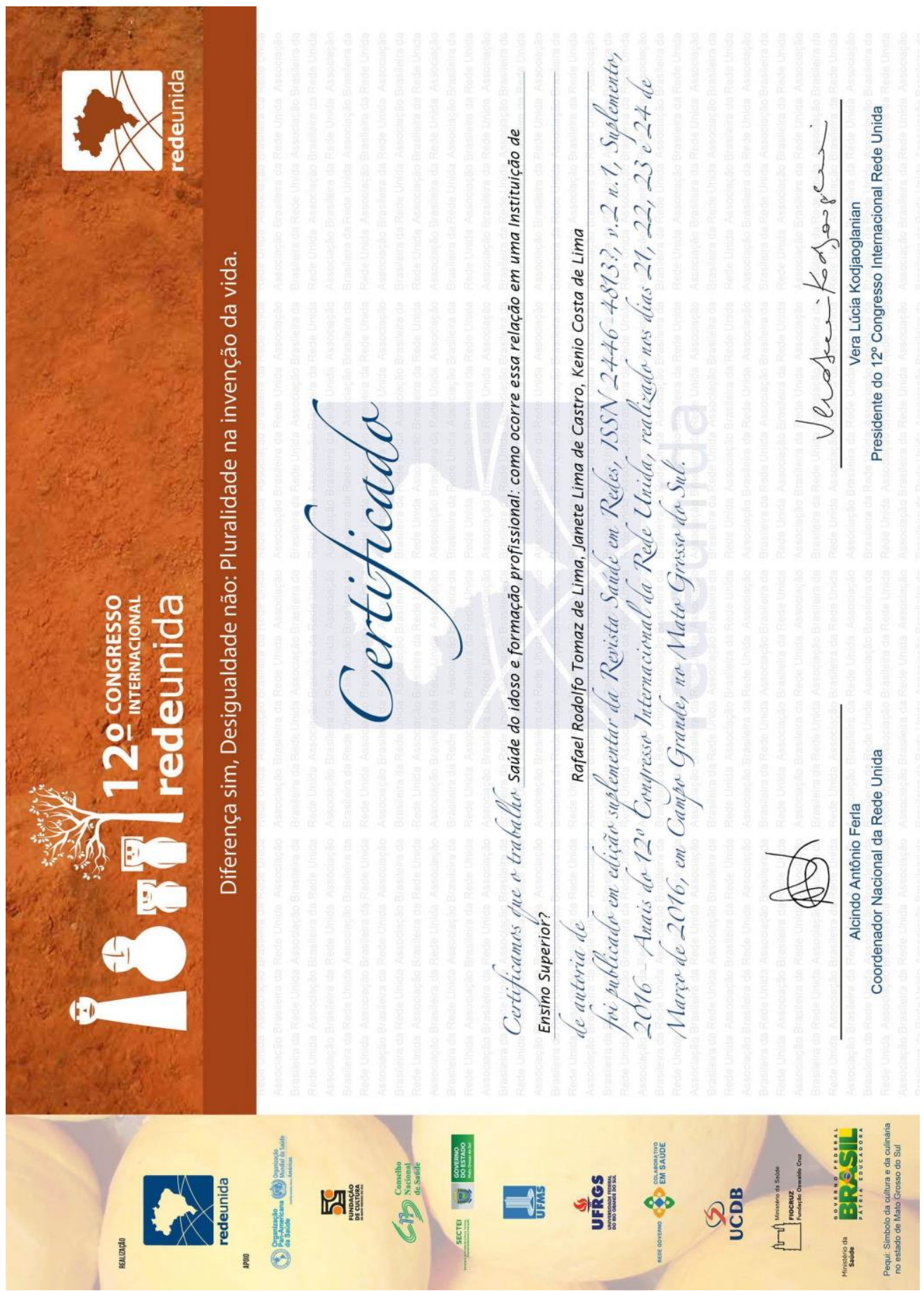




\section{Apêndice V}

\section{TRANSCRIÇÃO DO GRUPO FOCAL I}

Pesquisador: Quais são as necessidades de vocês? Do que vocês precisam no diaa-dia?

Participante 01: Uma área pra gente ficar a vontade, né?!

Participante 02: Você quer que eu responda?

Pesquisador: Pode responder.

Participante 02: Cadeira pra cá, pro pessoal que está faltando.

Pesquisador: Essas são as necessidades de vocês?

Participante 02: É, lógico. Aqui não tem cadeira pro pessoal sentar e fica todo mundo em pé.

Participante 03: Aqui a gente tem o espaço, mas não é da saúde, entendeu? É do CRAS. Nós tínhamos lá no posto de saúde só que agora retiraram até a cobertura que estava caindo, retiraram e abandonaram lá. Quer dizer, então a gente não tem espaço pra ficar. Segunda-feira a gente foi fazer uma aula de artesanato e ficamos numa salinha pequenininha, éramos mais de 30, entendeu? Então é um espaço pro idoso que nós não temos aqui.

Pesquisador: No Bairro?

Participante 03: É.

Pesquisador: Certo. Mais alguém quer falar alguma coisa? Ou já foi todo mundo contemplado nessa primeira pergunta? Posso pular pra próxima?

Várias participantes: Pode.

Pesquisador: Essas necessidades que foram relatadas por vocês são atendidas pela equipe de saúde?

Participante 02: Não. Aí eu não sei. Quem ter que responder é a enfermeira.

Pesquisador: Mas eu quero saber a percepção de vocês e não dos profissionais.

Participante 04: Assim, através da gente chega até eles e deles vai até o mais alto, não é? Porque eu acho que isso pertence à prefeitura, o estado, não é? Os agentes de saúde não podem dar jeito nessa situação de espaço e de cadeira.

Participante 02: Aqui tinha muita cadeira e sumiu.

Pesquisador: E ninguém dá notícias de onde estão essas cadeiras? 
Participante 04: As cadeiras não é nem por isso, porque a gente vem pra fazer exercício.

Participante 02: Mas tinham muitas cadeiras. Às vezes o pessoal chega agora e fica em pé. Não tem mais cadeira. Cadê as cadeiras daqui? Quebrou? O gato comeu?

Pesquisador: Alguém quer falar mais alguma coisa?

Várias participantes: Não.

Pesquisador: Certo. Como a equipe e os serviços de saúde atendem essas necessidades?

Participante 03: Pros idosos, atualmente nós temos assim a enfermeira que segunda e quarta antes da educação física ela tira a pressão. Mas... E tem alguns que são da área aqui mesmo que são atendidas lá no posto de saúde, mas aí é um atendimento precário, né?! Num dia não tem médico, pra marcar uma consulta ou um exame é um sacrifício, não tem hora e nem tem dia. A saúde tá precária.

Pesquisador: E vocês estão satisfeitos com esse tipo de atendimento que é dado pelos profissionais?

Participante 05: A gente não tá satisfeita não, né?! Mas tem que aceitar.

Pesquisador: Porque a senhora não está satisfeita?

Participante 05: Porque a gente não é atendida na hora que a gente quer, né?!

Participante 06: Na hora que precisa.

Participante 05: Aí não é atendido, vai ser atendido depois.

Pesquisador: E demora muito pra ser atendido?

Participante 06: Tem um exame meu que já faz mais de seis meses que tá lá pra marcar.

Participante 03: Mas o culpado não é o agente de saúde, né?! É o sistema enorme que tá falido.

Participante 06: É o sistema em geral.

Pesquisador: Mais alguém quer falar? A senhora queria falar, né? Quando eu perguntei se vocês estavam satisfeitos com o atendimento...

Participante 02: A gente tem que ficar... Vamos fazer o quê?

Pesquisador: A senhora está satisfeita?

Participante 02: É o jeito... Eu vou fazer o quê? Eu vou morrer, vou chorar, vou gritar, me rasgar? Olhe, eu fui bater uma ultra, perdi, já venceu os meus exames e eu ainda não consegui marcar a minha ultra. Eu tenho problema de rins. Eu não 
consegui ainda marcar a ultra. Venceu tudo. Venceu. Aí eu vou fazer o quê? Eu vou endoidecer?

Pesquisador: Tem que manter a calma, né?!

Participante 02: É, e pedir a ajuda de deus. O meu problema é sério. Eu falei com a enfermeira que era problema de rins, pedras nos rins e intestino, mas eu ainda não consegui bater a ultra.

Pesquisador: Mais alguém quer falar alguma coisa?

Participante 07: Faz bem uns três meses que eu tô pra marcar um exame, doente que só, só não morri porque não chegou o dia. Faz bem uns três meses que tá pra marcar e ainda não marcaram ainda. E se marcar pra levar lá eu dei o telefone, mas o telefone faliu e nunca mais eu tive condições de dar outro telefone, porque quando eu chego lá muito mal eu sou atendida. Muita gente na frente e essa história de idoso ser atendido primeiro é conversa.

Pesquisador: Vocês não tem prioridade quando chega lá na unidade?

Participante 07: Tem não. De jeito nenhum.

Participante 02: Essa mesma palestra que ele está fazendo com a gente aqui eu assisti hoje na televisão e não é só aqui não, é em todo geral. A mulher tava com os exames tudo vencido, vai fazer tudo de novo, uns exames pra fazer cirurgia.

Participante 04: Graças a deus, todos os exames que eu boto pra marcar lá no posto, eu consigo fazer.

Pesquisador: A senhora é daqui?

Participante 04: Não. Eu faço parte do grupo de idosos, mas na área de médico eu sou da unidade de lá.

Participante 02: Marcar é a maior dificuldade. Bater a ultra-renal que o médico passou é muito difícil. Bati uma porque paguei particular.

Pesquisador: Certo. Mas alguém quer falar alguma coisa ou eu posso ir pra próxima pergunta? A equipe de saúde está preparada para lidar com as necessidades de vocês? Por que vocês acham isso?

Participante 03: Olha, eu dependo muito pouco da unidade de saúde, né?! Eu tenho plano de saúde particular, mas eu acho assim, não tem nem é... Como fala? Funcionário suficiente, né?! A enfermeira, ela sai pra vim pra cá verificar a pressão da gente antes de fazer a ginástica então não tem quem substitua lá. A outra garota está de férias, tá entendendo? Então é problemático e aí eu acho que é falta de funcionário também. Não é qualidade deles, é a falta deles. 
Pesquisador: Então a qualidade dos profissionais está ok?

Participante 03: É, na medida do possível... Entendeu? Porque pode ser um funcionário qualificado, mas às vezes não tem o necessário pra atender. Ela faz preventivo, mas as vezes não tem material pra atender. E aí?! Então não é criticar o funcionário, eu acho que o problema está mais em cima, não é eles aqui embaixo.

Pesquisador: Mais alguém quer falar alguma coisa? O pessoal desse outro lado quer comentar alguma coisa dessa pergunta que eu fiz agora? Deixa eu repetir, a equipe de saúde, da unidade de saúde, está preparada para lidar com as necessidades de vocês?

Participante 08: Não.

Pesquisador: Não?

Participante 08: Não. De jeito nenhum! Eles não passam nem aonde a gente mora. Antigamente eles iam, passavam.

Participante 09: Mesmo assim, olhe, a gente quer fazer um tratamento, a gente vai no médico, o médico faz aquele papelzinho pra moça marcar pra gente fazer o exame, passa a vida do mundo todo pra fazer um exame e se for uma doença grave a pessoa morre e não faz o exame.

Participante 02: Pra fazer um curativo é a coisa mais difícil.

Pesquisador: Está faltando profissional. É isso?

Participante 02: Sei lá.

Participante 09: Não tem remédio suficiente pra gente tomar no posto.

Participante 04: Está faltando profissional.

Participante 09: Não tem médico pra atender a gente direito.

Participante 10: Tem mais de um mês que eu coloquei uns papéis pra fazer um exame, pra marcar um exame no posto de saúde e até hoje. Tive que ir pro Pajuçara pra ser atendida.

Participante 11: Eu não me consulto, eu pago as minhas consultas. Eu não vou esperar pelos exames.

Pesquisador: A senhora vai no privado, né?! Vai na rede particular.

Participante 11: Eu vou na rede particular, só faço exame no particular. Se eu não posso fazer certos exames, eu vou no particular.

Pesquisador: Certo. Mais alguém quer comentar alguma coisa? Não? Então eu vou pular para a próxima pergunta, certo? Se vocês fizessem parte dessa equipe de saúde, como vocês tratariam as necessidades que foram levantadas? 
Participante 02: Eu vivia na casa da pessoa, ficava lá direito tomando conta.

Pesquisador: A senhora dormiria na casa da pessoa?

Participante 02: Sim, na casa do idoso direto até ele ficar bom. Uns três dias, quatro dias... Agora tinha que dar a alimentação, né?!

Pesquisador: Mais alguém?

Participante 12: Olha, é porque não tem estrutura pro trabalho, pros profissionais. Não tem, não tem. Tem ambiente de trabalho, mas não tem estrutura pro trabalhador, pra trabalhar. Não tem.

Pesquisador: Aí se a senhora tivesse no lugar desses profissionais, nessa mesma situação...

Participante 10: Eu já passei por isso.

Pesquisador: A senhora trabalhou lá?

Participante 10: Eu já trabalhei e passei por isso, é por isso que eu estou dizendo. Anos e mais anos e mais anos e o que a gente escuta é isso, estrutura de trabalho não existe, não tem. Quando a gente chega na unidade de saúde se conta os funcionários. Por quê? Porque não tem. Não tem. Passei foi 30 anos no posto de saúde e o que eu escutava todas às vezes era isso. E entra ano e sai ano e é a mesma coisa, não tem nada. Não modifica nada. É uma coisa só.

Pesquisador: Mais aí no caso o quê que a senhora iria fazer pra atender as necessidades de saúde dos idosos?

Participante 10: Como que não tem? Não tem modo nenhum.

Participante 03: Você vai cumprir apenas o seu horário de trabalho. Sem estrutura o quê que você vai fazer? Vai tirar do seu bolso o que você às vezes nem recebe? Como é que vai fazer?

Participante 10: Você chega no posto de saúde e não tem gaze, não tem esparadrapo, não tem medicamento... Você vai tirar do seu bolso pra comprar? Você não vai.

Participante 03: Você é um mero funcionário. Não adianta culpar o funcionário, ele é a vítima porque lida com o público.

Participante 04: O culpado disso tudo são os governantes, só.

Pesquisador: Mais alguém quer comentar alguma coisa em cima dessa pergunta?

Participante 11: Já faz bem um ano que eu fui marcar um exame do coração no posto de saúde e até hoje não fiz esse exame. Estou com mais três exames indicados pra fazer que o médico passou, fui no posto pra marcar e o médico tá 
diferente, a menina que marca tá diferente... Eu tenho que ir lá no médico pra marcar de novo e ele vai mandar pro Pajuçara e eu não vou. É uma dificuldade pra gente ir, eu nessa idade pegar um ônibus pra descer lá e voltar, já tem essa dificuldade da gente... Aí eu tô com uns exames empancados pra fazer, aí eu pergunto a você como é que eu faço pra fazer esses exames.

Pesquisador: Seria necessário inserir outros profissionais na equipe para atender essas necessidades? Que profissionais seriam esses?

Participante 03: Não tem escolha meu filho. Eu acho que o que não tem é falta de profissional, falta de material, falta de estrutura... Quer dizer, a saúde está zero. Então...

Pesquisador: Então não é só inserir novos profissionais?

Participante 03: Não é.

Participante 04: Não. Os profissionais quando a gente chega na unidade eles são ótimos mas eles vão fazer o quê? Nada porque não tem. Não tem material de nada então eles não vão fazer nada.

Pesquisador: Então os profissionais que tem já são suficientes pra atender as demandas de vocês. O problema é porque são coisas além dos profissionais?

Participante 03: Não, não é que é número suficiente, mas não adianta vim mais funcionário, onerar mais ainda se não tem o principal que é estrutura, que é material, entendeu? Não é só mais funcionário. O funcionário vai chegar e vai ficar de braço cruzado porque não tem material, porque não tem como fazer? O quê que ele pode fazer? Olhar pro doente e dizer pra ele tipo assim: Não tem material. Eu acho que isso aí não é lógico.

Pesquisador: Mais alguém quer falar alguma coisa?

Participante 12: Eles são ótimos, eu acho, mas o que está faltando pra gente é um ambiente pra gente. Não tem um ambiente, um salão pra gente. Mas as meninas são ótimos, os profissionais são ótimos. Eu não tenho o que dizer de nenhuma.

Participante 02: Elas não têm nada a ver com isso não.

Pesquisador: Então pronto, era isso que eu queria saber de vocês. Alguém quer falar mais alguma coisa que não foi perguntado? Quer desabafar e aproveitar o momento pra botar pra fora?

Participante 02: Eu queria dançar um forró porque hoje é dia das mulheres, mas pelo visto não vai acontecer nada aqui. 


\section{Apêndice VI}

\section{TRANSCRIÇÃO DO GRUPO FOCAL II}

Pesquisador: Quais são as necessidades de vocês? Do que vocês precisam no diaa-dia?

Participante 13: Eu preciso de muita saúde, né?! Que a minha saúde tá muito pouca. E aqui no posto, graças a deus, até hoje, né?! Eu não tenho o que dizer de médico, de... Pronto, o corpo docente... É isso que o povo diz, né?! O diretor também é gente muito boa. Pronto, tanto os técnicos de enfermagem, como a nutricionista, as agentes de saúde, graças a deus até hoje eu venho nesse posto acho que fazem bem uns 20 anos, eu caminhava e tudo aqui, né?! Então agora começou essa atividade da gente aqui, né?! Essa ginástica, aí eu faltei dois anos porque eu fiz uma cirurgia, estava com um dreno e não podia vim, né?! Pra fazer a atividade, mas agora eu estou vindo. E o professor é uma benção. Aliás, vocês todos que chegam aqui são uma benção.

Participante 14: Essa turma que vem... Gostei! É do melhor do melhor, né não?!

Participante 13: Aquelas alunas que vieram no ano passado, não foi?! A gente chega chorou por causa delas.

Participante 15: Eu também digo a mesma coisa, eu não tenho o que dizer daqui.

Participante 14: Tudo o que ela (Participante 13) diz, tudo é certo.

Participante 15: Pra mim todos os profissionais são legais, são bons, atendem a gente bem graças a deus. Eu só posso dizer graças a deus porque eu escuto reclamação de muito posto, mas graças a deus o nosso... Eu digo o nosso no sentido de ser de todos, né?! Não existe essa grande preocupação de não conseguir se consultar, de não conseguir uma ficha... Mas toda a vida a gente consegue. Não tenho do que reclamar!

Pesquisador: Certo. Mas não focando muito na área da saúde e nem nos profissionais de saúde, mas além daqui, o quê que vocês precisam? O quê que vocês necessitam? Do quê vocês sentem falta de algo para poder viver melhor? Ou não, está tudo bem, tudo ok?

Participante 14: Aqui era pra ter sabe o quê?! Eu queria muito era um neurologista bom no posto de saúde porque eu precisava muito. Eu sou muito nervosa...

Participante 15: Neurologia, cardiologista... 
Participante 16: Eu tenho uma depressão tão triste que não tenho coragem de nem ir ao médico.

Pesquisador: A senhora?

Participante 16: Uhum.

Pesquisador: Esse é o principal problema que a senhora tem?

Participante 16: Esse é o meu maior problema.

Pesquisador: E a senhora falou que precisava de mais saúde. É isso?

Participante 13: É.

Pesquisador: Mas assim, mais ou menos o quê? A senhora precisa ter mais saúde? Tem algo que lhe incomoda?

Participante 13: É porque é o seguinte... A pessoa quando faz cirurgia de mama, de câncer, a pessoa não vai assim dizer que tá com saúde. Eu tô com saúde, mas não é essa saúde assim... 100\%. Antigamente eu não tinha, né?! Mas graças a deus eu fiz cirurgia, vou fazer uma tomografia, mas a gente fica meio assim... Depressiva, né?! Porque eu penso que pode dar alguma coisa. Aí pronto, mas tirando disso, graças a deus eu sou... Olhe, às vezes o médico já disse: A senhora é uma pessoa tão contente! Nem parece que está doente. Ai eu digo: Ô doutor, precisa eu chorar pra dizer que tô doente? Não! Eu chego lá no CECAM... Acho que vocês sabem, né?!

Pesquisador: CECAM é de câncer?

Participante 13: É. Lá na LIGA.

Pesquisador: Sim.

Participante 13: A primeira vez que eu cheguei lá, quando eu cheguei eu olhei assim e chega me desesperei com tanta gente. Aí depois eu me sentei assim e fiquei olhando, chegou aquele povo arrumado com muita coisa... Aí eu disse: Sabe de uma coisa? Eu vou deixar de besteira! Pronto, ali eu me animei e fiz meu tratamento e graças a deus eu estou aqui contando história, né?!

Pesquisador: É.

Participante 13: E tomara que seja por muito tempo, se deus quiser.

Pesquisador: A senhora iria falar alguma coisa naquela hora e eu interrompi, para que não ficasse muitas pessoas falando ao mesmo tempo.

Participante 15: Não, é assim... Eu estava falando que graças a deus eu não tenho do que reclamar daqui do posto. Eu não tenho do que reclamar porque todas as 
vezes que eu venho eu sou atendida, né?! Não posso reclamar nada. Pra mim tá tudo bem, graças a deus.

Pesquisador: Entendi. E... A senhora quer falar alguma coisa?

Participante 17: Eu tenho dificuldade demais de arrumar uma ficha. Quanto tempo não faz que meu marido procura uma ficha? E ele já é da terceira idade, né?!

Pesquisador: E não consegue?

Participante 17: Não. Eu não acho nada fácil na saúde. Aqui e em qualquer canto eu não acho não.

Pesquisador: E isso interfere no dia-a-dia da senhora?

Participante 17: Claro! Eu pago um negócio por aqui! Pago porque sou diabética faz vinte e poucos anos...

Participante 14: Você paga plano de saúde, é?

Participante 17: Pago, mas sem puder.

Pesquisador: Mas a senhora frequenta a unidade também?

Participante 17: Eu frequentei muito, muito...

Participante 14: E a frequência daqui?

Participante 17: Ah, é frequente, frequente... Direto. Mas eu vejo que... Eu já fiz, uns quatro ou cinco anos que eu já fiz e eu não só estou sem ele porque eu já me aposentei. É todinha, eu nem vejo a minha aposentadoria. Parece que eu nem sou aposentada.

Pesquisador: Só pra pagar o plano de saúde?

Participante 17: Não. A minha menina ainda completa. Porque eu sou diabética e hipertensa...

Participante 15: Precisa comprar os medicamentos, né?!

Participante 17: Alguns. Compro insulina que não dá no SUS, que é $R \$ 135,00$ e não passa nem um mês essa insulina. Tenho que comprar umas seringas pra ela que são 35, só dez seringazinhas.

Participante 15: Sim... De fato os remédios às vezes faltam. Falta muito e eu tenho bem pouco.

Participante 17: Tem dois meses que eu só recebo insulina sem seringa, sem nada. Ele foi comprar uma caixa de, de... De seringa lá no Alecrim, num canto que compra lá. Eu não acho nada fácil não nessa saúde do Rio Grande do Norte. Olhe, eu fiz isso aqui, eu tive CA de tireoide em 2013... Se eu não tivesse, como é que eu ia agir aquilo ali que o médico disse que tinha que agir logo? 
Participante 14: la morrer a míngua, né?!

Participante 17: Eu tive CA de tireoide. Eu ia morrer a míngua porque a gente passa por uma ruma de médico que diz que tem que ser logo. Eu estava cheia de nódulo... Eu não acho nada fácil nessa saúde não, deveria melhorar mais. Pra consultar aqui e tudo tem a consulta daqui... Olhe, como uma amiga minha, ela tinha um problema de cabeça simples, eclampse e tudo, ela passou nove meses pra fazer uma tomografia. Tem cabimento? E tudo nós estamos sabendo que o Rio Grande do Norte tá... Um caos. Demais, demais, demais.

Pesquisador: Mas o caos que a senhora se refere é só na saúde ou em outros setores?

Participante 17: Não. É no Rio Grande do Norte todinho.

Pesquisador: Segurança e saúde também? Ou só saúde que não presta e o resto está tudo bom?

Participante 17: Não... É aquele... Não, em tudo não. Eu estou aqui só falando da saúde, né?! Mas o resto também não presta não.

Pesquisador: Podem falar à vontade, não se sintam envergonhadas não.

Participante 17: Não, não... Eu estou aqui pra falar só da saúde, né?!

Pesquisador: Certo. Não, o que a senhora quiser falar a senhora fala.

Participante 17: Agora o meu esposo, faz mais de mês que tem que fazer uma consulta e nada.

Participante 15: E quem é a sua agente de saúde? Você já falou com ela?

Participante 17: Já, fazem umas quatro vezes. Eu tenho que entregar aqui pra depois levar pro cardiologista. Ainda bem que ele não tem problema de coração não. Participante 15: Eu acho que meu velho era diabético, teve AVC e era encaminhado daqui pra fazer o ecocardiograma no HUOL. Todo ano ele fazia. Exame da próstata todo ano eu fazia com ele encaminhado daqui. Eu falava com a menina e vinha aqui e trazia... Eu pedia ao médico logo quando ele ia lá em casa, eu pedia logo à ele o encaminhamento pro cardiologista, pra...

Participante 13: Pro encaminhamento.

Participante 17: É porque o marido da senhora já estava numa fase delicada.

Participante 15: Era, eu pedia o encaminhamento, ele me dava e eu trazia pra cá, elas marcavam e encaminhavam. Ele ainda viveu 26 anos. Olhe, o primeiro AVC dele foi em 90 . Em 2005 ia fazer 15 anos, né?! Ele teve outro aí de lá pra cá ele não andou mais. 
Pesquisador: Ficou acamado?

Participante 15: Ficou acamado. De 2005 pra cá ele andava dentro de casa, a gente pegava ele e levava ele pro banheiro, levava ele pra sala, sentava ele no sofá... As meninas cansaram de ir lá em casa com os médicos, chegavam lá e viam. Mas ele ainda viveu 26 anos, graças a deus. Morreu quando chegou o dia.

Pesquisador: Ele faleceu nesse ano?

Participante 15: Fez seis meses, completou segunda-feira.

Pesquisador: Essas necessidades que foram relatadas por vocês são atendidas pela equipe de saúde?

Participante 16: Pelo menos as agentes deviam, como nós somos idosas, facilitarem uma ficha pra gente, não era?!

Pesquisador: Exclusividade pro idoso, é isso?

Participante 16: Porque pra nós ficar numa fila já é tão difícil...

Participante 14: É difícil. É porque são 20 fichas, né?! Que elas dão. Eu acho que assim, devia ser a metade, né?! Acho que são 4 ou 5 pro idoso e o resto pros outros. Quem não pegou, volta.

Pesquisador: E não está dando certo desse jeito?

Participante 15: Ei, de primeiro era assim. Sempre foi assim.

Participante 14: Eu nunca mais tive aqui não, porque a minha médica e é muito boa. Eu tomo remédio de pressão e tomo remédio pros ossos aí venho aqui de 4 em 4 meses, aí quando termina que eu chego aqui eu nem pego nem ficha. Aí eu falo com a agente aí ela me dá o encaminhamento. Mas se vier aqui uma vez... Quantas vezes eu cheguei aqui e não tinha mais ficha? Eram 7 pessoas porque eu contei.

Pesquisador: Ficava sem atendimento porque não conseguia ficha?

Participante 15: É, fica.

Participante 14: Ficava pra outra semana.

Participante 17: Se for um caso de urgência? A pessoa morre.

Participante 14: Acho que não era pra ser assim. E outra coisa, era pra ter pelo menos duas vezes por semana um dentista, um de 8 em 8 dias. É nas terças, né?! Eu acho que é na terça-feira que tem gente aqui como formiga e a metade não tem ficha pra ser atendido aí tem que ficar pra outra terça. Aí não é certo, eu não acho certo, principalmente pra um idoso. 
Pesquisador: Verdade. E vocês? O quê que vocês acham? Vocês acham que os profissionais de saúde são capazes de atender, de resolver esses problemas que vocês falaram aí? Que cada uma de vocês falaram?

Participante 15: Os daqui de dentro?

Pesquisador: É, da unidade de saúde. Daqui dessa unidade, tanto os funcionários, os médicos, os dentistas, os enfermeiros, o pessoal do NASF que estava reunido segunda-feira ali com vocês... Vocês acham que essa equipe de profissionais, de funcionários, de pessoas, elas são capazes de atender, de resolver esses problemas que vocês elencaram?

Participante 13: Eu sei que a minha agente...

Pesquisador: Vamos falar uma de cada vez pra não atrapalhar, certo?

Participante 14: O que depender delas, elas fazem.

Participante 13: Eu digo: Eu queria... Aí ele diz mesmo assim: Tu quer ficha pra quando? Um dia desses eu estava precisando, né?! Aí ela disse: Vá. Eu vou tirar uma pessoa e me colocou. Eu tô com essa doença na perna muito inchada então eu não posso... Aí depois ela foi lá em casa: [...] eu acertei. Aí ela disse: E o encaminhamento? Aí eu disse: Não, ele me deu pra mim ir pro angiologista fazer aquele "doppler", né?!

Pesquisador: Sim.

Participante 13: Aí com pouco tempo que eu fui fazer a tomografia aí veio essa lesão na pélvica, aí... O quê mais meu deus? Foi na pélvica, aí eu vou fazer no dia 07 essa tomografia, né?! Mas eu fui no distrito, que é muito difícil... É porque parece que é muito caro, né?! Aí eu fui lá no distrito e marquei, quando foi num dia me chamaram. Aí tá marcado pro dia 07 pra fazer, aí eu não tenho do que reclamar.

Pesquisador: Então a senhora agradece? Acha que os profissionais daqui ajudaram...

Participante 13: Eu agradeço a deus por eles porque, né?! E pelos de lá também porque a gente... Muitos exames eu fiz pago porque eu não ia esperar, né?! Mas não que... Um exame de sangue eu vou lá e faço... Não tenho do que reclamar.

Participante 14: Pois é, graças a deus eu consegui.

Participante 17: Mas não, quem tem dinheiro pra pagar um exame tudo bem. Mas quem não tem?

Participante 13: Mas lá tem exame que faz de graça. O exame lá do CECAM, eu sou de oncologia, né?! Aí, mesmo assim tem gente que não é e vai lá e faz os 
exames. Tem uma mulher que fez o exame lá. É porque as pessoas querem tudo assim... Muito, de uma vez não pode.

Pesquisador: Rápido, né?!

Participante 13: Muito rápido, não pode minha gente.

Participante 14: Eu acho assim, que uma vez que não temos condições a gente tem que ter paciência de esperar, não é isso?! Tem gente que briga, esculhamba...

Participante 17: Não adianta, não adianta fazer isso.

Participante 13: Assim não pode.

Participante 17: Quantas vezes meu esposo não veio aqui atrás de dentista?

Pesquisador: E não tem?

Participante 13: Nunca teve dentista aqui não.

Participante 17: Pois é.

Participante 13: É só um dente, às vezes eu obturo lá...

Participante 17: Não obtura não, é limpeza, esses negócios...

Pesquisador: Aí está sem dentista aqui?

Participante 17: Tem, tem. Mas é uma dificuldade tão grande.

Pesquisador: É muita gente pra pegar ficha, né?!

Participante 17: É não, é não, não é muita gente não. Ela disse assim: [...] só tinham duas pessoas hoje... Quando ele tinha oportunidade, porque ele faz limpeza direto, só tinham duas pessoas hoje e a mulher anterior disse que não tinha, aí.. E é porque ele fala, ele fala com ela direitinho e tudo aí ela diz: Venha. Aí quando ele vem, duas pessoas. Tem cabimento? Duas.

Participante 14: Mas não é porque já tinha distribuído as outras fichas? Não era não.

Participante 17: Não minha filha, não era não. Ela marca, é marcação.

Participante 14: Porque num é 20 fichas que tem, né?!

Pesquisador: Pro dentista?

Participante 14: Sim, pro dentista. Pro dentista tem todo dia, né?!

Participante 17: Mas quem marca não é o dentista.

Participante 14: É, mas tem todo dia. Eu acho que é, pro dentista, né não?! Pra mim um dia desses tinha ficha pro dentista, todo dia tinha ficha.

Participante 17: Mas não é ficha não... É marcar. Eu não vou dizer a você que não tenho condições de jeito nenhum de pagar uns negócios pra mim, mas a gente paga. Eu abandono tudo, de comprar até uma roupa no final de ano, assim, um 
negócio... Tem gente que não faz não, mas eu faço. Eu sou diabética, fazem 24 anos...

Participante 13: Não tem ninguém que ajude não, assim, da sua família?

Participante 17: Tem não, só eu... Tem não minha filha, eu sou pobre.

Participante 14: Mulher, mas o diabético... Não tem medicamento pro diabético? Tem mulher.

Pesquisador: Tem, a unidade dá.

Participante 17: Mulher, eu tenho, faço tratamento e tudo, direto. De três em três meses eu vou. Mas o negócio é a alimentação e tudo... Eu não posso comer tudo, eu não posso lanchar qualquer coisa. Eu não posso lanchar um pedaço de bolo, eu vou lanchar dois pães... Não pode. Lanchar uma ruma de bolacha, não pode.

Participante 14: Eu acho que o diabético é uma das piores doenças que tem. É um tratamento sério, muito sério.

Participante 13: Doença é doença. Toda doença é ruim, não existe doença boa. Engraçado que ontem a minha irmã chegou lá em casa, né?! Essa é um anjo, um anjo da família... Aí ela olhou pra mim e disse: E o teu exame? Eu disse: Eu vou agora saber se alguém me chamou. Aí ela disse: Pois se você não conseguir minha irmã, diga que a gente arranja o dinheiro e você faz. Coisa boa é família, né?!

Participante 17: Não, mas a minha família não tem não. Na minha família tudo trabalha mas...

Participante 14: Família é boa, mas às vezes não tem não.

Participante 17: Não, a minha família é uma maravilha, meus irmãos... Eu tenho nove irmãos, mas tudo trabalha pra si, moram em Ceará-mirim, a mulher trabalha só pra eles mesmo de casa. Meu esposo é aposentado já, minhas filhas dão uma mãozinha... Se não fossem elas? Eu e as minhas filhas que ajudam, trabalham, elas trabalham...

Pesquisador: Como a equipe e os serviços de saúde atendem essas necessidades?

Participante 14: Eu acho muito difícil.

Pesquisador: Por quê?

Participante 14: Porque quem pode fazer tudo isso é, por exemplo... As autoridades federal, estadual, né?!

Pesquisador: Mas ninguém faz por quê? 
Participante 14: O federal está uma tristeza. Você está vendo aí como é que estão as greves, né?! Acabando com tudo, não quer aposentar ninguém... Está todo mundo correndo atrás pra se aposentar. Aí o quê que a gente pode esperar de bom? Eu não espero. Eu digo todo dia, eu sou muito estressada por isso e sei que vou pifar, porque tem hora que eu me agito tanto que eu nem assisto mais nem jornal.

Pesquisador: É. Se fizer mal a senhora é melhor nem ver.

Participante 14: Eu passo mal. Aquele lava-jato quando eu começo a assistir fico com um mal estar, desligo logo a televisão. Porque você não vê mais coisa boa. A gente na nossa idade tinha que ver coisa boa. Não tem! Eu fico perturbada.

Participante 13: Esse posto eu estou achando melhor do que do tempo que ele começou aqui, porque faltava tanta da coisa...

Participante 17: Esse aqui é o melhor que tem por aqui por essa zona norte.

Participante 13: Faltava... As meninas traziam daqui, dacolá... Trazia um negócio, trazia outro pra... Como é que se diz? Pra agradar o pessoal porque não tinha como, né?! Agora tá melhor, vixe...

Participante 17: Tá melhor, tá.

Pesquisador: Mais ou menos de quando começou a melhorar? Mais ou menos de que ano? Quanto tempo?

Participante 13: Com Carlos Eduardo, apesar de que eu não votei nele, né?!

Participante 14: Ai... Pois eu adoro Carlos Eduardo!

Participante 13: Eu não votei nele não, mas por opção... Mas até que melhorou um pouquinho...

Pesquisador: Quando ele voltou, quando ele assumiu a prefeitura?

Participante 13: Aqui no posto tá indo... Eu tô gostando. A gente tinha caminhada com a agente, né?! Sempre a agente no comando, sempre. Se ela faltar, eu acho que falta tudo. Mas tudo ela fazia e a gente fazia isso e aquilo outro... E agora está até melhor porque ela vai e arranja alguma coisa, vai e arranja isso, vai e consegue isso... Mas o povo não agradece, não reconhece. Pode fazer 99, mas se não fizer os 100 não presta. Eu sei que eu agradeço... Não é porque eu tô acostumada aqui, mas a gente tem que dizer a verdade, né?!

Participante 17: É mesmo, melhorou o atendimento.

Pesquisador: Então vocês estão satisfeitas com o atendimento que é dado aqui na unidade de saúde?

Participante 13: Eu estou. 
Participante 17: A minha doutora é [...], né?!

Participante 14: A minha também é ela, desde quando eu cheguei aqui é ela.

Pesquisador: Então vocês estão satisfeitas com o atendimento que é dado não só pelo médico, mas na unidade de um modo geral?

Participante 14: Em primeiro lugar é ela. Ela é maravilhosa.

Participante 18: Eu acho que sim, né?!

Participante 17: Os profissionais tudo bem, o problema é lá fora.

Participante 18: Eu gosto de tudinho. Gosto da médica, gosto da agente de saúde, gosto das meninas tudinho... Elas atendem muito bem a gente.

Participante 17: Pra vim, pra encaminhar a pessoa tem que vim uma, duas vezes, né?! Pra um encaminhamento... Eu tiro pelo meu esposo.

Pesquisador: Ah... Encaminhamento pra outros serviços?

Participante 17: É.

Pesquisador: Mas aqui, o atendimento na unidade está bom. É isso?

Participante 17: É.

Participante 18: Às vezes a gente bota uma requisição, né?! Pra marcar pra um médico lá fora... Isso aí é muito demorado. Tem vez que sai logo e tem vez que nem sai.

Participante 16: Mas a demora é deles daqui.

Participante 14: Ano passado eu marquei uma endoscopia... Até hoje não saiu. Nunca chegou.

Pesquisador: E não deram retorno?

Participante 14: Não. Não dão retorno nenhum e eu me acabando... Já bati em todo canto e nada.

Participante 18: Foi uma endoscopia?

Participante 14: Foi.

Participante 18: Eu fiz uma colonoscopia, mas eu falei... Eu estava muito aperriada pra fazer, sabe? Ai eu falei com a administradora e ela disse: Ai, agora eu não posso marcar. Não sei por quê. Aí eu falei com a agente... Ela é uma pessoa muito boa. [...], eu estou precisando fazer uma colonoscopia. Ela disse: Eu já falei com a administradora, mas ela disse que não pode agora. Eu sei que ela deu o jeitinho dela lá, olha... Num instante eu fiz.

Pesquisador: Mais alguém quer falar alguma coisa a respeito disso? 
Participante 14: A minha não saiu não. Eu já até esqueci... Não vou fazer a minha não.

Participante 18: Eu já fiz cirurgia e tudo.

Pesquisador: A equipe de saúde está preparada para lidar com as necessidades de vocês? Por que vocês acham isso?

Participante 14: Eu acho.

Participante 15: Ah, isso aí eu acho que são.

Participante 14: Todas nós achamos porque eles nos atendem muito bem, principalmente nós idosas somos muito bem cuidadas, né não?!

Participante 17: O diretor... Ele é muito simpático ele.

Participante 14: Ele é ótimo.

Participante 18: A administradora é legal demais. Ela não atende uma pessoa se não puder mesmo.

Pesquisador: Então eles estão preparados porque eles tratam vocês bem?

Participante 13: Com a gente... Quer dizer, eu digo comigo, né?! Cada qual que tenha o seu problema... Comigo graças a deus até hoje eu não tenho o que dizer.

Participante 16: É porque as coisas são difíceis.

Participante 13: É difícil.

Participante 18: A médica é um amor de pessoa.

Participante 15: Vocês conheceram doutora [...], né?!

Participante 13: Num era a minha médica ela?!

Participante 15: Uma vez uma mulher foi lá em casa com um negócio... Um abaixo assinado pra mim assinar, pra gente tirar doutora [...] daqui do posto. Olhei assim pra ela e disse: Minha filha você acertou com a minha casa? Você acertou com a casa errada, filha. Me desculpe se eu estiver errada também, mas eu não assino não porque pra mim ela é ótima. Eu nunca tive nenhuma reclamação contra a doutora. Ela ia atender na minha casa o meu velho... Ele necessitava. Mas...

Participante 17: Ela está muito emotiva ainda.

Pesquisador: Eu entendo, faz parte. Mas ela saiu daqui já, essa médica?

Participante 15: Saiu. Ela se aposentou. Cansei de ouvir o povo dizer que ela era doida, que não sabia de nada, mas pra mim ela era ótima. Eu quero dizer assim à vocês que Jesus Cristo que não teve pecado, o povo encontrou pra botar nele, quanto mais um pecador aqui em terra...

Participante 14: Justamente. 
Pesquisador: Se vocês fizessem parte dessa equipe de saúde, como vocês tratariam as necessidades que foram levantadas?

Participante 15: Eu ia correr pro prefeito, pro governador... Pra esse povo. Porque eles quem podiam dar conta.

Participante 14: O secretário de saúde também, que faz parte... Que eu acho que é um dos principais, o secretário de saúde.

Pesquisador: Então se vocês fossem profissionais de saúde vocês iam recorrer aos gestores, à secretaria de saúde pra poder resolver?

Participante 14: É, são essas pessoas aí que podem resolver. Por exemplo, às vezes falta gaze pra fazer um curativo e não tem, não pode, né?! Já aconteceu do pessoal de trazer de casa.

Pesquisador: Alguém quer falar mais alguma coisa?

Participante 13: É porque eu já trabalhei muito, já trabalhei demais no hospital...

Participante 14: Tu trabalha em hospital é?

Participante 16: Ela num era enfermeira?!

Participante 13: Eu trabalhei em hospital infantil por vinte anos e nove no HUOL.

Participante 14: Eu não sabia não. Pensei que você era da educação.

Participante 13: Eu também fiz magistério, mas é porque eu sou quieta, não gosto de me apresentar.

Pesquisador: Mas já que a senhora já teve essa experiência na área da saúde, trabalhando como técnica... Técnica ou como enfermeira?

Participante 13: Auxiliar de enfermagem.

Pesquisador: Como auxiliar de enfermagem...

Participante 13: Eu trabalhei no tempo de Aluísio Alves, naquele tempo era muito difícil, né?! Eu trabalhei por vinte anos aí fiz o concurso da universidade, passei em 1984 e fui pra lá.

Pesquisador: Pro HUOl?

Participante 13: Pro HUOL. Fiquei lá, trabalhei na medicina comunitária...

Pesquisador: Na unidade de saúde de medicina comunitária?

Participante 13: Pronto.

Pesquisador: Sei.

Participante 13: Eu trabalhava ali. Então foi ali que eu me aposentei, graças a deus, mas a gente sofre. Quem não trabalha em hospital diz assim: Ah, é muito bom trabalhar de branco e não sei mais o quê... Mas eu fazia aquelas visitas ali no morro 
de Mãe Luiza pra aculá, Alto do Juruá essas coisas... Menina, a gente sofria, viu?! Eu com doutora [...], parece até que ela é irmã de um médico da saúde, da Secretaria de Saúde.

Pesquisador: Não conheço não.

Participante 13: Eu com doutora [...]... Menino olhe, a gente andava por aculá tudo fazendo vacina e essas coisas, mas eu nunca reclamei na vida. Eu atendia aquele pessoal com as caras tudo, olhe... Tudo cheio de maconha essas coisas. Aí quando eles chegavam eles diziam: Eu quero aquela enfermeira ali. Uma vez chegou um rapaz, olhe... Com um abscesso daqueles. Aí eu disse: Meu jesus, e agora? Aí ele disse: Vai doer? Eu disse: Vai não. Deite aqui nessa maca que eu vou passar um sorinho e depois eu limpo. Só sei que eu ajeitei e ele disse: Muito bem! Valeu, viu irmã?! Valeu! Aí foi embora e depois ele mandou outra pessoa.

Pesquisador: Só você que ficava atendendo.

Participante 13: Mas eu tinha medo. Quem nunca trabalhou dizia que é muito bom, mas não é nada.

Participante 17: É nada. Enfermeira faz tudo.

Participante 13: A gente sofre, sofre. É professora, é enfermeira, é médico... Tudo, é tudo.

Pesquisador: Mas e agora? Se você fosse voltasse a ser profissional de saúde e trabalhasse aqui nessa unidade...

Participante 13: Eu não quero mais não.

Pesquisador: Mas vamos especular...

Participante 13: Eu queria trabalhar só com criança.

Pesquisador: Aí o que você ia fazer pra resolver esses problemas que vocês falaram aqui?

Participante 13: Eu ia fazer sabe o quê? Eu ia pedir à quem tem as autoridades as coisas pra ajudar o posto.

Pesquisador: Material?

Participante 13: Material, esses negócios de seringa, gaze...

Participante 15: Remédio! Pra não deixar faltar remédio.

Participante 13: Pra eles virem aqui fazer reunião com o pessoal...

Participante 15: Prometem de trazer, de dar resultado, de ver acontecer e nada.

Pesquisador: E não tem retorno nenhum? 
Participante 13: Aqui não tem muitos exames complementares que é pra fazer, né?! Não tem.

Participante 17: Nem tem muito... No SUS nem tem... Angiologista e esses negócios é a coisa mais difícil pelo SUS.

Participante 14: Mas eu nem culpo muito o governo do estado, eu culpo mais é os federais. Então ao meu ver tudo é de lá porque tem que vir de lá, né?!

Participante 15: Mas se eles mandam de lá e os daqui não entregam, como é que a gente pode receber?

Participante 14: Pois é, aí eu também não sei.

Pesquisador: É porque depende. Tem coisas que, por exemplo... As unidades básicas de saúde são de competência do município. Um hospital que nem o Walfredo, que nem o Giselda, é de competência do estado. Aí o HUOL é do governo federal. Entendeu?

Participante 14: Mas todos é do governo federal, né não?!

Participante 13: Mas lá às vezes faltava as coisas e era federal.

Pesquisador: Mas falta também. Não é só aqui no município não... Mas falta.

Participante 14: Todas as verbas vem do governo federal.

Participante 17: Lá no Onofre a pessoa ia fazer uma triagem, tirar uma ficha era tão mais fácil antigamente.

Pesquisador: É porque a demanda também era menor, né?! Não tinha tanta gente como tem agora.

Participante 13: E agora tem o hospital novo.

Participante 14: Aqui na zona norte era pra ter um hospital só pro idoso.

Pesquisador: A senhora acha que deveria ter um hospital só para o idoso?

Participante 16: Aqui era pra ter porque aqui tem idoso demais. Ave Maria!

Participante 14: Aqui nesse Santarém aqui tem gente demais...

Participante 18: Só uma fila pros idosos e não organizam uma fila...

Participante 14: Já falei.

Participante 18: A pessoa vai pra uma fila e quando... Aquelas gestantes tudinho tem direito também a nossa fila, né?! Bota um bebezinho no braço, tem direito... $\mathrm{O}$ menino já andando, mas tem direito também porque tá no braço.

Pesquisador: No colo, né?!

Participante 18: No colo. Aí a gente, olha... Fica esperando. 
Participante 13: Se fosse fazer um hospital pra velho tinha que ser um hospital grande, viu?! Porque é gente demais.

Pesquisador: Mas se fizesse esse hospital pro idoso, pra gente velha como vocês falam, será que ia resolver a situação, os problemas?

Participante 17: lam reclamar ainda.

Participante 14: $O$ hospital das clínicas, num fim de mundo daquele, era pra facilitar... Quem pega ônibus como eu, uma vez tive que sair as seis horas e cheguei na médica era oito horas. Pega um engarrafamento daqui e quando cheguei lá o médico já estava. Se tivesse tudo aqui era bem melhor.

Participante 13: Eu dou graças a deus por ter esse posto aqui e por ser bem atendida, viu?!

Participante 19: Até um exame de sangue que a gente vai fazer, um idoso fica aí até nove horas aí na fila.

Pesquisador: Essa unidade aqui faz exame de sangue? Esse posto de saúde aqui faz exame de sangue?

Participante 15: Não, ele encaminha.

Participante 14: Ali pra perto do Nordestão... Pra policlínica.

Participante 15: Esse daqui eu acho um dos melhores.

Participante 14: Eu também acho que esse posto daqui é um dos melhores que tem aqui na zona norte.

Participante 15: A vista de muitos que tem por aí, aqui é um dos melhores. Você assistiu ontem o repórter? Conhecendo os postos de saúde pras bandas de Extremoz, pra banda de aculá... Tanto posto de saúde que não tem nada.

Participante 14: É a maior bagunça. $O$ daqui nunca ninguém vê, nunca senti nada de ruim nesse posto.

Participante 15: Eu acho que esse daqui é um dos melhores.

Participante 16: Esse posto aqui ainda dizem que é um dos melhores.

Pesquisador: Alguém quer falar mais alguma coisa ou eu posso partir para a próxima pergunta?

Participante 14: Eu quero escutar o que você vai dizer a gente. Agora quem fala é você.

Participante 15: A gente vai ouvir a sua voz agora. 
Pesquisador: Eu vou pra última pergunta. Seria necessário inserir outros profissionais na equipe para atender essas necessidades? Que profissionais seriam esses?

Participante 14: A gente já tem muitos. Tem muitos funcionários aqui.

Participante 15: Eu acho que o que tem já é suficiente.

Participante 14: E agora entrou um bucado, não foi?

Pesquisador: Mas vocês não sentem falta de nenhum outro profissional?

Participante 13: Olhe, a não ser que seja um psiquiatra... E o quê mais?

Participante 14: Aqui tem psicóloga.

Participante 17: Em Ceará-Mirim tem, no posto de saúde de lá.

Pesquisador: Um psiquiatra?

Participante 17: Um psiquiatra em Ceará-Mirim.

Participante 18: Tem uma reunião na quarta-feira com a psiquiatra, né?! Ela vem de 15 em 15 dias.

Participante 17: Tem uma psicóloga aí quem estiver com problema mais sério é aí que ela faz o acompanhamento.

Pesquisador: Mas já tem uma psicóloga, né?! Do NASF?

Participante 17: Tem. Ela é assim, quem estiver com problema mais sério aí ela pode acompanhar, aí ela fica acompanhando. O meu foi um pouco mais leve aí ela não me chamou mais.

Participante 13: Porque no meu caso, lá no CECAM, né?! Se eu precisar de um psicólogo lá tem, porque tudo que eu precisar fazer tem que ser por lá, né?! Outra coisa que lá não tem eu tenho que fazer por aqui. Mas graças a deus até agora eu não precisei...

Participante 17: Sua irmã trabalha lá, é?

Participante 13: Não. Ela trabalha no Luiz Antônio, mas eu vou lá pra me consultar. Pesquisador: Então na opinião os profissionais que tem aqui são suficientes? Não precisaria mais trazer nenhum?

Participante 15: Aí quem sabe se precisa mais é eles, né?!

Pesquisador: Mas vocês como usuárias do serviço, vocês acham que já está legal? Que pra atender as necessidades de vocês, do que vocês precisam, as consultas... Não precisa mais de ninguém? Os que tem já são suficientes?

Participante 18: Eu acho que precisa mais de dentista, né?! Só tem uma dentista aqui na unidade. 
Participante 17: Não, tem duas.

Participante 13: Tem mais dentista.

Participante 18: Cadê a outra?

Participante 14: Só tem uma dentista aqui agora.

Participante 18: Pois é, só tem uma.

Participante 13: Porque cada área tem a sua dentista.

Pesquisador: São três dentistas, né?!

Participante 13: É.

Pesquisador: Então cada equipe tem uma dentista.

Participante 18: Eu já dei tanta viagem aqui atrás de uma dentista da área da gente, né?! Porque da área da gente eu nem sei o nome dela.

Participante 13: No ano passado só tinha um consultório de dentista. Uma sala pra [...] e as outras.

Participante 14: Melhorou muito esse posto. Não faz nem uns três meses que o prefeito veio pra uma reunião aqui, não foi?!

Participante 15: Ele prometeu e cumpriu, né?!

Participante 18: Agora devia ter uma reunião assim, dos idosos ser só dos idosos, a outra parte dos mais novos ser só dos mais novos, porque é uma misturada medonha.

Pesquisador: Como assim? Uma unidade de saúde só pro idoso?

Participante 18: É. Pro idoso.

Participante 14: Tem que ser uma só pra gente. O diretor tá bom de fazer isso mesmo.

Participante 18: Separar os novos dos idosos.

Participante 17: Tem muita gente nova no grupo da caminhada.

Pesquisador: No grupo de vocês?

Participante 17: É. Mas eu acho que é porque a médica manda. Eu penso assim, que seja isso. Porque é alguém que tem algum problema.

Participante 18: Mas tem gente aí de quando começou a gente caminhar aqui e nunca deixaram. 


\section{Apêndice VII}

\section{TRANSCRIÇÃO DO GRUPO FOCAL III}

Pesquisador: Quais são as necessidades de vocês? Do que vocês precisam no diaa-dia?

Participante 20: Para mim está tudo bom, pela idade que eu tenho, né?! Eu tenho transporte de graça, vou pra onde eu quero, graças a deus, né?! O pessoal do postO de saúde dali são todos ótimos. Aculá naquele outro são outras belezas. Ninguém tem o que falar e nem o que dizer, né?! Ninguém pode dizer que é ruim. A cada dia mais nós estamos achando bem porque nós temos reunião, nós passeamos... O pessoal aqui é bom para nós, nós nos damos muito bem, né?! Graças a deus para mim está ótimo!

Participante 21: Pronto, a mesma coisa que ela disse eu digo... Tenho o meu transporte de graça...

Participante 22: A unidade está precisando muito de... Nem sei mais dizer o quê que a unidade está precisando mais. De mais médicos, mais profissional pra trabalhar... E outra coisa, a construção aí está muito atrasada, a construção. Aí a gente está num cantinho muito...

Pesquisador: No posto de saúde?

Participante 22: É, no posto de saúde. Estamos precisando que adiante mais essa construção porque está muito devagar.

Pesquisador: Teve alguma interferência? Por exemplo, essa construção interferiu na demora de consultas?

Participante 20: De consultas não, mas na nossa reunião que estamos fazendo em um ambiente que não é o nosso canto.

Pesquisador: As reuniões do grupo de idosos sempre aconteceram aqui ou eram em outros locais?

Participante 22: Era pra ser lá no posto, mas não tem espaço. Depois da reforma nos tiraram de lá e agora nós estamos aqui.

Participante 23: Eu preciso de uma cirurgia da vista.

Pesquisador: Faz quanto tempo que a senhora precisa dessa cirurgia? 
Participante 23: Já vai fazer bem um ano que está lá a consulta e não tenho retorno.

Pesquisador: No posto de saúde?

Participante 23: É.

Pesquisador: E não consegue agendar?

Participante 23: Não, não tem jeito pra agendar. Faz é tempo que o médico mandou suspender o medicamento e que ia mandar me chamar. Eu suspendi e até hoje!

Pesquisador: Não tem resposta de ninguém e nem retorno?

Participante 23: De ninguém. Esse mês eu vou lá.

Participante 25: Isso aí é com todos nós, sabe? Com qualquer um de nós, porque eu mesma já tive que procurar não sei quantas vezes para eu fazer a consulta no particular... É exame, é eco, é... Todos os meus exames são no particular. No posto, os médicos daqui não me passam não porque não tem. Se tem médico para atender eles não encaminham ninguém, aí por isso que eu faço logo no particular porque vai ser encaminhado logo. Mas os médicos daqui eu não tenho fé em nenhum. A gente coloca um encaminhamento e passa dois, três anos para marcar... Então tem que fazer... Ou você procura um médico particular ou então você fica sem.

Participante 22: Dez pessoas na semana para... Para conseguir. Fica uma "ruma" de gente, mais de cem pessoas, aí vem embora. Tem gente que dorme lá para ver se consegue e não consegue.

Participante 25: Paga. Tem gente que paga para pegar ficha.

Participante 22: Eu mesma estou com uma ultra mamária faz mais de ano, mais de ano esperando essa ultra e ainda não saiu.

Participante 25: Tem que pagar quinze, dez, doze se quiser se consultar.

Participante 21: Eu paguei foi oitenta no raio-x que eu bati aqui e quarenta nesse pé aqui.

Participante 25: Eu paguei duzentos e trinta da consulta, mais oitenta e sete, mais cento e quarenta... Agora o eletro foi de graça. Mas todos que eu vou fazer é tudo pago. Nem faz aqui e nem faz naquele outro porque tem o médico, mas não tem o encaminhamento e não dá certo, nunca deu certo.

Participante 20: Eu só faço no particular também.

Participante 22: Nós precisamos muito também é de segurança no bairro. Segurança que a gente não tem. 
Pesquisador: $E$ isso interfere na saúde de vocês?

Participante 22: Demais! A gente não pode sair, não pode sair de casa fora de hora. De dia a gente sai com medo, imagine a noite.

Pesquisador: E tem muito assalto aqui?

Participante 22: Muito! Há pouco tempo deram não sei quantos tiros ali para baixo.

Participante 26: Já aconteceu em outro dia deles virem assaltando da outra parada, de parada em parada, bem umas três ou quatro, um cara numa bicicleta. Pegaram celular, dinheiro... O que tiver eles levam.

Participante 27: A gente bota um encaminhamento lá e passa um ano, dois e não chamam. Já aconteceu comigo, de eu levar o encaminhamento para lá, eles marcarem e quando dão o retorno já passou da data que marcou. Já aconteceu comigo nos dois postos de saúde.

Pesquisador: E aqui tem dois postos de saúde?

Participante 27: Tem, tem um lá embaixo, que é a unidade mista.

Participante 21: Meu marido está com dois anos que precisa fazer uma cirurgia da próstata e ainda não conseguiu.

Participante 28: Quem tem condições de pagar paga, quem não tem...

Participante 20: No dia que morrer, ligam no outro dia para dizer que marcaram.

Participante 29: Eu meu filho, graças a deus, até hoje eu não dependo do posto porque as minhas doenças eu curo assim mesmo em casa com água, com chá, com xarope, com lambedor... Eu tive chikungunya e não fui nenhuma vez no posto. Tomei vacina e comprimido e não deu jeito. Eu sou fumante e tenho muita vontade de deixar de fumar, sabe? Aí fui para o médico e o médico passou uma série de exames, um raio-x... Quando é que eu vou receber isso? Eu preciso criar vergonha e não preciso nada disso para deixar de fumar. Não precisa fazer exame para parar de fumar.

Pesquisador: Essas necessidades que foram relatadas por vocês são atendidas pela equipe de saúde?

Participante 20: Não. Eles sabem atender, mas não podem fazer nada, coitados. Não recebem nem o dinheiro que trabalham.

Participante 29: Um dia entraram no posto e levaram o celular de todo mundo, até do meu filho que estava lá para ser atendido.

Participante 22: Tem deles, coitados, que passam dois, três meses sem receber nem o salário daqui, viu?! Nós sabemos de tudo, só somos pobres. 
Pesquisador: Vocês falaram que eles não conseguem atender em virtude, por exemplo, do salário que está atrasado e por não haver recursos na unidade para trabalhar.

Participante 22: É. E eles também não têm um pouco de imaginação do que a gente precisa... É de nós que eles vivem. Se não fossem nós como eles iriam ganhar dinheiro? Eles não tinham quem consultar, né?! Então, eles têm que atender a gente bem, tratar bem, né?! Porque é do nosso corpo que sai o dinheiro deles, viu?!

Pesquisador: Vocês estão satisfeitos com esse atendimento? Por que?

Participante 25: Eles tratam a gente bem, né?!

Participante 22: Tem que melhorar muito, tem que melhorar. Os empregos deles, o dinheiro deles... Para receber, né?! Material que falta, né?!

Pesquisador: Falta o quê de material?

Participante 20: Eu fui com o meu menino lá tratar um negócio do pé, que estava uma ferida, eu cheguei lá e as meninas disseram que não tinha material, gaze, um "bucado" de coisa. Aí eu vim na farmácia e comprei treze reais de material.

Participante 22: Elas atendem mal-humoradas por conta disso, está entendendo? Porque não tem... A gente é quem paga o mau humor delas.

Participante 26: Eu fiz uma cirurgia no dente uma vez e na época não tinha ninguém lá para tirar os pontos. Eu rodei pra conseguir tirar e tirei lá na LIGA, foi lá que eu consegui tirar. E quase que não tirava porque não podia, tinha que ser no posto de saúde, mas no posto não tinha luva.

Participante 23: Nem uma agulha tem.

Pesquisador: $O$ básico, né?!

Participante 23: É.

Participante 29: Agora está faltando até os genéricos.

Participante 20: Está faltando até papel higiênico. Aí como elas podem ser boas?

Participante 30: Está faltando tudo para a saúde e o povo não pode fazer nada, porque quem deve fazer são os governantes e eles não fazem. Aí eles vão fazer o quê, coitados? Trabalhar de graça? Tentam ajudar, mas não podem. Está todo mundo aí querendo marcar exames, mas cadê as condições para eles trabalharem? Falta o pagamento deles, falta tudo... Falta o material e eles vão fazer o quê? Vão tirar do bolso deles sem puder? Falta os governantes tomarem providência com isso. 
Participante 29: Eles não vão resolver nunca porque o dinheiro está lá na mão dos ricos. Só juntando e levando, só juntando e levando e os pobres se lascando.

Pesquisador: A equipe de saúde está preparada para lidar com as necessidades de vocês? Por que vocês acham isso?

Participante 20: Eles são educados. Se tiver tudo, se tudo que a gente precisar tiver no posto, eles todos tem a obrigação com a gente. Recebe a gente muito bem, trata muito bem, no horário certo... Agora não tem nada porque eles não podem fazer nada, né?!

Pesquisador: Mais alguém quer falar alguma coisa? Não? Se vocês fizessem parte dessa equipe de saúde, como vocês tratariam as necessidades que foram levantadas?

Participante 26: Eu faria um abaixo assinado e levaria ao... É o prefeito, é? Governador?

Pesquisador: Para a gestão da unidade de saúde?

Participante 26: Sim.

Pesquisador: É para o prefeito.

Participante 26: Então eu fazia um abaixo assinado e levaria para ele.

Pesquisador: Se a senhora trabalhasse na saúde era isso que a senhora iria fazer?

Participante 26: É... Eu iria convocar a população porque até o funcionário não pode fazer isso, né?!

Pesquisador: Então a senhora iria fazer isso para tentar resolver os problemas?

Participante 26: Era. Incentivar a população.

Pesquisador: Mais alguém quer falar alguma coisa? Se vocês estivessem no lugar dos profissionais de saúde o quê que vocês iriam fazer para solucionar os problemas levantados aqui?

Participante 29: Diretas já!

Participante 31: Eu gostaria de mais união para resolver mais a parte de medicamento, de atendimento melhor e mais segurança para eles, né?! Se movimentarem lá dentro. Porque tem uns que podem até atender mal algumas vezes porque tem essa pressão. Eu vejo muito isso, essa pressão de chegar e dizer "ah, você não faz porque não quer!" Não é porque não quer. Eu estou trabalhando voluntariamente lá e vejo que não é porque não quer, é porque não tem. É como aquela parte de você colocar no sistema... Aí eu vejo que é difícil, mas é porque lá... O pessoal pensa que é só aqui, mas não é. Depende muito para onde vai o seu 
exame, porque liberam para poder eles fazerem, né?! Antes eu até pensava isso, mas como eu já estou voluntária lá dentro, eu estou vendo isso. E o sistema não é só para a gente aqui, né?! É para geral.

Participante 25: Para marcar os exames ali só é de meio dia para a tarde. O povo chega bem cedinho e quando a gente vai marcar não tem mais nada.

Pesquisador: E não tem uma fila prioritária para o idoso?

Participante 31: Não tem.

Participante 24: Eu estou com uma receita para o cardiologista, acho que já faz bem uns dois meses ou três, só que não marcam. E olhe que o meu cardiologista não demora muito assim não. Agora elas, seja a enfermeira ou a diretora, têm que ir lá na Ribeira marcar e não vão.

Participante 21: Coisa boa é quem tem dinheiro e pode pagar um plano de saúde, entendeu?

Participante 31: Mas o plano de saúde está a mesma coisa do público. Passa um ano para ser atendido. A minha filha tem dois planos de saúde e passa dois anos para agendar uma consulta. Um ano não, mas dois meses ou três meses passa.

Pesquisador: Seria necessário inserir outros profissionais na equipe para atender essas necessidades? Que profissionais seriam esses?

Participante 31: Eu acho que profissional não, tem que mudar é os governantes. Eu acho que não são os profissionais porque tem profissional aqui que atende de mão cheia, só falta até dar a cura da gente, mas não pode fazer nada, né?! Se chegar alguém para fazer um curativo elas procuram uma gaze e não tem, procura uma seringa para aplicar e não tem... Então a "sem-vergonhisse" vem de lá de cima.

Participante 24: A gente tem que dar graças a deus porque aqui tem quatro médicos. Tem bairro aí que não tem nenhum. $\mathrm{E}$ o médico já disse que qualquer coisa que o idoso precisar, ele está ali para ajudar. A única coisa que tem errado aí é a pessoa ter que ir marcar o cardiologista lá na Ribeira e a direção não manda ninguém ir. É isso que está errado, mas o resto não. A culpa é da Secretaria de Saúde e da direção da unidade. 


\title{
ANEXOS
}

\section{Anexo I}

\section{PARECER DE APROVAÇÃO DO COMITÊ DE ÉTICA EM PESQUISA}

\author{
HOSPITAL UNIVERSITÁRIO \\ ONOFRE LOPES-HUOL/UFRN
}

\section{PARECER CONSUBSTANCIADO DO CEP}

DADOS DO PROJETO DE PESQUISA

Título da Pesquisa: Competências profissionais frente às necessidades de saúde da população idosa versão II

Pesquisador: Rafael Rodolfo Tomaz de Lima

Área Temática:

Versão: 1

CAAE: 53796016.4 .0000 .5292

Instituição Proponente:Pós-Graduação em Ciências da Saúde

Patrocinador Principal: Financiamento Próprio

\section{DADOS DO PARECER}

Número do Parecer: 1.462 .796

Apresentação do Projeto:

Trata-se de uma pesquisa do tipo qualitativa, com abordagem exploratória e descritiva. Com a previsão de inclusão de 96 participantes divididos em 8 municípios de RN [idosos atendidos pela Estratégia Saúde da Família (ESF) e no Núcleo de Apoio à Saúde da Família (NASF)].

Objetivo da Pesquisa:

Objetivo Primário: Analisar a formação e as competências necessárias aos profissionais que atuam na Estratégia Saúde da Família (ESF) e no Núcleo de Apoio à Saúde da Família (NASF) para atender à população idosa. Objetivo Secundário: a) Mapear os aspectos referentes à saúde do idoso e ao envelhecimento humano abordados na formação dos profissionais de nível médio e superior que atuam na ESF e no NASF;b) Conhecer a percepção da população idosa coberta pela ESF e pelo NASF quanto às suas necessidades de saúde;c) Compreender a percepção dos idosos assistidos pela ESF e pelo NASF sobre as competências profissionais necessárias para lidar com o cuidado ao idoso;d) Identificar se o que é discutido na formação dos profissionais atuantes na ESF e no NASF condiz com a percepção das necessidades de saúde da população idosa.

Avaliação dos Riscos e Beneficios:

Riscos: O possivel risco para o desenvolvimento dessa pesquisa, bem como para os seus participantes, seria a identificação dos sujeitos respondentes no momento da análise, ou na

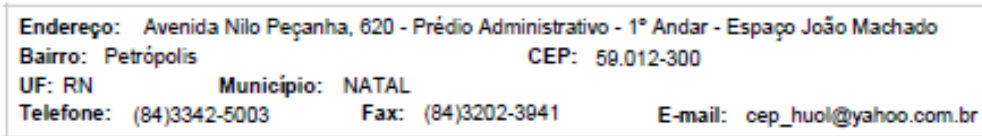




\section{HOSPITAL UNIVERSITÁRIO Platoforma ONOFRE LOPES-HUOL/UFRN}

Contnuaçăo do Parecer: 1.462 .796

publicação dos resultados, ou durante a guarda inadequada das transcrições dos áudios dos grupos focais. Entretanto, na tentativa de amenizar esse risco em relação à identificação dos sujeitos, um código ou um pseudônimo será atribuído para cada participante. Do mesmo modo, os dados coletados ficarão guardados sob a responsabilidade do pesquisador responsável durante o período de cinco anos e, posteriormente, serão incinerados. Ressaltamos que os grupos focais serão realizados em locais com condições condignas, confortáveis, que protejam a privacidade dos voluntários e que possibilite um bom registro do que é discutido. Ademais, será garantido o respeito ao participante da pesquisa em sua dignidade e autonomia, reconhecendo sua vulnerabilidade, assegurando sua vontade de contribuir e permanecer, ou não, na pesquisa, por intermédio de manifestação expressa, livre e esclarecida. Caso essa pesquisa não consiga dar uma devolutiva satisfatória para o público-alvo, ou seja, não consiga encontrar soluções para atender as necessidades de saúde percebidas pela população idosa, nem como definir quais são as competências profissionais essenciais para cuidar do idoso, isso se configurará como mais um risco. Além disso, se um grande número de idosos se recusarem à participar do grupo focal, isso poderá se configurar como uma dificuldade para o desenvolvimento da pesquisa. Portanto, as estratégias aqui mencionadas estarão explícitas no TCLE, com o intuito de estimular a participação do público-alvo, sem garantir danos e constrangimentos para os participantes.

Benefícios: A realização dessa pesquisa poderá contribuir para o conhecimento científico na área do envelhecimento humano e na formação de recursos humanos em saúde, auxiliando no desenvolvimento de outros estudos com populações idosas de outros estados e quem sabe, até de outros paises que possuam perfil populacional e políticas de saúde semelhantes ao Brasil.A divulgação dos resultados permitirá conhecer a formação dos profissionais de saúde para atuar na atenção à saúde do idoso. Além disso, espera-se identificar a percepção sobre as principais queixas e necessidades de saúde que a população idosa possui. Acredita-se também que pesquisas, assim como esta, são pertinentes para subsidiar a implementação de políticas públicas na área da saúde e da educação, englobando os aspectos sociais que estão envolvidos no processo de envelhecimento populacional. É preciso preparar os recursos humanos em saúde, desde a formação até o desenvolvimento de ações de educação permanente para os profissionais já inseridos nos serviços de saúde, visando qualificar a assistência prestada aos idosos usuários do SUS. Os resultados também podem evidenciar a necessidade para a criação de novas profissões. Tais profissões poderão ter competências específicas para cuidar da pessoa idosa, bem como poderão complementar o processo de trabalho e de cuidado desenvolvido pelas profissões já existentes.

\footnotetext{
Endereço: Avenida Nilo Peçanha, 620 - Prédio Administrativo - $1^{\circ}$ Andar - Espaço Joăo Machado Bairro: Petrópolis UF: RN Município: NATAL

Telefone: (84)3342-5003 Fax: (84)3202-3941 E-mail: cep_huolgyahoo.com.br
} 


\section{HOSPITAL UNIVERSITÁRIO Plotoformo ONOFRE LOPES-HUOL/UFRN}

Contnuaçăo do Parecer: 1.462 .796

Comentários e Considerações sobre a Pesquisa:

Pesquisa na qual será abordado os temas do cuidados na saúde dos idosos.

Considerações sobre os Termos de apresentação obrigatória:

Todos os termos foram apresentados de acordo com a resolução 466/12. Entretanto fio detectado uma discrepância em relação ao número de participantes declarados no TCLE (10 participantes por grupo focal) e informados na plataforma (12 participantes por grupo focal).

Recomendações:

1- Adequação/definição em relação ao número de participantes a serem incluídos no projeto.

Conclusões ou Pendências e Lista de Inadequações:

Parecer do relator é para aprovação do projeto.

Considerações Finais a critério do CEP:

1. Apresentar relatório parcial da pesquisa, semestralmente, a contar do início da mesma.

2. Apresentar relatório final da pesquisa até 30 dias após o término da mesma.

3. O CEP HUOL deverá ser informado de todos os efeitos adversos ou fatos relevantes que alterem o curso normal do estudo.

4. Quaisquer documentações encaminhadas ao CEP HUOL deverão conter junto uma Carta de Encaminhamento, em que conste o objetivo e justificativa do que esteja sendo apresentado.

5. Caso a pesquisa seja suspensa ou encerrada antes do previsto, O CEP HUOL deverá ser comunicado, estando os motivos expressos no relatório final a ser apresentado.

6. O TCLE deverá ser obtido em duas vias, uma ficará com o pesquisador e a outra com o sujeito de pesquisa.

7. Em conformidade com a Carta Circular $n^{\circ}$. 003/2011CONEP/CNS, faz-se obrigatório a rubrica em todas as páginas do TCLE pelo sujeito de pesquisa ou seu responsável e pelo pesquisador.

Endereço: Avenida Nilo Peçanha, 620 - Prédio Administrativo - $1^{\circ}$ Andar - Espaço Joăo Machado

Bairro: Petrópolis

UF: RN Município: NATAL

Telefone: (84)3342-5003 Fax: $(84) 3202-3941 \quad$ E-mail: cep_huolgyahoo.com.br 


\section{HOSPITAL UNIVERSITÁRIO ONOFRE LOPES-HUOL/UFRN}

Continuaçăo do Parecer. 1.462.796

Este parecer foi elaborado baseado nos documentos abaixo relacionados:

\begin{tabular}{|c|c|c|c|c|}
\hline Tipo Documento & Arquivo & Postagem & Autor & Situação \\
\hline $\begin{array}{l}\text { Informações Básicas } \\
\text { do Projeto }\end{array}$ & $\begin{array}{l}\text { PB_INFORMAÇÖES_BÁSICAS_DO_P } \\
\text { ROJETO 671776.pdf }\end{array}$ & $\begin{array}{c}03 / 03 / 2016 \\
16: 50: 02\end{array}$ & & Aceito \\
\hline Outros & CartaDeAnuenciaCOSEMSRN.pdf & $\begin{array}{c}03 / 03 / 2016 \\
16: 49: 33\end{array}$ & $\begin{array}{l}\text { Rafael Rodolfo } \\
\text { Tomaz de Lima }\end{array}$ & Aceito \\
\hline $\begin{array}{l}\text { Projeto Detalhado / } \\
\text { Brochura } \\
\text { Investigador }\end{array}$ & ProjetoDePesquisa.pdf & $\begin{array}{c}02 / 03 / 2016 \\
14: 19: 10\end{array}$ & $\begin{array}{l}\text { Rafael Rodolfo } \\
\text { Tomaz de Lima }\end{array}$ & Aceito \\
\hline Outros & CartaDeAnuenciaPpgcsa.pdf & $\begin{array}{c}02 / 03 / 2016 \\
14: 14: 53\end{array}$ & $\begin{array}{l}\text { Rafael Rodolfo } \\
\text { Tomaz de Lima }\end{array}$ & Aceito \\
\hline $\begin{array}{l}\text { TCLE / Termos de } \\
\text { Assentimento / } \\
\text { Justificativa de } \\
\text { Ausência }\end{array}$ & TCLE.pdf & $\begin{array}{c}02 / 03 / 2016 \\
14: 08: 10\end{array}$ & $\begin{array}{l}\text { Rafael Rodolfo } \\
\text { Tomaz de Lima }\end{array}$ & Aceito \\
\hline Folha de Rosto & FolhaDeRosto.pdf & $\begin{array}{c}02 / 03 / 2016 \\
14: 07: 41 \\
\end{array}$ & $\begin{array}{l}\text { Rafael Rodolfo } \\
\text { Tomaz de Lima }\end{array}$ & Aceito \\
\hline Outros & folha_pesquisador.pdf & $\begin{array}{c}01 / 03 / 2016 \\
20: 09: 05\end{array}$ & $\begin{array}{l}\text { Rafael Rodolfo } \\
\text { Tomaz de Lima }\end{array}$ & Aceito \\
\hline
\end{tabular}

Situação do Parecer:

Aprovado

Necessita Apreciação da CONEP:

Não

NATAL, 23 de Março de 2016

Assinado por:

HELIO ROBERTO HEKIS

(Coordenador)

Endereço: Avenida Nilo Peçanha, 620 - Prédio Administrativo - $1^{\circ}$ Andar - Espaço João Machado

Bairro: Petrópolis

UF: RN Municipio: NATAL

Telefone: (84)3342-5003 Fax: (84)3202-3941 E-mail: cep_huol@yahoo.com.br 
Anexo II

\section{ARTIGO PUBLICADO NO PERIÓDICO INTERNATIONAL ARCHIVES OF MEDICINE}

\section{A Look at Professional Education in Health with Emphasis on Aging}

\begin{abstract}
Rafael Rodolfo Tomaz de lima', Natanael de Freitas $\mathrm{Neto}^{2}$, Thais Paulo Teixeira Costa ${ }^{3}$, Rosana Lúcia Alves de Vilar ${ }^{4}$, Janete Lima de Castro ${ }^{5}$, Kenio Costa de Lima 6
\end{abstract}

\section{Abstract}

This paper purpose is to analyze the insertion of the population aging theme in the education of professionals working in the Family Health Strategy (ESF) and in the Family Health Support Nucleus (NASF). This is a study with a qualitative approach and documentary type, carried out in the state of Rio Grande do Norte, located in the Northeastern region of Brazil. To reach the objective, the pedagogical projects of the courses for the professions that work in the $\mathrm{Fa}$ mily Health Strategy and in the Family Health Support Nucleus were searched. The documents analysis was based on the content analysis method, using the thematic analysis technique in three pre-established registration units: (i) skills and abilities; (ii) professional profile; and (iii) curricular structure. From the analysis of the pedagogical projects, two analytical categories emerged: discussion about aging and training for health care of the elderly. The research result was that the discussion about the thematic of the aging in the process of formation of human resources in health is still insipient. There is a clear necessity to prepare people to provide adequate attention to the elderly population, as well as to formulate and manage public policies for the mentioned population that benefits from Unified Health System (SUS).
1 Postgraduate Program in Health Sciences; Federal University of Rio Grande do Norte (UFRN). Natal, Rio Grande do Norte, Brazil.

2 Postgraduate Program in Science, Technology and Innovation; Federal University of Rio Grande do Norte (UFRN). Natal, Rio Grande do Norte, Brazil.

3 Postgraduate Program in Professional Education; Federal Institute of Education, Science and Technology of Rio Grande do Norte (IFRN). Natal, Rio Grande do Norte, Brazil.

4 Department of Nursing; Federal University of Rio Grande do Norte (UFRN). Natal, Rio Grande do Norte, Brazil.

5 Department of Public Health; Federal University of Rio Grande do Norte (UFRN). Natal, Rio Grande do Norte, Brazil.

6 Department of Dentistry; Federal University of Rio Grande do Norte (UFRN). Natal, Rio Grande do Norte, Brazil.

Contact information:

Rafael Rodolfo Tomaz de Lima.

Address: Vereador Manoel Sátiro, 440, Ponta Negra, Natal, Rio Grande do Norte, Brazil. Zip Code: 59.090-180.

$\equiv$ limarrt@gmail.com.
Keywords

Aging; Health of the Elderly; Human Resources in Health; Professional

Education in Health; Primary Health Care 


\section{Anexo III}

\section{ACEITE DO ARTIGO NO PERIÓDICO INTERFACE - COMUNICAÇÃO, SAÚDE E EDUCAÇÃO}

\section{Interface - Comunicação, Saúde, Educação}

Decision Letter (ICSE-2017-0466.R1)

From: vianacostam@yahoo.com.br

To: limarrt@gmail.com

CC: interface.edicao@gmail.com

Subject: ICSE-2017-0466.R1 Avaliação editorial de submissão: Aceitar

Body: Prezado Lima

Informo que o manuscrito de sua autoria intitulado A educação interprofissional e a temática sobre o envelhecimento: uma análise de projetos pedagógicos na área da saúde foi aprovado para a seção o Suplemento Educação e Trabalho Interprofissional em Saúde no Brasil, de Interface - Comunicação, Saúde, Educação, conforme síntese dos pareceres, abaixo relacionada

"A nova versão apresenta melhorias significantes. Os autores tiveram a preocupação de atender as sugestões de correções.

Os revisores decidiram pelo aceite do artigo, porém fazem algumas sugestões a serem incorporadas no texto final.

1 - O texto ainda mas não deixa clara na conclusão do texto qual a contribuição do manuscrito para o avanço no estudo da temática. Os autores desde a introduçao argumentam a importância da educação interprofissional na temática no envelhecimento.

Já havia sido dito na introducão, sem retomar mesmo oue brevemente, as contribuiçoes e especificidades do estudo.

3 - Sugerem revisấo da conclusão de modo a apresentar de maneira suscinta as contribuicoes do estudo e como ele se diferencia do que já vem sendo produzido na temática no país. .

Solicito que aguarde informações complementares da secretaria da revista quanto aos procedimentos iniciais de edição de seu manuscrito para publicação.

Em caso de dúvidas, envie suas questões para intface@fmb.unesp.br.

Atenciosamente,

Dr. MARCELO VIANA DA COSTA

Comunicaçăo, Saúde, Educação

Date Sent: 30 -Jan-2018 


\title{
Anexo IV
}

\section{MODELO DE MANUSCRITOS DE TESES E DISSERTAÇÕES - PPGCSA/UFRN}

\author{
[Ltppgesa \\ UNIVERSIDADE FEDERAL DO RIO GRANDE DO NORTE \\ CENTRO DE CIÊNCIAS DA SAÚDE \\ PROGRAMA DE PÓS-GRADUAÇÃO EM CIÊNCIAS DA SAÚDE \\ Programa de Pós-Graduação em Ciências da Saúde - PPGCSa
Portaria n ${ }^{\circ}$ 006/2016-PPGCSa, de 22 de março de 2016
}

A Coordenação do Programa de Pós-Graduação em Ciências da Saúde do Centro de Ciências da Saúde da Universidade Federal do Rio Grande do Norte, no uso de suas atribuições legais e estatutárias, considerando o Art. $5^{\circ}$, parágrafos $1 .^{\circ} \mathrm{e} 2 .^{\circ}$ do Regimento Geral da UFRN e, em decisão tomada em reunião do Colegiado deste Programa, realizada em 17 de dezembro de 2015.

\section{RESOLVE}

Designar normas sobre a formatação dos manuscritos de dissertações e teses apresentadas para realização das defesas, considerando dois modelos de manuscritos: Modelo Preferencial do Manuscrito de Tese e Dissertações e Modelo Tradicional do Manuscrito de Tese e Dissertações.

A Comissão de Formatação do PPGCSa, designada pelo Colegiado, com a finalidade de analisar, avaliar e emitir parecer sobre a formatação dos manuscritos das dissertações e teses apresentadas para realização das defesas, deverá receber o material para ser avaliado com antecedência de 30 (trinta) dias da data da defesa.

\section{MODELO PREFERENCIAL DO MANUSCRITO DE TESE E DISSERTAÇÖES}

FONTE: Arial, tamanho 12, espaçamento 1,5, papel A4.

MARGENS: Esquerda $3 \mathrm{~cm}$; Direita, Superior e Inferior $2 \mathrm{~cm}$.

CAPA: Encadernação francesa (volume final), cor vinho bordeaux (Doutorado) ou azul royal (Mestrado).

LOMBADA: Nome do aluno, título da dissertação ou tese, ano; Ex: LACERDA, F.G.

IMPRESSÃO: somente frente da página

\section{ELEMENTOS PRÉ-TEXTUAIS:}

Folha de rosto

Ficha catalográfica

Folha de identificação

Folha de aprovação (componentes da banca sem assinaturas)

Dedicatória (Opcional)

Agradecimentos (Opcional)

Epigrafe (Opcional)

Resumo (da dissertação ou tese, abrangendo os principais resultados obtidos. Mencionar a interface multidisciplinar)

Abstratc

Listas

Sumário 


\section{ELEMENTOS TEXTUAIS}

1 INTRODUÇÃO: Deve ser breve (no máximo 05 laudas). O assunto deve ser apresentado com texto claro e inteligivel, ressaltando o estudo frente à evolução do conhecimento. Descrever a hipótese ou intenção com precisão e coerência. Incluir apenas citações consideradas relevantes.

2 JUSTIFICATIVA: Descrever os motivos que fundamentaram o desenvolvimento do estudo e ressaltar a pertinência e abrangência do tema. Utilizar apenas uma lauda.

3 OBJETIVOS: Geral e específicos.

4 MÉTODO

5 ARTIGOS PRODUZIDOS: Incluir no corpo da tese ou dissertação todos os artigos publicados e ou aceitos para publicação, neste caso apresentar o documento de aceite.

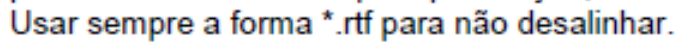

\section{COMENTÁRIOS, CRITICAS E SUGESTÕES:}

1. Descrever suscintamente sobre o anteprojeto inicial e fazer um paralelo com o estudo desenvolvido, considerando alterações e/ou adequações metodológicas bem como limitações;

2. Ressaltar sobre o mérito, a originalidade, a multidisciplinaridade e a contribuição científica e/ou técnica da produção;

3. Identificar a evolução intelectual na trajetória do mestrado e/ou doutorado;

4. Referir sobre as metas atingidas e outras perspectivas de progresso;

5. Pontuar inserção em grupos de pesquisa, orientações acadêmicas de naturezas diversas e perspectivas futuras em Programas de Pós-graduação;

6. Incluir informações de produção técnico-cientifica que foram geradas do projeto de pesquisa. Ex.: participações em eventos científicos, geração de patentes, etc.

\section{ELEMENTOS PÓS-TEXTUAIS}

7 REFERÊNCIAS: Citar apenas aquelas referenciadas nos itens Introdução, Justificativa, Método e Comentários, Críticas e Sugestões. As referências do(s) artigo(s) já estão contidas no próprio texto. Seguir normas Vancouver.

8 APÊNDICE: textos elaborados pelo autor a fim de complementar sua argumentação. Os apêndices compreendem material que não foi inserido no local citado (tabelas, quadros, protocolos, resultados estatísticos), que permitam melhor julgamento da dissertação ou tese.

9 ANEXO: textos não elaborados pelo autor mas que servem de complementos. Ex: parecer da Comissão de Ética em Pesquisa e outros documentos.

Obs.: Entregar uma cópia da tese ou dissertação em um único arquivo de texto, tipo word ( ${ }^{*}$.doc), em CD-R. 